\title{
Humorale Autoimmunität - Prinzip und pathogene Folgen
}

\author{
Humoral Autoimmunity - Principle and pathogenic Effects*
}

E. W. Rauterberg

Medizinische Laboratorien der Deutschen Klinik für Diagnostik Wiesbaden (Leiter: Prof. Dr. med. Ernst W. Rauterberg)

\begin{abstract}
Zusammenfassung:
Neue experimentelle Ergebnisse haben unsere Vorstellungen über die humorale Autoimmunität erheblich verändert. Da die beiden Typen antigenspezifischer Rezeptoren, die T-Zell-Rezeptoren (auf T-Zellen) und die Antikörper (auf B-Zellen), jeweils durch Rearrangements vorbestehender Genabschnitte (jedenfalls teilweise) nach Zufallsprinzipien entstehen, ist voraussagbar, daß ein großer Teil dieser Rezeptoren auch mit "Selbst"Antigenen reagieren. Experimente mit transgenen Mäusen haben kürzlich die Burnetsche Klonale Selektionstheorie voll bestätigt: Der Thymus hat eine wichtige Funktion bei der Entfernung solcher "verbotener Zellklone", deren Rezeptoren mit "Selbst" reagieren, und selektioniert positiv solche T-Zellen, die schwach mit den eigenen HLA-Strukturen reagieren. Damit ist die Entstehung der MHC-Restriktion ("major histocompatibility complex" = HLA) geklärt. Darüber hinaus geben unsere neuen Kenntnisse über die HLA-Strukturen als antigenpräsentierende Strukturen nun auch eine Erklärung für die HLA-Assoziation zahlreicher Autoimmunkrankheiten: Sie dürfte Ausdruck der spezifischen Interaktion einzelner HLA-Allele mit krankheitsfördernden Peptiden sein. Diese Übersichtsarbeit versucht unser heutiges Wissen über die Rolle der sogenannten "nativen" d. h. keimbahnnahen, polyreaktiven Antikörper zusammenzufassen. Dieser Teil des humoralen Immunsystems zeigt ein hohes Maß an Verknüpfung und gegenseitiger Regulation als Zeichen einer möglicherweise krankheitsverhindernden Funktion der natürlichen Autoreaktivität. Autoantikörper der IgG-Klasse scheinen aus diesem System der Selbstkontrolle ausgebrochen zu sein. Die Basis hierfür liegt entweder in der Hypermutation ihrer variablen Abschnitte oder einer anderen Durchbrechung des Idiotyp/Anti-Idiotyp-Systems. IgG-Autoantikörper können entweder direkt schaden durch Interaktion mit der Bindungsstelle auf zellstāndigen Rezeptoren (indem sie die Wirkung des Liganden imitieren oder blockieren), oder durch Bindung an extrazelluläre Strukturen, deren Funktion verändert wird, oder indirèkt Läsionen auslösen, indem sie Effektorsysteme, wie etwa Killerzellen, das Komplementsystem oder Makrophagen, aktivieren. Die daraus folgenden Pathomechanismen einer Gewebszerstörung werden beschrieben. Das Zusammenspiel all dieser Faktoren und Zellen, die insgesamt Autoimmunkrankheiten auslösen, ist schematisch in dem "Mosaik der Autoimmunität" zusammengefaßt.
\end{abstract}

Schlüsselwörter:

Autoantikörper - Bindungsstärke - Polyreaktivität - Vernetzung - Toleranz - Autoantigene - didaktische Schemata

\section{Summary:}

Recently accumulating experimental evidences have greatly changed our view upon humoral autoimmunity. Since the two types of antigen-specific receptors in the immune system, e. g. the antibodies on B-lymphocytes and the T-cell-receptors are both products of rearrangements of preformed gene segments which lead to a - at least in parts - randomly generated diversity, it is predictable that a high proportion of the receptors can react with "self". Experiments with transgenic mice have allowed to delineate the functional role of the thymus for tolerance: Indeed, the hypothesis of Burnet opon tolerance as product of the removal of "forbidden clones" has been completely confirmed and the molecular basis for the MHC-restriction of the T-cell dependent immune response was elucidated. Furthermore, our new knowledge about the tasks of the HLA-molecules as "antigen-presenting structures" and about the specific interaction of single HLA-alleles with presumably morbidity-associated peptides allows to deduce a hypothesis about the well known HLA-associations in autoimmune diseases. The review summaries recent data upon the role of "native" germline derived polyreactive antibodies which show a high degree of connectivity and points to a tentatively helpful function of this natural autoreactive system. Autoreactive antibodies of the $\mathrm{lg}$ G class seem to escape from this system of self-assertion either by hypermutation of their variable chains or other pertubations of the idiotype/anti-idiotype control. IgG autoantibodies may be harmful either directly by reaction with recepor bindings sites (mimicking the ligand or blocking its activity) and by altering the function of extracellular structures or indirectly by inducing the activation of effector systems like killer-cells, complement or macrophages. The ensuing pathomechanisms of tissue destruction are explained. An interplay of all these factors and cells resulting in autoimmune diseases is schematicly summarized as the "mosaic of autoimmunity" of Shoenfeld (67).

Keywords:

autoantibodies - avidity - polyreactivity - connectivity - tolerance - autoantigens - tutorial diagrams

* Prof. Dr. K. Rother zum 65. Geburtstag 
DasLPY00vonDrLange gitisuRechoals Univers sal-phorometerschilechoo thino

Universeflim Eimsatz8, als Mép placz fürdieroutine füpden Noffall)(24atsiun: den=Bereitschinaft), im Nachedienstiund ISpeziats labon Oder afs Back=upo Raborsystem, falls der Auromasplóczlich auso ralle.

Universelliniden. Methodeng:Enzyme, Subo iscrace, Lipipides Gerinnung frormone, Tumormarkers CABA $\mathrm{A}=$ = meht ats $100 \mathrm{mofgs}$ ouchel Mertios dena Neue Mechoden sind leechtaufs zunehumen, vors bandenelenche zuânderno Uhifversellinden Verfahreens Endpunktbe= stimmung; Ends punkcemitunnlinearen Bezugskurven, Kinetiken b́Enzymo immunoassays, Fixed:Absorbance Undluniversellim Betrieb? ểfache Bedienung, hoofie:Prazisision, biochste Wirtschaftelichs Reibinder:Anschaffung undimtäglichen Betrieb. MituBedienerfubroung und grafikfähigem Druckers

DrB Brunollange GmbH Konngsweg 10 Defo00Berfin 37 Telefon $(030) 81602=0$

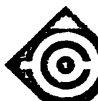

DR LANGE
Das Universal=Phorometer LP 700 von Di. Lange: über 100 Methodem, mehr alls 10 Eins@irgebiere,

Weitere Unterlagen gewünscht?

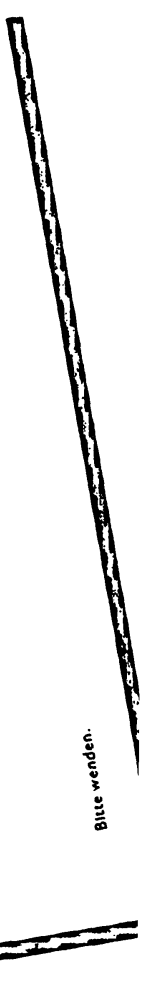

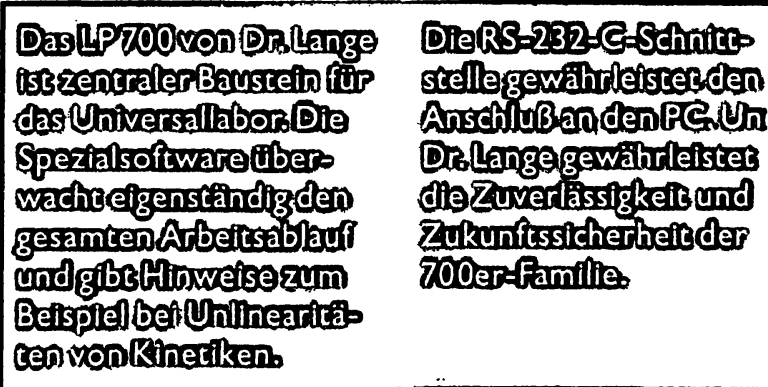




\section{"... eine ähnliche Provokation wie die satanischen Verse"}

(L'Express)

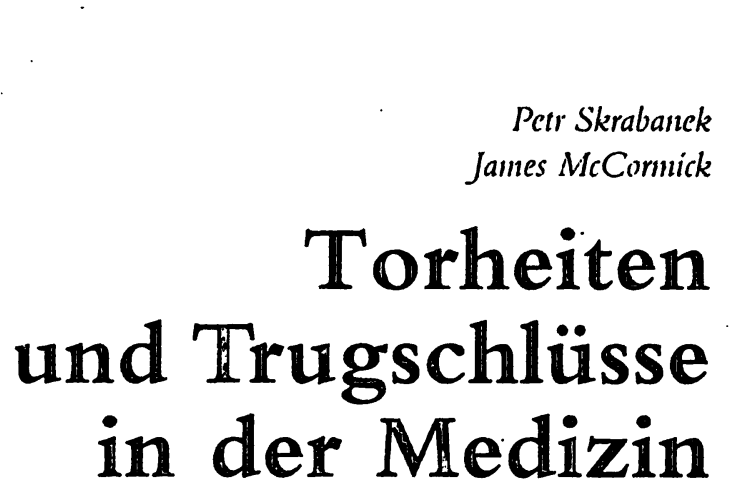

ISBN 3-87409-050-7, 164 Seiten, Fadenheftung, 35,- DM (kongenial übersetzt von

Dres. Chantelau, Cleveland, Sawicki und Richter, alle Med. Klinik der Heinrich-Heine-Universität, Düsseldorf)

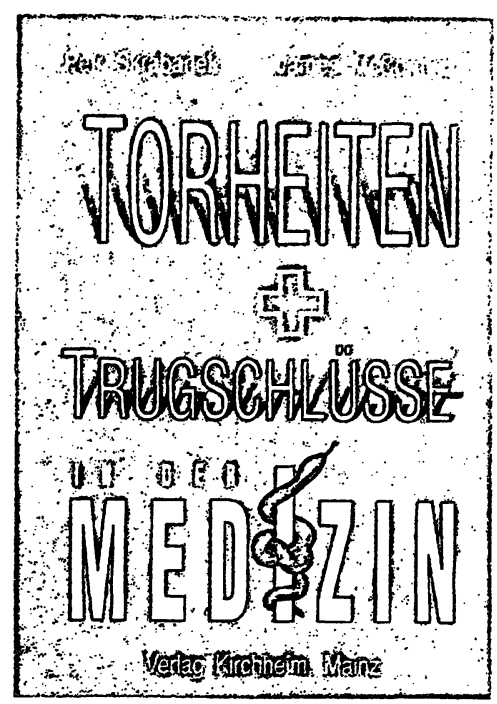

\section{Endlich auch in Deutschland:}

"Torheiten und Trugschlüsse in der Medizin" attackiert die Selbstgefälligkeit des zeitgenössischen ärztlichen Denkens und fordert eine rationale Bestandsaufnahme etablierter medizinischer Praktiken. Die Autoren empfehlen Skepsis gegenüber Diagnosen, Behandlungen und Heilmethoden und setzen sich mit angelsächsischem, bisweilen triefend schwarzem Humor mit "Absurditäten und Modeerscheinungen" des Medizinbetriebes auseinander vom Placebo über Homöopathie und Akupunktur bis zur Prävention: "Das Buch ist wichtig für alle, die besser verstehen wollen, was Medizin ist und was nicht" (New England Journal of Medicine zur britischen Originalausgabe).

\section{Verlag Kirchheim, Postfach 25 24, 6500 Mainz}

Ich bestelle Expl. Skrabanek/McCormick, Torheiten und Trugschlüsse in der Medizin, ISBN 3-87409-050-7, 35,- DM

Name:

Straße:

PLZ/Ort:

Datum: Unterschrift: 
Verfeinerte Analysemöglichkeiten zeigen bei immer mehr Krankheiten, daß Autoimmunprozesse an der Pathogenese beteiligt sind. Autoimmunität ist die Reaktivität des Immunsystems gegen Strukturen des eigenen Organismus (Autoantigene), also gegen „Selbst". Länger anhaltende Autoimmunreaktionen werden als Dysregulationen des Immunsystems angesehen. Entscheidend sind Persistenz und Stärke der Autoimmunreaktion. Die Stärke findet ihren Ausdruck in der Zahl spezifischer Lymphozyten und/oder der Konzentration an Antikörpern und in deren Bindungsstärke mit den entsprechenden Autoantigenen. Autoantikörper von schwacher Bindungsstärke (Avidität: $K_{\mathrm{a}} 10^{-3}-10^{-6} \mathrm{M} /$ ), die mit mehreren strukturell ähnlichen (Auto-)Antigenen reagieren (sog. polyreaktive Antikörper), sind auch schon normalerweise beim Gesunden vorhanden (1). Es muß daher zum richtigen Verständnis des Begriffes Autoreaktivität auch immer die Bindungsstärke des T-Zell-Rezeptors (TCR) oder des Antikörpers (AK) mit berücksichtigt werden. Stark bindende Autoantikörper haben $\mathrm{K}_{\mathrm{a}}$-Werte von $10^{-9}-10^{-12} \mathrm{M} / \mathrm{l}$.

Für die Entstehung einer Autoimmunkrankheit ist außerdem die Lokalisation der betreffenden Autoantigene maßgeblich: Für eine Functio laesa, eine Einschränkung der Organfunktion(en), muß das Autoantigen für Lymphozyten oder Antikörper anatomisch erreichbar sein.

Von pathogenetisch großer Bedeutung sind daher Autoantigene auf den leicht zugänglichen Zelloberflächen und extrazellulären Strukturen, aber auch intrazelluläre Autoantigene, sofern sie bei Zellzerstörung oder Zellmauserung freigesetzt werden. Letzteres führt aber eher zur Bildung von Immunkomplexen und dadurch ausgelösten Gewebsschäden und weniger zu einer direkten Beeinträchtigung von Organfunktionen (2).

Der Beginn autoimmunologischer Prozesse unterscheidet sich wahrscheinlich in nichts von einer normalen Immunantwort. Am Anfang kommt es immer zu einer Vermehrung sowohl von sensibilisierten T-als auch B-Lymphozyten (knappe deutsche Übersicht: [3]). Autoantikörper (Auto-AK) reflektieren daher nur einen Teil der Autoimmunphānomene, d. h., ein negativer Auto-AK-Test schließt das Vorhandensein zellulärer Autoimmunphänomene keinesfalls aus. T-Lymphozyten können selbst oder im Verein mit Makrophagen verschiedene Zytotoxizitätsreaktionen hervorrufen.

Autoantikörper gegen Pröteine oder Peptide reagieren jeweils mit einer Sequenz von ca. 5 Aminosäuren (Epitop) auf dem Antigen. Mensch und Säugetiere können Antikörper gegen 1-18 × $10^{9}$ verschieden Antigenepitope bilden (gut verständliche Übersicht: [4]). Ein von einem BLymphozyten abstammender Zellklon (Zellfamilie) bildet jeweils einen spezifischen Antikörper gegen ein Antigenepitop. Es gibt bereits vor Antigenkontakt ca. 1-18 $\times 10^{9}$ B-Lymphozyten(-Familien) mit unterschiedlicher Antigenspezifität. Antikörper gegen verschiedene Antigen-Epitope unterscheiden sich in den (hyper-)variablen Teilen ihrer Leicht- und Schwerketten. Diese Teile bilden die Antigenbindungsstelle und werden als Idiotyp (Id) bezeichnet (5).

Die für die Antikörperbildung wichtigen Gensegmente (auf Chromosomen Nr. 14 für die Schwerkette und auf Chromosomen Nr. 2 bzw. Nr. 22 für Kappa- oder LamdaLeichtketten) werden bei der Entwicklung von unreifer Vorläufer-B-Zelle zur reifen B-Zelle rearrangiert, d. $h$. in eine neue Reihenfolge gebracht. Der variable Abschnitt einer Leichtkette besteht auf der Genebene aus zwei Abschnitten, einem V-Gen-Abschnitt sowie einem J-Gen-Ab- schnitt. Vor dem Genrearrangement gibt es ca. $150 \mathrm{~V}$ Gen-Abschnitte sowie $5 \mathrm{~J}$-Gen-Abschnitte. Die Individualität einer bestimmten Leichtkette wird dadurch erzielt, daß während des Rearrangements jeweils ein V-Gen-Abschnitt und ein $1 \mathrm{~J}$-Gen-Abschnitt aus der Zahl der vorgebildeten Genabschnitte ausgewählt und mit dem C-Gen (konstanter Abschnitt der Leichtkette) verbunden wird. Durch Variation der Feinschnittstelle zwischen den Genabschnitten können insgesamt ca. 7500 verschiedene Leichtkettenkombinationen entstehen. Bei den Schwerketten ist die durch die Keimbahn vorgegebene Variation noch größer: Der variable Teil wird hier aus 3 Teilen (V, D und J) zusammengesetzt. Die Häufigkeit der entsprechenden Genabschnitte in der Keimbahn-DNS ist 80 für $V$ Gene, ca. 50 für die D-Abschnitte und 6 für die J-Gene. Dies ergibt insgesamt ca. 24000 Kombinationsmöglichkeiten $(4,6,7)$.

Durch Kombination von ca. 300 genetischen Elementen aus der Keimbahn-DNS können bei der Differenzierung zur reifen $B$-Zelle so $18 \times 10^{9}$ verschiedene Antikörper entstehen.

Das genetische Rearrangement des Schwerkettengens, die Auswahl einer Leichtkette (Kappa- oder Lamda-) und das Rearrangement dieses Leichtkettengens sind zudem dafür verantwortlich, daß eine B-Zelle nur einen Antikörper produzieren kann (sog. „allelic exclusion“).

Es sind aber nicht alle $18 \times 10^{9}$ verschiedene B-Zellklone in gleicher (Vorläufer-)Frequenzen im Organismus vertreten. Falls bei dem Rearrangement B-Zellen entstehen, deren Antikörper eine starke Affinität zu Autoantigenen haben, werden sie wahrscheinlich schon im Knochenmark eliminiert. Nicht entfernt werden aber B-Zellen, die nur schwach-affine selbstreaktive Antikörper produzieren, sowie B-Zellen, die anti-idiotypische Antikörper bilden. Solche anti-idiotypischen Antikörper (Anti-ld-AK) sind also schon vor einer Immunisierung mit Fremd-Antigen in der Immunglobulin M Klasse im Serum vorhanden. Teilweise deckt sich die sie produzierende Gruppe von B-Zellen mit einer Gruppe, die Antikörper mit einer Polyreaktivität (Reaktion mit verschiedenen Antigenepitopen bei schwacher Affinität) bilden. Die „polyreaktiven” B-Zell-Familien bilden ein Netzwerk (Abb. 1) von Interaktionen ("connectivity"), durch das normalerweise selbstreaktive B-Zellklone "in Zaum” gehalten werden $(5,8-10)$. Wahrscheinlich besteht ein großer Teil des „normalen” IgM und ein kleinerer des IgG im Serum Gesunder aus derartigen schwach-aviden polyreaktiven Antikörpern mit Keimbahnkonfiguration. Diese Antikörper sind für die „Background"-Reaktion unverdünnter Seren in ELISAs verantwortlich. Hiervon zu unterscheiden sind die $90 \%$ der B-Zellklone bzw. deren Antikörper, die im Laufe einer Immunantwort gegen "fremde" Antigene entstehen. Hier ist das begrenzende Netzwerk weniger dicht: Anti-idiotypische Antikörper entstehen erst im weiteren Verlauf der Immunantwort und sorgen hier nur dafür, daß diese nicht überschießt und später langsam herunterreguliert wird. Anti-ld-AK und polyspezifische schwach-avide Antikörper, obzwar im engen Sinne auch Autoantikörper darstellend, werden wegen ihrer regulatorischen Funktion in der folgenden Darstellung nicht unter dem Begriff Autoantikörper subsummiert.

Prinzipiell existieren zwei Wege für die Immunantwort gegen Fremd-Antigene (11-14): Im einen Fall wird ein Fremd-Antigen von der eigenen Zelle intrazellulär synthetisiert, so bei virusspezifischen Proteinen im Laufe einer Virusinfektion. Diese neu gebildeten Fremd-Antigene werden teilweise gleich wieder zerspalten (prozessiert) in 
Abb. 1: Die B-Zellen in dem AU. TOANTIGEN-REAKTIVEN POOL sind hauptsächlich gegeneinander lim Sinne von Idityp/Anti-ldio typl gerichtet und zeigen eine sog. "Polyreaktivität" (schwache Bindung an vorschiedene Autoantigene). Innerhalb dieses Zell. pools finden sich zahlreiche B-Zel. len mit lüberwiegend unmutierten) Antikörpern $\left(A K_{x}\right)$ gegen Thyreoglobulin, Myelin, DNS, Phospholipide, Fc-Teil bzw. Fab-Fragment von lgG, "heat shock proteins", d. h. die Hauptautoantigene. Die Interaktionen innerhalb dieses Pools ("connectivity") sind so häufig, die gegenseitige Kontrolle ist so eng, daß eine Proliferation und ein Umschalten von IgM auf andere Immunglobulinklassen und damit eine Hypermutation in den Keimzentren verhindert wird. Die sezernierten Auto$A K$ dieser Zellen sind für die sog. "Background-Reaktion" bei ELISAs verantwortlich.

Daneben existiert ein zweiter EXOANTIGEN-REAKTIVER B-ZELLPOOL. Hier sind die Ant,körper gegen Epitope von exogenen Antigenen gerichtet. Die durch Antigen-Kontakt hervorgeruferse Proliferation einer B-Zellfamilie $A K_{a}$ induziert ca. 7-10 Tage später die Proliferation einer zweiten Familie $A K_{b}$, deren Antikörper gegen den Idiotypen (Id) des ersten gerichtet sind. Diese zweiten Antikörper (Anti-ld) bewirken nach weiteren 5-10 Tagen die Proliferation und Sekretion mehrerer dritter Familien AK. Ein Teil der Antikörper (Anti-anti-ld) ist mit dem ersten Antikörper $\left(A K_{a}\right)$ identisch, andere nicht; einige tragen einen identischen ldiotyp wie $A K_{a}$, an dere nicht. Auch diese $A K_{c}$ können nun wieder die Proliferation weiterer B-Zellfamilien induzieren (Anti-anti-anti-ld). Je weiter von der ursprünglichen Immunantwort entfernt, um so schwächer werden die Reaktionen. Insge-

ES EXISTIEREY ZWEI HUYORALE IMOAUSYSTEYE:

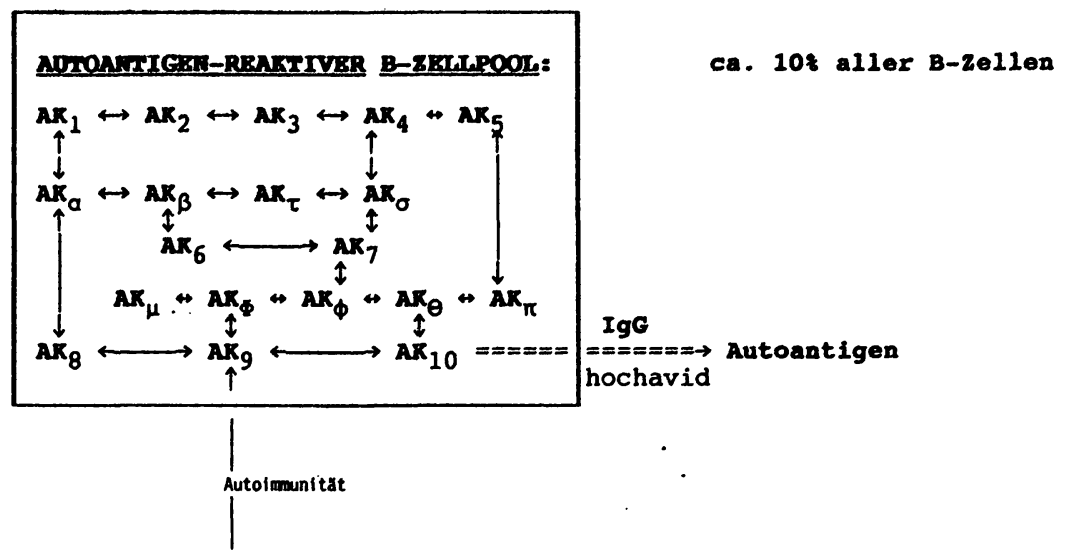

BXONETIGEAT-RRAKTIVER B-Z.TITPOOL:

90 allex B-zellen

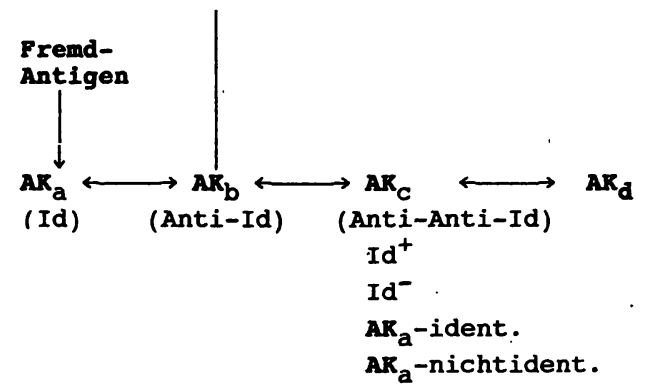

Zeitachse

samt verhält sich die Immunantwort also wie eine gedämpfte Schwingung. Auf diese Weise wird das Ausmaß einer Immunreaktion gegen exogene Antigenepitope begrenzt.

Unter besonderen genetischen Bedingungen (HLA bzW. TCR) kann die Immunantwort gegen

\begin{abstract}
ein exogenes Antigen in ihrer Folge Antikörper generieren, die mit Idiotypen autoreaktiver Antikörper reagieren und so das Netzwerk dieser autoreaktiven B-Zellen verändern: Es resultiert Autoimmunität mit stark-aviden lgGAntikörpern gegen Autoantigene, nun der Kontrolle entzogen.
\end{abstract}

Bruchstücke, die jeweils 8 bis 11 Aminosäuren lang sind. Die Bruchstücke verbinden sich dabei intrazellulär mit HLA-Klasse I Molekülen zu Komplexen, die anschließend an die Zelloberfläche wandern. Dies kann praktisch bei alIen Zellen passieren, da alle Körperzellen (außer Erythrozyten) HLA-Klasse I Moleküle auf ihrer Oberfläche exprimieren. Die Komplexe werden dann von CD8-positiven TLymphozyten (sog. Suppressor-/Killer-Zellen) mittels deren TCR und den CD8-Molekülen (als Corezeptor) erkannt (15), und diese Zellfamilie vermehrt sich nun stark.

Im anderen Fall handelt es sich um Fremd-Antigene etwa von Bakterien -, die extrazellulär zerfallen und dann von Makrophagen oder anderen antigenpräsentierenden Zellen aufgenommen und im lysosomalen Kompartment weiter zu Peptiden abgebaut werden. Diese Peptidbruchstücke verbinden sich in diesem Falle mit HLA-Molekülen der Klasse II (HLA-DR, -DQ, -DP) zu Komplexen, die eben- falls an die Zelloberfläche gelangen (16). Die HLA-KlasseII-Peptid-Komplexe werden hier von den T-Helferzellen mittels deren TCR und dem CD4-Molekül als Corezeptor erkannt (Abb. 2). Durch die Bindung werden die T-Helferzellen aktiviert, sie setzen Lymphokine frei, die die Vermehrung reaktiver T-Zellklone bewirken ( $z$. B. IL-1, IL-2, IL-4) oder in der Nähe befindliche B-Lymphozyten (durch IL-1, IL-2, IL-4, IL-5, IL-6) zur Proliferation anregen (17).

Die von Mensch zu Mensch überwiegend unterschiedlichen HLA-Antigene (auf dem HLA-A, -B, -C sowie HLADR -DQ und -DP Locus gibt es jeweils zahlreiche Allele [18]) unterscheiden sich erheblich in ihren Bindungsfähigkeiten und Spezifitäten für Peptid-Antigene. Da T-Zellen über ihren T-Zell-Rezeptor (TCR) nur solche Antigene erkennen können, die ihnen von den eigenen HLA-Molekülen präsentiert werden (sog. MHC-Restriktion), liegt in dieser Selektivität der HLA-Strukturen für Peptide ein ent- 
scheidender Faktor für die individuelle Ausprägung der Immunantworten gegen verschiedene Antigene. Hier liegt wahrscheinlich die entscheidende Ursache für die bei vielen Autoimmunkrankheiten beobachtete HLA-Assoziation und für die familäre Häufung bei Autoimmunkrankheiten. Die häufigsten Assoziationen bei Autoimmunkrankheiten bestehen zU HLA-B8, -DR2, -DR3 und -DR4. Außer mit bestimmten HLA-Allelen ist Autoimmunität auch mit der Expression bestimmter T-Zell-Rezeptoren assoziiert $(19,20)$.

Bei fast jeder Autoantikörperbildung kommt es parallel auch zur Vermehrung autoreaktiver T-Zellen. Das den TZellen über eine HLA-Struktur präsentierte Peptid führt zur Aktivierung und Teilung der T-Zellen, die gleichzeitig zahlreiche Zytokine abgeben. Einige dieser Zytokine sind für die B-Zell-Aktivierung notwendig. Zur Aktivierung von B-Zellen sind zwei Signale notwendig: Das Binden des Antigens an Oberflächen-Immunglobuline der B-Zelle, sowie ein Zytokin, wie IL-2, IL-4 oder IL-6, oder ein Komplementbruchstück, wie C3d, als zweites Signal.

$B-Z e l l e n$ reagieren also mit unprozessierten Fremdantigenen, wenn sie ein zusätzliches Signal (z. B. Cytokine von T-Zellen) erhalten, während T-Lymphozyten das Antigen nur eingebettet in eine HLA-Struktur erkennen können.

Nach Stimulation fremdantigenspezifischer B-Zellen beginnen diese sich zu teilen und zu vermehren. Ein Teil der Zellen schaltet von der IgM- auf die IgG-Produktion (bzw. IgA- oder IgE) um (sog. „isotyp switch”), differenziert zur Plasmazelle und beginnt mit der Massensekretion der entsprechenden Antikörper. Interessanterweise kommt es bei B-Lymphozyten in den primären Keimzentren der Lymphknoten etwa zwischen dem 10. bis 14. Tag nach der Immunisierung zu einem Prozeß, der die Bildung hochavider spezifischer Antikörper fördert: Die sogenannte "somatische Hypermutation" (21-24). Hierbei wird selektiv der variable Abschnitt der Leicht- und Schwerketten auf Codon und Anti-Codon punktmutiert (25). Nach Teilung entstehen Tochterzellen mit veränderten variablen Abschnitten ihrer Immunglobuline. Über einen im einzelnen noch nicht vollständig aufgeklärten Selektionsmechanismus werden anschließend nur solche Tochterzellen weiterhin ausgewählt, bzw. zur Poliferation angeregt, die stark mit dem Antigen reagieren und ebenfalls ein weiteres zweites Signal aus dem Milieu des Lymphknotens erhalten. Der. Prozeß fördert die Bildung hochavider Antikörper. Die meisten Auto-Antikörper entstehen wahrscheinlich durch somatische Hypermutation $(26,27)$.

Völlig unklar ist es heute noch, warum es so gehäuft zur Bildung von Antikörpern gegen spezielle Autoantigene, wie etwa Thyreoglobulin, Myelin oder die sogenannten Schockproteine (",heat shock proteins" [HSP] wie etwa HSP65 oder HSP90). kommt (28). Dies ist erstaunlich, da doch die T-Zellrezeptoren und Antikörper in ihrem variablen Teil jeweils durch Zufallsmechanismen aus in der Keimbahn vorhandenen Gen-Abschnitten zusammengesetzt werden. Es ergab sich daraus die Frage, ob bestimmte Gensegmente (insbesondere der V-Gen-Abschnitte) für solche Autoimmunreaktionen besonders häufig benutzt werden und die Basis dieser Häufung darstellen. Während - in der Tat - einige der sogenannten VGenabschnitt-Familien (z. B. VH6) gehäuft bei Autoantikörpern vorkommen (29), ist die Bedeutung dieses Befundes allerdings unklar, da praktisch alle Autoantikörper zusätzlich eine somatische Hypermutation aufweisen und also nicht einfach aus präformierten Abschnitten zusammengesetzt sind.
Antigen-präsentierende Zelle

HLA-Klasse II Molekül

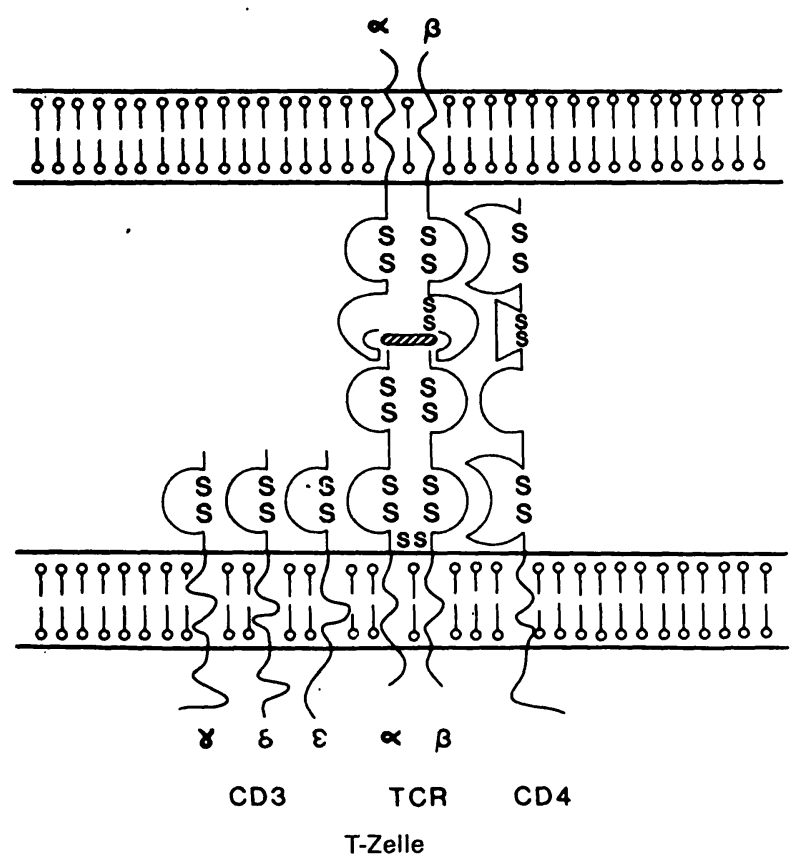

Abb. 2: T-Helferzellen (unten) erkennen ein Antigen (schraffiert) nur, wenn es an ein HLA-Klasse II Molekül gebunden dem T-Zellrezeptor angeboten wird. Um an ein HLA-Klasse II. Molekül gebunden zu werden, muß das exogene Antigen zunächst phagozytiert und in den Phagolysosomen in Peptidfragmente zerlegt werden. Letztere werden denn intrazellulär an neu-synthetisierte HLA-Klasse II Moleküle gebunden, und der Komplex wandert zur Zellob̈erfläche der antigenpräsentierenden Zelle (modifiziert nach [63]).

Viele Autoantikörper reagieren mit Antigenen, die nicht nur beim Menschen, sondern bei zahlreichen anderen Spezies exprimiert werden. Beispiele finden sich insbesondere bei der Gruppe der anti-nukleären Antikörper. Diese Reaktivität zahlreicher Auto-AK über viele Speziesgrenzen hinweg. ist von besonderem Interesse hinsichtlich der Genese der Autoimmunität: Die meisten Proteine wurden während der Entwicklung der Arten an so vielen Stellen ihrer Aminosäuresequenz durch Zufall mutiert, daß es nur sehr selten Sequenzen von fünf identischen Aminosäuren (d. h. in der Größe eines Antikörperepitops) auf zwei analogen Proteinen verschiedener Spezies gibt, wenn dieser Bereich nicht von großer Bedeutung für die Funktion des betreffenden Proteins ist. Es zeigt sich schon mit der relativ einfachen Methode der indirekten Immunfluoreszenz, daß Auto-AK überwiegend gegen funktionell iwichtige Epitope, wie aktive Zentren in Enzymen, entscheidende Bindungsgruppen in Rezeptormolekülen, etc. gerichtet sind. Meist tragen diese Autoantigene aber viel mehr Epitope auf ihrer Oberfläche - wie durch Immunisierung von Tieren mit solchen Antigenen beweisbar: In der Restriktion der Immunantwort auf bestimmte funktionell wichtige und stark konservativ gehaltene Antigenepitope liegt also ein Selektionsprinzip. Dies hat die Hypothese aufkommen lassen, daß sich das humorale Immunsystem von einem Erkennungssystem sol- 
cher konservativer "eigener" Strukturen als eine Art "Identitätssicherungssystem" ("self-assertion" [28]) ableite.

Wenngleich in ihrer molekularen Basis noch ungeklärt, sind Zusammenhänge zwischen Immundefekten und Autoimmunität sehr interessant: IgA-Defekte - normalerweise in gesunder Bevölkerung mit einer Prävalenz von 150 bis 250 pro 100000 Einwohnern vorhanden, scheinen gehäuft in Assoziation mit systemischen Autoimmunkrankheiten wie SLE, rheumatoider Arthritis, idiopathischer thrombozytopenischer Purpura, Dermatomyositis, Sjögren-Syndrom aufzutreten (30-32): Möglicherweise hat IgA oder ein den IgA-Spiegel regulierendes übergeordnetes Prinzip (etwa im HLA-Bereich) einen protektiven Autoimmunität verhindernden Effekt.

Darüber hinaus gibt es eine deutliche Assoziation von Autoimmunkrankheiten mit Komplement-(C2 oder C4)Defekten (33). Das Komplementsystem ist insbesondere bei der Verhinderung der Immunkomplexbildung und bei der Clearance von Immunkomplexen von Bedeutung (34). Ein Defekt mag hier eine Immunkomplexkrankheit auslösen, da entstehende Immunkomplexe nicht mehr aufgelöst werden können.

Komplement $\mathrm{C} 2$ und $\mathrm{C} 4 \mathrm{~A}$ sowie $\mathrm{C} 4 \mathrm{~B}$ werden als $\mathrm{MHC}$ ("major histocompatibility complex") Klasse III bezeichnet, da ihre Genorte auf dem Chromosomen 6 zwischen HLA-A, - B, -C und -DR liegen. Null-Allele von C4A oder $\mathrm{C} 4 \mathrm{~B}$ oder $\mathrm{C} 2$ auf beiden Chromosomen führen zu Komplementdefekten und sind insbesondere mit LE-ähnlichen Syndromen assoziiert.

\section{T-ZELLENTWICKLUNG IM THYMUS}

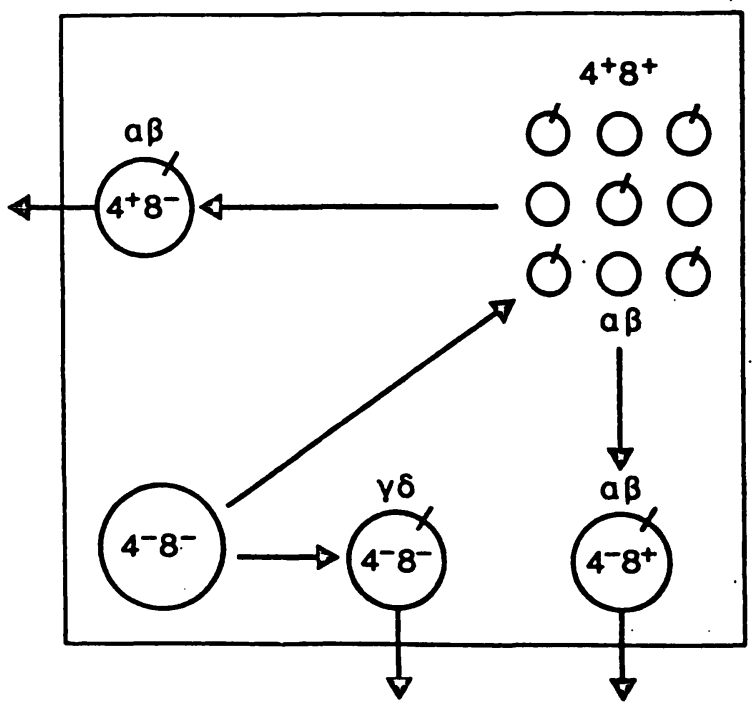

$\mathrm{Zu}$ weitere Autoimmunität auslösenden Faktoren gehören Steroidhormone: Viele Autoimmunkrankheiten treten erstmals während der Pubertät auf und sind bei Frauen häufiger als bei Männern. In vitro verändern Steroidhormone die Funktion insbesondere der $\mathrm{CD}^{+}{ }^{+}$-Suppressor-l Killer-Zellen.

Ursachen der Autoantikörperentstehung - Immunisierung gegen "Verändertes Selbst", Toleranz und genetische Faktoren"

Das Immunsystem hat die Funktion zwischen "Selbst" und "Nicht-Selbst" zu unterscheiden und somit die Integrität und Identität des Organismus zu sichern. Dabei haben sich die für die Spezifität entscheidenden Rezeptoren (d. h. die T-Zellrezeptoren auf den T-Lymphozyten und die Oberflächen-Antikörper auf den B-Lymphozyten) aus der (Super-)Familie der Adhäsionsproteine entwickelt (35, 36). Sie zeigen eine Verwandtschaft zu Zellmembranproteinen, die in erster Linie für den Zell-Zell-Kontakt und damit für die Ausbildung von Geweben verantwortlich sind. Schon auf der Ebene der Gewebsbildung wird von den Zellen gefordert, mit Zellen ähnlicher Funktion in Kontakt zu treten, d. h. sie zu erkennen, nicht aber mit Zellen anderer Funktionen. Prinzipiell ist das ein ähnliches Problem wie die Unterscheidung zwischen "selbst" und "fremd".

Wie wird nun aber normalerweise eine gewebsschädigende Immunreaktion gegen "Selbst-Antigene" verhindert? Im Laufe der Zeit sind verschiedene Hypothesen entwickelt.worden, wie es zu der Nicht-Reaktivität (passiv) oder Toleranz (aktiv) gegen "Selbst" kommt. Die von

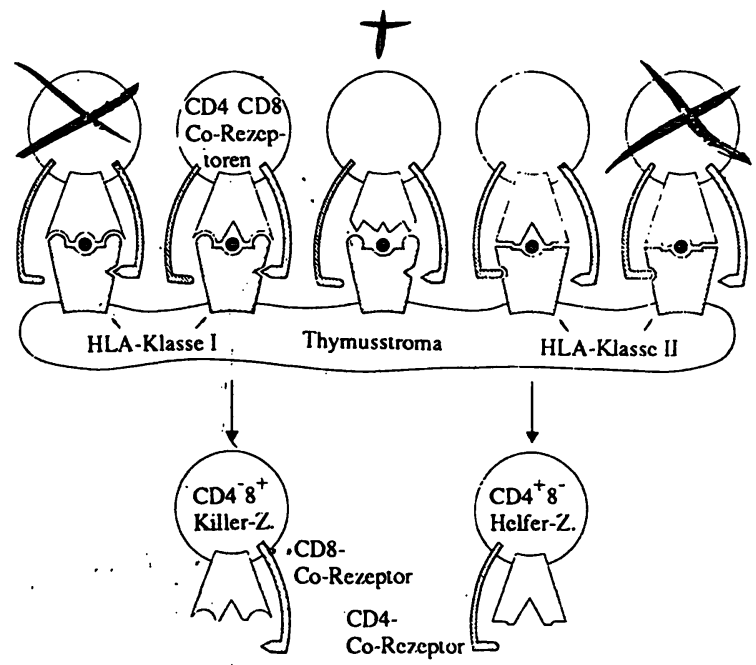

Abb. 3: Links: Unreife T-Zellen (links unten) im Thymus (repräsentiert durch den Rahmen) sind primär CD4-8 In diesem Stadium kommt es zum Rearrangement der Gene und zur Expression der TCR $\beta$ - und $\alpha$-Ketten. Gleichzeitig exprimieren die T-Zellen nun die beiden Co-Rezeptoren CD4 und CD8 auf der Oberfläche (rechts oben). In diesem Stadium findet die positive und negative Selektion statt. Ca. $90 \%$ der Zellen sterben durch Apoptosis ab. Solche, die eine schwache Bindung an ein (Selbst-)Antigen plus HLA-Klasse II Molekül zeigen, verlieren ihren CD8-Co-Rezeptor; diejenigen Zellen, die eine schwache Bindung an ein (Selbst-)Antigen im Kontext mit einem HLA-Klasse I Molekül zeigen, bauen ihren CD4-Co-Rezeptor ab. Nur diese CD4- (links oben) oder CD8-einfach-positiven T-Zellen (rechts unten) können nun den Thymus verlassen.

Rechts: Die eigentliche Selektion findet durch Interaktion der doppélt-ṕositiven T-Lymphożyten mit dem Thymusepithel statt: Die $\mathrm{CD}^{+} 8^{+}-Z e l l e n$ reagieren mittels ihrer T-Zellrezeptoren (TCR) mit (Selbst-)Antigenen, die diesen durch HLA-Klasse I oder HLA-Klasse II Moleküle angeboten werden. Eine starke Bindung (1. und 5. Zelle) gibt der T-Zelle das Signal zur Selbsttötung (Apoptosis). Ähnlich sterben auch die Zellen, deren TCR überhaupt nicht bindet (mittlere Zelle). Nur solche Zellen, deren TCR ein Antigen im Kontext mit HLA-Klasse I (zweite Zelle von links) oder im Kontext von HLA-Klasse II (vierte Zelle von links) schwach-bindend erkennen, erhalten vom Thymusepithel Faktoren zum Überleben. Nur diese Zellen können den.Thymus verlassen (modifiziert nach [64, 65]). 


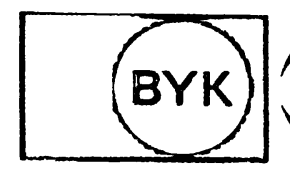

Sangrec

\section{Lurnineszzenz hor ainen Notring}
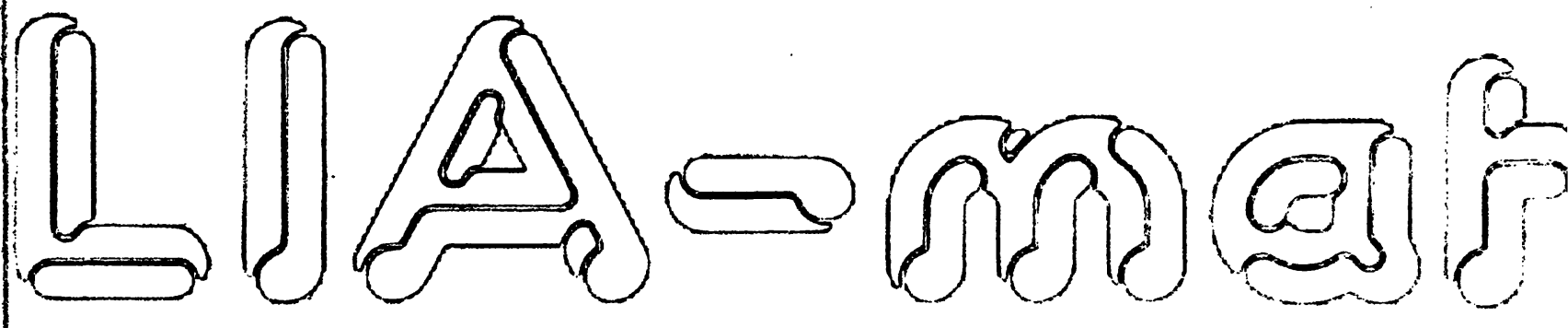

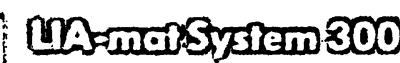

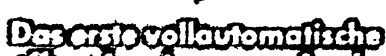

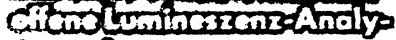
cosintion

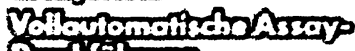
0 indis

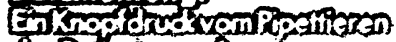

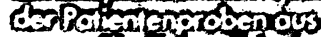

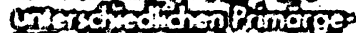

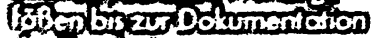
Siscolise

Cinzensins Som

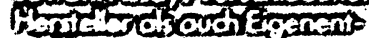

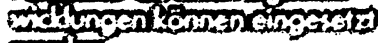
merchos

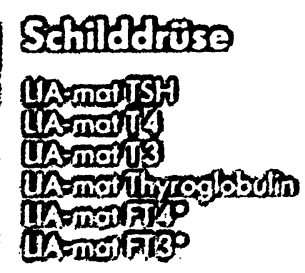

Brveturtiven

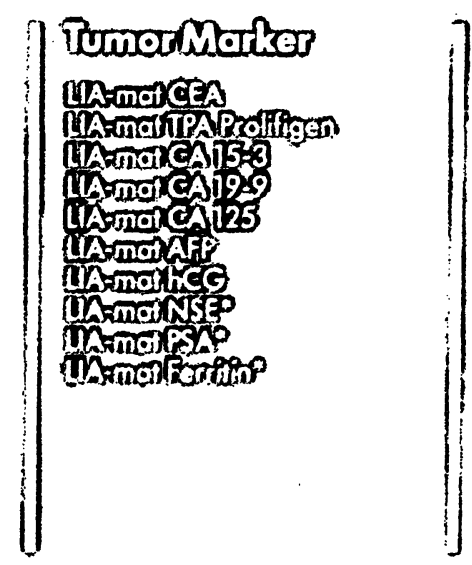

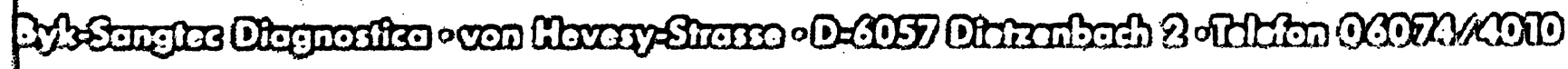




\section{Dio ansloged lichtigen.

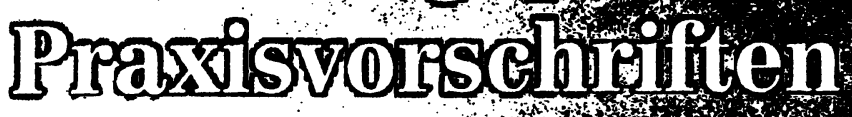 \\ (iIA SATTDEUTSCDIEAOSGABE}

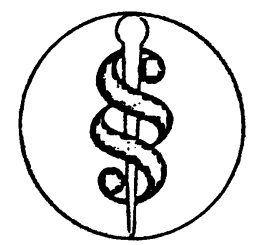

\section{(Ärzte, Zahnärzte, Tierärzte) von W. M. Nentwig (Notar) und R. J. Gläser (Rechtsanwalt)}

220 Seiten, Broschur, 39,80 DM, ISBN 3-87409-186-4, 4. ergänzte Auflage

Eine komplette Sammlung aller Gesetze und Verordnungen, die in jeder Praxis ausgelegt werden müssen. Geldbußen bis zu 1.000 DM drohen, wenn auslegepflichtige Vorschriften dem (ohne vorherige Anmeldung in der Praxis erscheinenden) Beamten des Gewerbeaufsichtsamtes nicht vorgelegt werden können.

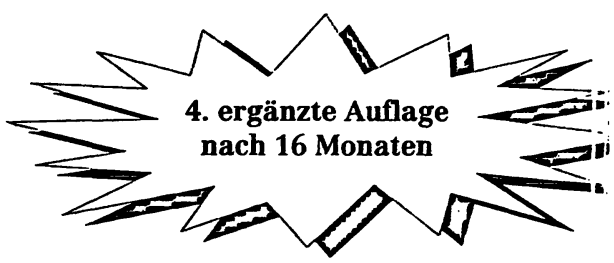

- Jugendarbeitsschutzgesetz, wenn regelmäßig mindestens ein Jugendlicher beschäftigt wird,

- Mutterschutzgesetz, wenn regelmäßig mehr als drei Frauen beschäftigt werden,

- die Arbeitszeitordnung in jedem Fall,

- die Unfallverhütungsvorschrift (Berufsgenossenschaft) in jedem Fall

- die Röntgenverordnung, wenn ein Röntgengerät betrieben wird,

O das Bestandsverzeichnis oder Gerätebuch gem. Medizingeräteverordnung, wenn energetisch betriebene med.-technische Geräte betrieben werden.

Kann ein Bestandsverzeichnis oder Gerätebuch nicht vorgelegt werden, droht eine Geldbuße bis zu 10.000 DM!
Die Anschaffung dieses Werkes kann daher ohne Übertreibung als "Pflichtlektüre für jede Praxis" bezeichnet werden. Demgemäß sind die Anschaffungskosten selbstverständlich als Praxisausgaben steuerlich absetzbar.

Jetzt als "gesamtdeutsche" Ausgabe mit den Ergänzungen des Einigungsvertrages und dessen Auswirkungen auf Praxen und ärztlich geleitete Polikliniken in den fünf neuen Bundesländern. Darüber hinaus wurden die verlängerten Fristen zur Abnahme von Röntgengeräten gemäß § 45 Abs. 3 RöV sowie die neue Verordnung über die ärztlichen Untersuchungen nach dem Jugendarbeitsșchutzgesetz eingearbeitet.

\section{$C$}

KIRCHHEIM Postfach 25 24, 6500 Mainz, Telefon $06131 / 671081$

Ich bestelle ... Exemplare:

Nentwig/Gläser

Die auslegepflichtigen

Praxisvorschriften
Name:

Straße:

PLZ/Ort: 
P. Ehrlich vorgetragene Vermutung, es gäbe einen „horror autotoxicus" läßt sich heute nicht mehr halten: Es lassen sich auch im Gesunden selbst-reaktive T- und BLymphozyten nachweisen. Allerdings sind Häufigkeit und Bindungsstärke ihrer TCR, respektive Antikörper meist gering.

Bei T-Lymphozyten resultiert ein wichtiger Teil der Toleranz bzw. Nicht-Reaktivität aus ihrer Reifung und Teilung im Thymus (Abb. 3): Analog zum Prozeß bei der B-Zellreifung gibt es auch beim Übergang von unreifen in reife T-Lymphozyten ein Genrearrangement für den variablen Teil der $\alpha$ - und $\beta$-Ketten des TCR. Dieses Genrearrangement, d. h., die Zusammensetzung aus Keimbahnelementen (analog zu VDJ bei Antikörpern) erfolgt auch hier nach dem Zufallsprinzip: Es können also leicht autoreaktive T-Zellen entstehen. Die primär gebildeten reifen TLymphozyten tragen auf ihrer Oberfläche sowohl das CD4 als auch das CD8 Molekül (doppelt-positive Zellen). Zeigen nun solche doppelt-positive T-Lymphozyten eine starke Bindung an eigene HLA-Strukturen oder Komplexe aus HLA mit Selbstantigenen; so bekommen sie das Signal zur Selbstzerstörung (Apoptosis). Diese erst kürzlich erfolgte Bestätigung der Burnetschen „clonal deletion theory" ist sicherlich eine der wichtigsten Ursachen für die T-Zell-Toleranz (37).

Neben der Zerstörung von Lymphozyten mit selbst-reaktivem, stark bindendem TCR (negative Selektion) gibt es aber auch eine positive Selektion im Thymus: Zur Teilung und weiteren Differenzierung gelangen nur solche T-Lymphozyten, deren TCR eine schwache Bindung an eigene HLA-Moleküle (+ Selbstantigene) zeigen. Ist der TCR eines T-Lymphozyten hierzu nicht in der Lage, so stirbt der T-Lymphozyt ab. Prinzip der positiven Selektion ist also eine schwache Bindung mit eigenen HLA Klasse I bzw. II Molekülen. Die Gesamtheit der T-Zellen, die dieses Kriterium erfüllen, ist erstaunlicherweise groß genug, um ein T-Zellrepertoire gegen eine große Zahl (ca. 107) von Antigenen zu ermöglichen. Wie Transfektionsexperimente (Übertragung von TCR-DNS) zeigten, können aber T-Zellen, die trotz dieser negativen und positiven Selektion mit einem autoreaktiven TCR überleben, auch nach dem Austritt aus dem Thymus in das periphere Blut in ihrer Aktivierbarkeit reguliert und inhibiert werden. Möglicherweise bewirkt freies im Überschuß vorhandenes und nicht in HLA-Strukturen eingebettetes Antigen eine NichtReaktivität von T-Zellen.

Ähnliches gilt prinzipiell auch für die B-Zellreihe: Auch hier soll es eine Elimination von stark autoreaktiven Zellen schon im Knochenmark geben. Durch die selektive Hypermutation des variablen Teils der Schwer- und Leichtketten der Immunglobuline kann es aber auch später immer wieder zufällig zu autoreaktiven B-Zellklonen und Autoantikörperbildung kommen. Bei unreifen B-Zellen scheint der Kontakt mit Antigenen eine Arretierung in der Differenzierung zu bewirken („clonal anergy"); wie dies erzielt wird, ist im einzelnen noch unklar.

Toleranz scheint also das Ergebnis verschiedener zusammenwirkender Prozesse auf unterschiedlichen Ebenen zu sein:

- Elimination stark selbst-reaktiver T-Lymphozyten im Thymus.

- Einschaltung einer Nicht-Reaktivität von T-Helferlymphozyten gegenüber körpereigenen Strukturen.

- Aktive Unterdrückung der Autoimmunantwort durch TSuppressorzellen (Vorhandensein antigenspezifischer Suppressorzellen ist jedoch neuerdings umstritten).
- Unterdrückung der Antikörperbildung durch Anti-idiotypische Antikörper (evtl. spezieller Immunglobulinklassen oder -subklassen).

- Blockierung von Autoimmunreaktion gegen Selbst durch Immunkomplexe.

Die Toleranz und Nicht-Reaktivität gegen "Selbst" kann auf verschiedene Weise gestört werden:

(1) Zur Ausbildung der Toleranz in der Prae- und Postnatalphase ist es notwendig, daß die Antigene via HLA-Molekül den T-Lymphozyten präsentiert werden, d. h. daß sie für antigenpräsentierende Zellen und Lymphozyten zugänglich sind. Dies ist bei einigen „Selbst-Antigenen", etwa Schilddrüsenkolloid oder Thyreoglobulin, Augenlinsen-Antigenen oder Spermatozoen aus anatomischen Gründen nicht der Fall. Gegen solche Antigene kann keine postnatale Toleranz bestehen. Eine Durchbrechung der natürlichen Barrieren, etwa bei entzündlicher Thyreoditis oder beim Einschwemmen der Antigene in den Organismus, z. B. Spermatozoen bei Vasektomie, kann zu einer massiven (Auto-)Immunisierung führen.

(2) Ein Teil der zytoplasmatischen Strukturen wird permanent abgebaut und teilweise an HLA Klasse I Molekülen gebunden auf der Zelloberfläche exprimiert. Gegen die meisten dieser Antigene besteht normalerweise eine Toleranz auf B- und T-Zellebene. Im Rahmen von RNSoder DNS-Virusinfektionen kommt es häufig zu einer veränderten Toleranz und - neben der Immunreaktion gegen virusspezifische Antigene - zur Bildung von Autoantikörpern. Ein Beispiel ist die Entstehung von Autoantikörpern gegen das als Rezeptor wirkende CD4-Molekül nach HIV-Infektion (38, 39) oder gegen den Mykoplasmenrezeptor (desialyliertes I) bei Kälteagglutininen (40). Möglicherweise wird das Rezeptorprotein bei den in das Cytoplasma aufgenommenen Keim-Rezeptor-Komplexen anders an HLA-Strukturen gebunden und/oder anders zerschnitten und zu Peptidbruchstücken prozessiert, als dies bei Rezeptormolekülen ohne gebundene Keimantigene der Fall ist.

(3) Ähnliches gilt wahrscheinlich auch für die Autoantikörperbildung nach massiver Konformationsänderung von körpereigenen Antigenen. Es ist unklar, inwieweit dies durch bakterielle Proteasen, Entzündungen oder Tumoren auch in vivo bewirkt werden kann. Es werden andere Epitope exprimiert oder durch verändertes AntigenProzessieren gebildert. Beispielsweise können Autoantikörper entstehen, die mit "verändertem Selbst" reagieren oder - noch weitergehend - über das Idiotyp-AntiIdiotyp-Netzwerk die normale Suppression der Antikörperbildung gegen „unverändertes Selbst” aufheben. So läßt sich beim Schaf experimentell eine Anti-glomeruläre Basalmembrannephritis auslösen, wenn es mit isoliertem und dadurch in ihrer Konformation veränderten Antigenen aus heterologem GBM-Material immunisiert wird (41). (Hier spielt auch das Adjuvans bei der Aufhebung der Toleranz eine Rolle.)

(4) Konformationsverändernd wirken wahrscheinlich auch diejepigen Medikamente, die eine Autoimmunreaktion hervorrufen können. Viele Medikamente liegen im Gewebe oder Blut nicht in freier Form, vor, sondern binden an Plasmaproteine, Zellen oder Strukturproteine. Die Bindung kann eine Konformationsänderung des beteiligten Proteins (= Expression von Neoantigenen) bewirken und damit entweder eine Antikörperbildung gegen solche medikamenteninduzierten Neoantigene auslösen ( $z$. B. bei medikamenteninduzierter Thrombozytopenie) oder die. Bildung von Antikörpern, die auch imit "normalen” 
Abb. 4: Mechanismen der aktuen Gewebsschädigung durch Antikörper am Beispiel der Niere: (1) einige Auto-AK gegen glomeruläre Basalmembranepitope können die Filtrations-Funktion der glomerulären Basalmembran (GBM) direkt verändern: Ohne Mithilfe von Mediatoren resultiert eine Proteinurie; (2) eine Ablage. rung von Auto-AK in den glomerulären Kapillarschlingen bewirkt aber meist (außer bei lgG4) eine lokale Komplementaktivierung; dies führt zu einer kovalenten Bin. dung von $\mathrm{C} 3 \mathrm{~b}$ (Opsonisierung), zur Freisetzung der potenten Entzündungsmediatoren $\mathrm{C} 3 \mathrm{a}$ und C5a (Anaphylatoxin), bzw. lokalen Bildung von C5b-9 (Membranangriffskomplex: Irritation von benachbarten Granulozyten, Plättchen, Endothelzellen, Mesangialzellen, Induktion der Freisetzung sekundärer Entzündungsmediatoren wie Leukotriene, Cytokine etc.l; (3) neutrophile Granulozyten werden durch ihre Fc-Rezeptoren an lokal abgelagerte Auto-AK gebunden, durch $\mathrm{C} 5 \mathrm{a}$ oder $\mathrm{C} 5 \mathrm{~b}-\mathrm{9}$ aktiviert und zur Freisetzung lysosomaler Enzyme, wie Mikroperoxydase und Elasase angeregt, sie geben außerdem gewebsschädigende Sauerstoffradikale ab; 14 ,

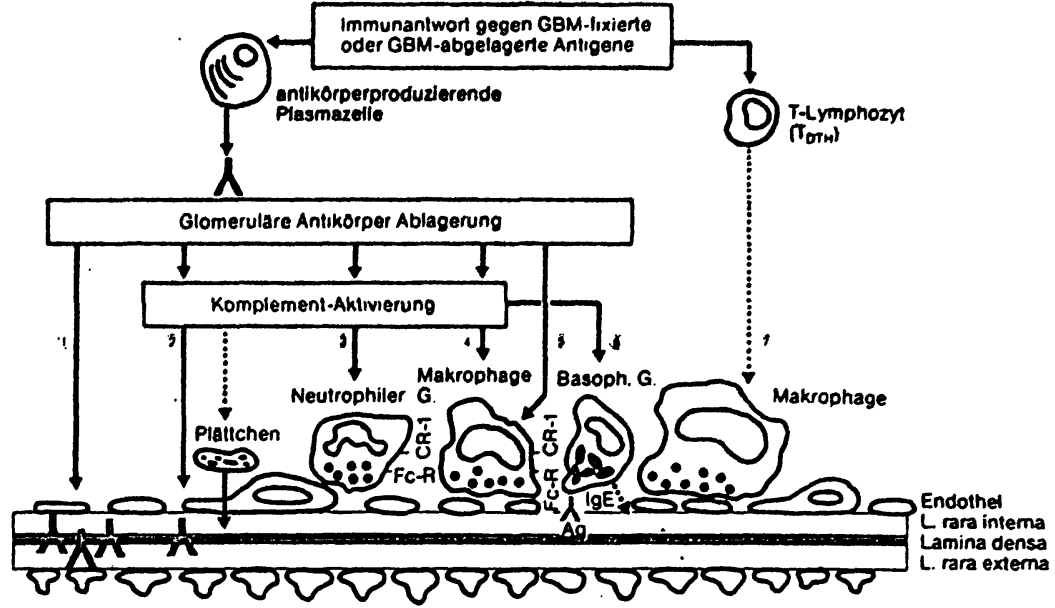

5) ähnlich werden auch Monozyten/Makrophagen lokal gebunden und aktiviert, sie können auch mittels ihrer CR1-Rezeptoren mit dem gewebsgebundenen C3b reagieren; (6) durch lokal gebildetes C5a werden insbesondere basophile Granulozyten aktiviert; sie können auch durch ihr oberflächengebundenes IgE getriggert werden: (7) via Fc-Rezeptor oder CR-1 gebundene Monozyten/Ma-

\begin{abstract}
krophagen können zusätzlich durch autoreaktive T-Zellen entzündungsfördernde Signale, wie gamma-Interferon oder andere Lymphokine, erhalten. Alle diese Mechanismen bewirken eine Proteinurie. Monozyten/Makrophagen können außerdem die GBM durchbrechen und eine extrakapilläre Proliferation und Halbmondbildung hervorrufen (Schema: $E$. W. RAUTERBERG, aus [66]).
\end{abstract}

Strukturen des Organismus reagieren (42). Für ein verändertes Prozessieren solcher Medikament-Protein-Komplexe spricht auch indirekt die häufig beobachtete HLAAssoziation solcher Autoimmunreaktionen. Hier handelt es sich wahrscheinlich um die präferentielle Bindung von Peptidabschnitten, die solche Medikamente gebunden haben, an bestimmte HLA-Moleküle.

Autoantikörper können aber auch durch weitere Mechanismen gegen solche Antigene entstehen, gegen die normalerweise eine Toleranz oder Nicht-Reaktivität besteht. Dies wurde bei Zellmembranantigenen, extrazellulären Bindegewebs- bzw. Strukturantigenen und Plasmabestandteilen beobachtet.

(5) Eine Autoimmunreaktion - zumindest auf der B-Zell-I Antikörperebene kann ausgelöst werden, wenn Strukturen von Keimen (Viren, Bakterien, Paraisten) eine konformationelle Ähnlichkeit mit körpereigenen Strukturen aufweisen ("molecular mimicy”). Dies ist z. B. für die sogenannten "nephritogenen" Streptokokkenstämme vermutet worden, die auf ihrer Oberfläche ähnliche Proteoglykane wie die meñschliche glomeruläre Basalmembran (GBM) tragen und so zur Auslösung einer Poststreptokokkenglomerulonephritis führen. Ein weiteres Beispiel sind die sogenannten Schockproteine (", heat shock protein" = HSP), die während der Entwicklungsgeschichte erstaunlich konservativ erhalten wurden und sogar zwischen Prokaryonten und Eukaryonten eine große Ähnlichkeit aufweisen. Sie helfen in der Zelle häufig anderen Proteinen, eine bestimmte funktionell wichtige Konformation einzunehmen ("chaperones"). Möglicherweise können die Schockproteine von Bakterien in bestimmten Fällen eine Autoimmunreaktion gegen körpereigene Schockproteine auslösen $(43,44)$ : Die letzten gemeinsamen Vorläufer zwischen Menschen und Mycobakterien gab es vor 1,5 Millarden Jahren, und dennoch ist etwa das HSP65-Molekül zwischen beiden $>50 \%$ in der Aminosäuresequenz identisch.

(6) Für eine Autoimmunität kann wahrscheinlich auch eine chronische Entzündung des Zielorganes auslösend sein. Möglicherweise ist hier eine andauernde Freisetzung von Zytokinen wie gamma-Interferon von Bedeutung (45).

(7) Eine permanente Autoantikörperbildung kann schließlich das Produkt einer generellen Dysregulation des gesamten Immunsystems sein. Ein Beispiel ist der systemische Lupus erythematodes, bei dem Autoantikörper gegen eine Vielzahl körpereigener Strukturen auftreten können oder Polyendokrinopathien, bei denen ebenfalls typische Reaktionsmuster von Autoantikörpern beobachtet werden $(46,47)$. Das Auftreten einer Vielzahl von Autoantikörpern ist insgesamt eher die Ausnahme, die nur beim SLE beobachtet wird: Bei den meisten anderen, insbesondere den organspezifischen Autoimmunkrankheiten, werden Autoantikörper gegen weniger als drei Antigene beobachtet.

\section{Pathomechanismen durch Autoantikörper}

\section{Autoantikörper können}

- unmittelbar die Funktion der betroffenen Zelle stören, sofern sie gegen Zelloberflächenantigene gerichtet sind. Sind sie gegen spezifische Zelloberflächenrezeptoŕen gerichtet, so können sie die Wirkung von Überträger-Substanzen (Hormonen, Cytokinen etc.) blockieren oder imitieren. Beispiele sind etwa Auto-AK gegen den TSH-Rezeptor auf Schilddrüsenzellen. In einem Fall kann die Zelle nicht mehr aur'den Botenstoff reagieren, im anderen Fall wirkt der Antikörper wie eine 
Überdosis des Botenstoffes und kann damit die Zelle aktivieren. Im letzteren Fall kann die Bindung des Autoantikörpers demnach auch zur Freisetzung zellulärer Inhaltsstoffe führen, wie z. B. für Proteasen nach Bindung von Pemphigusantikörpern berichtet (48). In allen diesen Fällen wirkt der Auto-AK also direkt, d. h. ohne Mediator. Beim Pemphigus konnte kürzlich gezeigt werden, daß auch Pemphigus-Antikörper der Subklasse lgG4, die das Komplementsystem nicht zu aktivieren vermögen, eine Blase verursacht hatten (49);

- direkt die Funktion extrazellulärer Strukturen und Gewebsbestandteile, wie etwa der glomerulären Basalmembran (GBM), verändern (Abb. 4);

- durch Bindung an das Autoantigen dieses opsonisieren, d. h. dessen Aufnahme (Phagozytose) durch Monozyten/Makrophagen oder Granulozyten dụrch deren membranständigen Fc-Rezeptoren fördern. Die durch Autoantikörperbindung ausgelöste Komplementaktivierung führt zur kovalenten Bindung von C3b auf der Zielzelle. Dies beschleunigt die Phagozytose stark, da die Monozyten/Makrophagen auf der Oberfläche die sogenannten CR1-Rezeptoren tragen. Dies gilt etwa für die beschleunigte Elimination von antikörperbesetzten Erythrozyten, Thrombozyten aus der Zirkulation oder für die Clearance von löslichen Autoantigenen im Komplex mit Autoantikörpern (50);

- durch Bindung an zelluläres Autoantigen eine Aktivierung des Komplementsystems und damit eine Zerstörung oder massive Irritation der Zelle durch Insertion des C5b-9-Komplexes bewirken $(51,52)$;

- durch Bindung an Autoantigene auf körpereigenen Zellen direkt deren Zerstörung durch "Killer"-Lymphozyten (via antikörperabhängige zelluläre Zytotoxizität = $A D C C)$ einleiten $(53,54)$;

- in der Blutbahn mit löslichen Autoantigenen reagieren und damit zur Bildung von zirkulierenden Immunkomplexen führen. In Gegenwart des Komplementsystems wird das Wachsen solcher Immunkomplexe durch Intercalation von Komplement $\mathrm{C} 3 \mathrm{~b}$ behindert und bestehende große Immunkomplexe werden dadurch schnell in kleinere Bruchstücke zerlegt (55). C3b-tragende Immunkomplexe können nach Bindung an die Komplementrezeptoren (CR1) auf Erythrozyten zur Leber transportiert werden, wo sie von den von Kufferschen Sternzellen aufgenommen werden. Versagt dieser Klärmechanismus, so kann es zur pathogenen Ablagerung der zirkulierenden Immunkomplexe aus dem Serum in das Gewebe kommen;

- mit extravasalen löslichen oder unlöslichen Autoantigenen reagieren und damit zur lokalen Bildung von Immunkomplexen führen (Abb. 4) mit folgender Komplementaktivierung und allen. Folgen einer dadurch ausgelösten entzündlichen Gewebsläsion (Immunkomplexkrankheit, früher: Serumkrankheit). Bei persistierender lokaler Immunkomplexbildung kann es schließlich zur chronischen Gewebszerstörung (Abb. 5) kommen (56).

Die Pathomechanismen einer Gewebsschädigung durch Auto-AK sind am Beispiel der Glomerulonephritiden in den Abbildungen 4 und 5 zusammengefaßt.

\section{Diagnostik der humoralen Autoimmunität}

Zur Diagnostik der Autoantikörper existieren sehr ausführliche Übersichten $(46,47,57)$. Autoantikörper sind in der Mehrzahl der Fälle von Krankheiten, die durch humo-

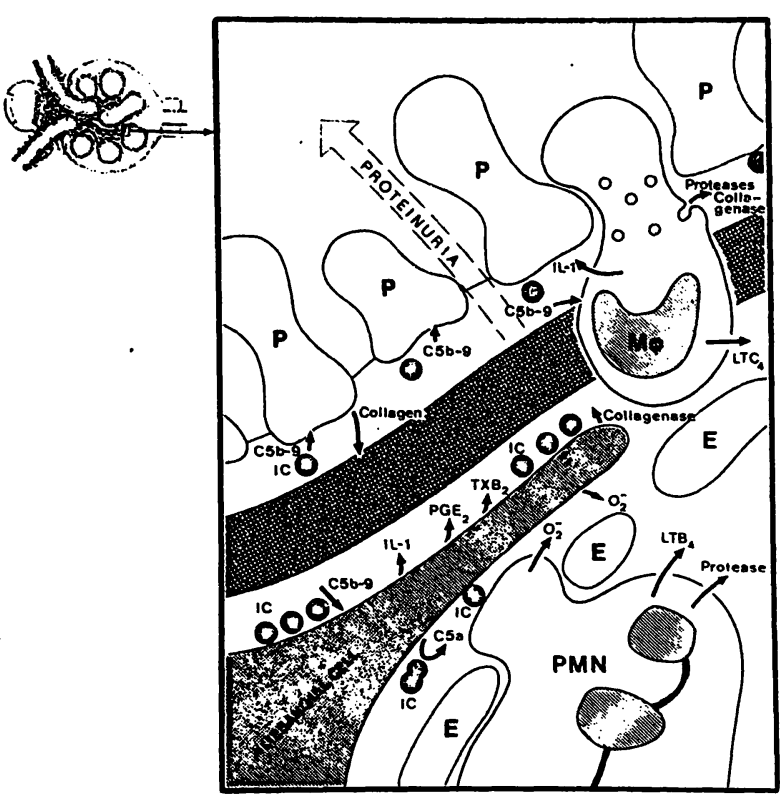

Abb. 5: Mechanismen der chronischen Gewebsschädigung: ein Ausschnitt aus einem Glomerulus (links) zeigt den Übergang von dem akuten in den chronischen Gewebsschaden (rechts) durch Autoantikörper bzw. Auto-AK enthaltende Immunkomplexe (IC): Unter dem Endothel (E) liegende IC aktivieren das Komplementsystem (C) und induzieren somit die Freisetzung von C5a. C5a bewirkt einen Sauerstoffradikal-,"Burst" auf herangelockten Granulozyten zu Beginn der IC-Ablagerung. Bei Mesangialzellen bewirkt die durch IC in ihrer Nähe induzierte C-Aktivierung - insbesondere durch die Penetration von C5b-9 Komplexen in ihre Membran - die Freisetzung der Prostanoide $P G E_{2}$ und Thromboxan, die Sekretion des Cytokins IL-1 und eine vermehrte Kollagensynthese (mesangiale Matrixvermehrung). Auch die Podozyten $(P)$ reagieren auf eine chronische C-Aktivierung via C5b-9 - oder auf einen chronischen Reiz mit IL-1 - mit einer veränderten und verstärkten Kollagensynthese. Makrophagen (Mc) beschleunigen den Prozeß durch IL-1 und $L_{T C}{ }_{4}$ bzW. durchbrechen die glomeruläre Basalmembran ldunkelgrau schraffiert). Sie setzen dazu Kollagenasen und andere Proteasen frei. Insgesamt resultiert aus der chronischen IC-Ablagerung und C-Aktivierung eine Sklerose (modifiziert nach [56]).

rale Autoimmunität ausgelöst werden, im Serum oder anderen Körperflüssigkeiten nachweisbar. Auto-AK sind wie alle Antikörper - gegenüber Denaturierung relativ stabil: Serumproben können ohne Schwierigkeiten einige Tage bei $4^{\circ} \mathrm{C}$ gelagert oder bei normalen Außentemperaturen verschickt werden. Bei einer nicht geringen Anzahl von Patienten mit besonderen Autoimmunkrankheiten läßt sich allerdings die humorale Autoimmunität nicht im Serum, sondern nur im betroffenen Gewebe nachweisen: Alle Autoantikörper werden von dem jeweiligen körpereigenen Antigen abgefangen. Die Autoantikörper sind daher nur im betroffenen Gewebe nachweisbar. Dies betrifft etwa einen Teil der Patienten mit Goodpasture-Syndrom bzw. Anti-Basalmembran-Nephritis, oder mit IgA-Nephritis bzw. Schönlein-Henoch-Nephritis oder mit membranöser Glomerulonephritis oder Poststreptokokken-Nephritis (58). Aber auch bei autoantikörperinduzierten Hautkrankheiten, wie den blasenbildenden Dermatosen, z. B. bullöses Pemphigoid, Pemphigus vulgaris oder -foliaceus oder bei Herpes gestationis oder Epidermolysis bullosa aquisita fehlen die Antikörper teilweise im Serum vollständig. In dieser Situation ist immer nur eine Gewebebiopsie wegweisend (59). Die Biopsiepräparate müssen entweder (Niere) sofort in schmelzenclem 


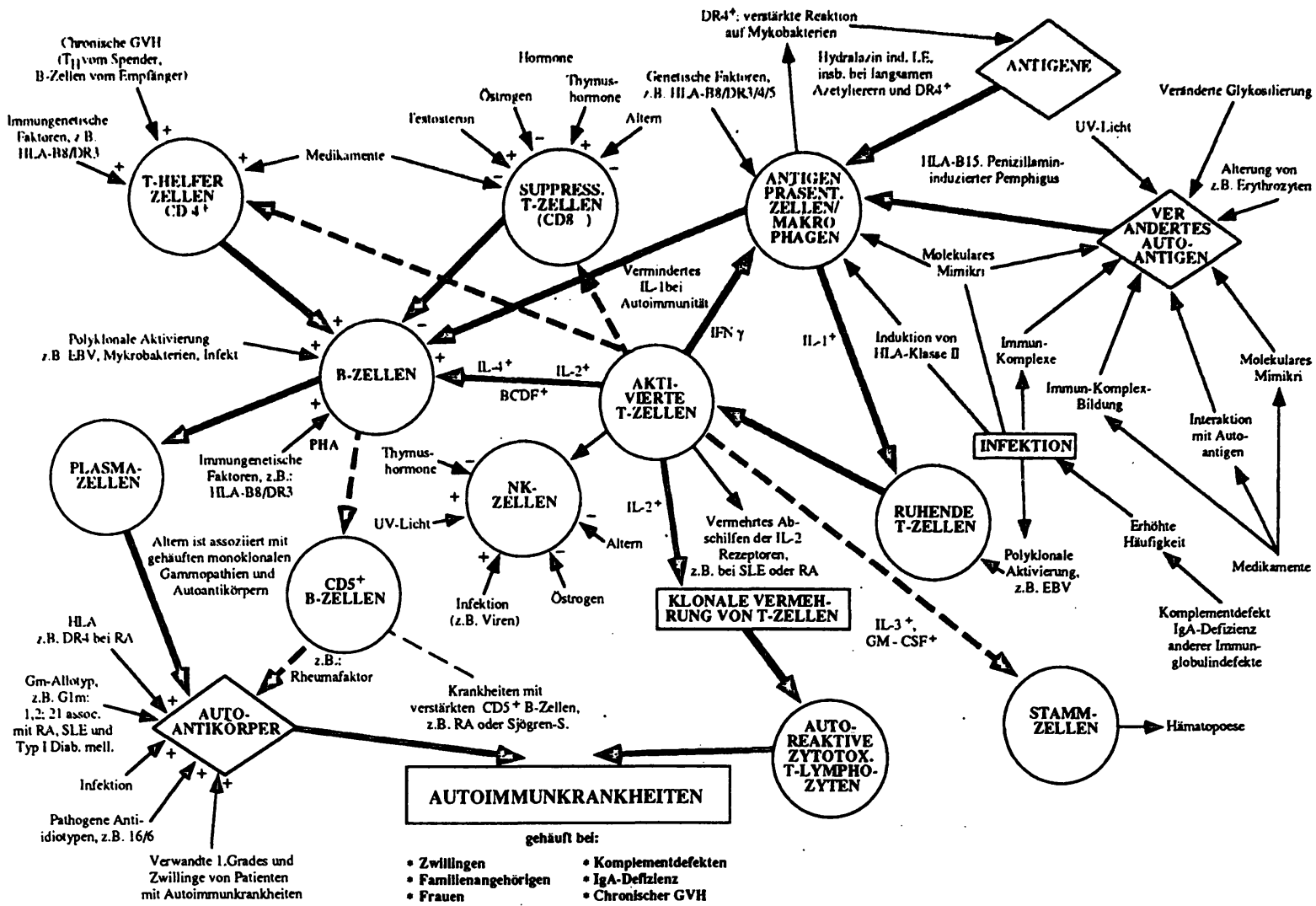

Abb. 6: Das Mosaik oder Autoimmunität; Abkürzungen: - verminderte Zahl oder Aktivität; + vermehrte Zahl oder Aktivität; EBV: Epstein-Barr Virus; GM-SCF: "granulocyte-monocyte stimulating factor"; GVH: "graft versus host disease"; HLA: humanes LeukozytenAntigen; IFN: Interferon; IL-1, IL-2, etc.: Interleukin-1, bzw. -2; PHA: Phythämagglutinin; RA: Rheumatoide Arthritis; SLE: systemischer Lupus erythematodes (entnommen und übersetzt aus [67]).

Isopentan schockeingefroren werden oder (Haut) können in Gewebekulturlösung innerhalb eines Zeitraumes von 24 bis 48 Stunden (max. $25^{\circ} \mathrm{C}$ ) verschickt werden. Unbedingt muß eine Fixierung der Gewebeproben mit Formalin oder ähnlichen Lösungen vermieden werden. Sonst ist die Identifizierung aller im Gewebe abgelagerten Immunglobuline oder Komplementkomponenten und anderer Entzündungsmediatoren (z. B. Elastase) nicht mehr möglich. Gerade die Analyse gewebsgebundener Komplementkomponenten erlaubt häufig zusätzlich abzụschätzen, wie akut der immunkomplexmediierte Prozeß ist (59-61). Dies ist vor allem bei der Diagnostik der Vaskulitiden (60) und Myositiden (62) empfehlenswert.

\section{Danksagung}

Für Arbeiten am PC möchte ich Frau J. Beer danken sowie Dr. med. Astrid Rauterberg für inhaltliche und formale Korrekturen, die zum besseren Verstehen beitragen.
Schriftum:

1. CASALI, P., NOTKINS, A. L.: CD5+ B lymphocytes, polyreactive antibodies and the human B-cell repertoire. Immunol. Today 10, 364-368 (1989).

2. COUSER, W. G.: Mechanisms of glomerular injury in immune-complex disease (clinical conference) Kidney int. 28, 569-583 (1985).

3. RAUTERBERG, A.: Die Körperabwehr In: JUNG, E. G. (Edt): Dermatologie, II. Auflage, Hippokrates, Stuttgart, im Druck (1991).

4. LEDER, P.:. Die Vielfalt der Antikörper. In: G. KÖHLER und K. EICHMANN (Edts.) Immunsystem. Spektrum der Wissenschaft Verlag Heidelberg, S. 64-76 (1988).

5. JERNE, N. D.: Towards a network theory of the immune system. Ann. Immunol. Inst Pasteur (Paris) 125C, 375-384 (1974).

6. ROITT, I., BROSTOFF, J., MALE, D. K.: Kurzes Lehrbuch der Immunologie. Thieme. Stuttgart (1989).

7. KLINMAN, N. R., DECKER, D.' J.: Diversity 1990. Immunol. Rev. 115, 211-238 (1990). 8. ROSSI, $F$, DIETRICH $G$ KAZATCHKINE, M. D.: Anti-idiotypes against autoantibodies in normal immunoglobulins: evidence for network regulation of human autoimdies in normal immunoglobulins: evidence for network

mune responses. Immunol. Rev. 110, 135-149 (1989). 9. PEREIRA, P., BANDEIRA, A., COUTINHO, A., MARCOS, M. A., TORIBIO, M., MART-
NEZ, C.: V-region connectivity in T cell repertoires. Annu. Rev. Immunol. 7, 209-249

NEZ, C.
(1989).

10. COUTINHO, A., BANDEIRA, A.: Tolerize one, tolerize them all: tolerance is self-assertion. Immunol. Today 10, 363-364 (1989).

11. ASKONAS, B. A., OPENSHAW, P. J.: MHC and antigen presentation. Immunol. Today 10, 396-397 (1989).

12. BRACIALE, T.J, BRACIALE, V. L.: Antigen presentation: structural themes and functional variations. Immunol. Today 12, 124-129 (1991).

13. LONG, E. O.: Intracellular traffic and antigen processing. Immunol. Today to, 13. LONG, 234 (1989).

232-234 (1989). 14. TEW, J. G., KOSCO, M. H.,
nol. Today $10,229-232$ (1989).

nol. Today 10, 229-232 (1989).
15. PARNES, J. R.: Molecular biology and function of CD4 and CD8. Adv. Immunol. 44 , 15. PARNES, J.

265-311 (1989). 16. JANEWAY, C. A.: The role of CD4 in T-cell
ceptor? Immunol. Today 10, 234-238 (1989).

17. BALKWILL, F. R.; BURKE, F.: The cytokine network. Immunol. Today 10, 299-304 (1989).

18. BODMER, J. G., MARSH, S. G., ALBERT, E.: Nomenclature for factors of the HLA system, 1989. Immunol. Today 11, 3-10 (1990). 
19. DEMAINE, A. G., RATANACHAIYAVONG, S, POPE, R EWINS, D., MILLWARD, B. A., MCGREGOR, A. M. Thyro globulin entibodies in Graves' disease are associated with T-cell receptor beta chain and major histocompatibility complex loci. Clin. Exp. Immunol. $7,21-24$ (1989). 20. GORONZY, J., WEYAND, C. M., FATHMAN, C. G.: Shared $T$ cell recognition sites on human histocompatibility leukocyte antigen class II molecules of patients with seropositive rheumatoid arthritis. J. Clin. Invest. 77 with seropositive

21. MILSTEIN, C.: From antibody structure to immunological diversification of immune response. Science 231 1261-1268 (1986)

22. ROES, J., HUPPI, K., RAJEWSKY, K., SABLITZKY, F.: V gene rearrangement is required to fully activate the hypermutation mechanism in B cells. J. Immunol. 142 1022-1026 (1989).

23. FRENCH, D. L., LASKOV, R., SCHARFF, M. D.: The role of somatic hypermutation in the generation of antibody diversity. Science 244, 1152-1157 (1989).

24. ALLEN, D., CUMANO, A., DILDROP, R., KOCKS, C. RAJEWSKY, K., RAJEWSKY, N., ROES, J., SABLITZKY, F., SIEKEVITZ, M.: Timing, genetic requirements and functional consequences of somatic hypermutation during B-cell development. Immunol. Rev. 96, 5-22 (1987).

25. MANSER, T.: The efficiency of antibody affinity maturation: can the rate of B-cell division be limiting? Immunol. Today 11, 305-308 (1990).

26. DAVIDSON, A., MANHEIMER-LORY, A., ARANOW, C. SHEFNER, R.: Possible mechanisms of autoantibody production. Biomed. Pharmacother. 43, 563-570 (1989). 27. DAVIDSON, A., SHEFNER, R., LIVNEH, A., DIAMOND, B.: The role of somatic mutation of immunoglobulin genes in autoimmunity. Annu. Rev. Immunol. 5, 85-108 (1987).

28. COHEN, I. R., YOUNG, D. B.: Autoimmunity, microbial immunity and the immunological humunculus. Immunol. Today 12, 105-110 (1991)

29. LOGTENBERG, T., YOUNG, F. M., VAN ES, J. H., GME LIG-MEYLING, F. H., ALT, F. W.: Autoantibodies encoded by the most Jh-proximal human immunoglobulin heavy chain variable region gene. J. Exp. Med. 170, 1347-1355 (1989).

30. CUNNINGHAM-RUNDLES, C.: Genetic aspects of immunoglobulin A deficiency. Adv. Hum. Genet. 19, 235-266 (1990).

31. FRENCH, M. A., DAWKINS, R. L.: Central MHC genes, IgA deficiency and autoimmune disease. Immunol. Today 11, 271-274 (1990).

32. GOSHEN, E., LIVNE, A., KRUPP, M:, HAMMAR STROM, L., DIGHIERO, G., SLOR, H., SHOENFELD, Y.: Antinuclear and related autoantibodies in sera of healthy subjects with IgA deficiency. J. Autoimmun. 2 , $51-60$ (1989).

33. LACHMANN, P. J.: Complement deficiency and the pathogenesis of autoimmune immune complex disease. Chem. Immunol. 49, 245-263 (1990).

34. SCHIFFERLI, J. A., PETERS, D. K.: Complement, the immune-complex lattice, and the pathophysiology of complement-deficiency syndromes. Lancet 2 (8356), 957-559 (1983).

35. HOGG, N.: The leukocyte integrins. Immunol. Today 10. 111-114 (1989)

36. DUSTIN, M. L., STAUNTON, D. E., SPRINGER, T. A.: Supergene families meet the immune system. Immunol. Today 9, 213-215 (1988).

37. VON BOEHMER, H., TEH, H. S., KISIELOW, P.: The thymus selects the useful, neglects the useless and destroys the harmful. Immunol. Today 10, 57-61 (1989).

38. KOWALSKI, M., ARDMAN, B., BASIBIPOUR, L., LU, Y C., BLOHM, D., HASELTINE, W., SODROSKI, J.: Antibodies to CD4 in individuals infected with human immunodeficiency virus type 1. Proc. Natl. Acad. Sci. U.S.A. 86, deficiency virus typ

39. WILKS, D., WALKER, L. C., HABESHAW, J. A., YOULE M., GAZZARD. B., DALGLEISH, A. G.: Anti-CD4 autoantibodies and screening for anti-idotypic antibodies to anti-CD4 monoclonal antibodies in HIV-seropositive people. AIDS 4, 113-118 (1990).

40. HENGGE, U. R., KIRSCHFINK, M., KONIG, A. L., NICKLAS, W., ROELCKE, D.: Characterization of I-yFI-glycoprotein as an acceptor for mycoplasma pneumoniae. Infection Immunity, in press (1991).

41. STEBLAY $R$. W: Glomerulonephritis induced in sheep by injections of heterologous glomerular basement membrane and Freund's adjuvant. J. exp. Med. 116, 253-266 (1962).

42 CHRISTIE, D. J., MULLEN, P. C., ASTER, R. H.: Fabmedieted binding of drug-dependent antibodies to platelets in quinidine- and quinine-induced thromborytopenie. J. Clin. Invest. 75, 310-314 (1985).

43. LYDYARD, P. M., VAN EDEN, W.: Heat shock proteins: immunity and immunopathology. Immunol. Today 11, 228-229 (1990).

44. KAUFMANN, S. H.: Heat shock proteins and the im mune response. Immunol. Today 11, 129-136 (1990).

45. SARVETNICK, N., SHIZURU, J., LIGGITT, D., MARTIN, L., MCINTYRE, B, GREGORY, A. PARSLOW, T., STEWART T.: Loss of pancreatic islet tolerance induced by beta-cell T.: Loss of pancreatic islet tolerance induced by beta-cell
expression of interferon-gamma. Nature 346, 844-847 expression

46. RAUTERBERG, E. W., ROTHER, K.: Autoantikörper ge gen Organgewebe und Thrombozyten. In: (Hrsg.: L. Tho- mas) Labor und Diagnose, III. Auflage. Medizinische Verlagsgesellscheft, Marburg, 829-883 (1988).

47. RAUTERBERG, E. W., ROTHER, K.: Autoantikörper gegen Organgewebe und Thrombozyten (vollständig neu bearbeitet) In: (Hrsg. L. THOMAS) Labor und Diagnose, IV. Auflage. Medizinische Verlagsgesellschaft, Marburg, im Druck (1991).

48. NAITO, K., MORIOKA, S., NAKAJIMA, S. OGAWA H.: Proteinase inhibitors block formation, of pemphigus H.: Proteinase inhibitors block formation of pemphigus acantholysis in experimental models of neonatal mice einase inhibitors on pemphigus acantholysis. J. invest. Dermatol. 93, 173-177 (1989).

49. RAUTERBERG, A. D., KOHL, P. K., HARTSCHUH, W., RAUTERBERG, E. W.: Komplement-unabhängige Blasenbildung bei Pemphigus vulgaris durch lgG4. Hautarzt 39, 426-429 (1988).

50. GRIFFIN, F. M.: Opsonisation, phagocytosis and intracellular microbial killing. In: Complement (eds.: $K$. O . ROTHER and G. TILL). Springer Verlag, Heidelberg, $p$. 395- 418 (1987).

51. RAUTERBERG, E. W., UNGEMACH, B., GEBEST, H. J.: Quantitative measurement of $\mathrm{C9}$ sites and their association to ring-like "lesions" on complement lysed membranes: A morphometric immuno-ferritin study $\mathrm{J} \mathrm{Im}$ munol. 112, 355 (1979).

52. HÄNSCH, G. M.: The complement attack phase. In: Complement (eds.: K. O. ROTHER and G. TILL). Springer Verlag, Heidelberg, p. 202-230 (1987).

53. RAUTERBERG, E. W.: Similarities between complement lysis and killing by lymphocytes. In: Complement (eds.: K. O. ROTHER and G. TILL). Springer Verlag, Heidelberg, p. 237-262 (1987)

54. FANGER, M. W., SHEN, L., GRAZIANO, R. F., GUYRE, P. M.: Cytotoxicity mediated by human $F c$ receptors for IgG. Immunol. Today 10, 92-99 (1989).

55. MEDOF, M. E.: Complement-dependent maintenance of immune complex solubility. In: Complement (eds.: K $O$. ROTHER and G. TILL). Springer Verlag, Heidelberg, p. 418-443 (1987)

56. ROTHER, K., HÄNSCH, G. M., RAUTERBERG, E. W.: Complement in Inflammation: Induction of Nephritides and Progress to Chronicity. Monogr. Allerg. Appl. Immunol., in press (1991).

57. SEELIG, H. P.: Antikörper gegen Zellkernantigene. Fischer, Stuttgart (1983).

58. RAUTERBERG, E. W: Pathogenetische Differentialdiagnose: Immunhistologie. In: Nierenkrankheiten (Hrsg. H. SARRE). Thieme, Stuttgart, S. 369-385 (1988). 59. RAUTERBERG, E. W.: Demonstration of complement components in the tissue. In: Complement leds.: K. 0 . ROTHER and G. TILL). Springer Verlag, Heidelberg, p. 287-326 (1987)

60. RAUTERBERG, E. W.: Complement-related mediators of inflammation: Immunohistological demonstration in the vessel walls of skin and kidney. Prog. appl. Microcirc. 12, 170-184 (1987).

61. RAUTERBERG, E. W., WINGEN, A.-M., GEHRIG, T., LIEBERKNECHT, L., MACHER, S.: Immunohistological detection of C3d - a "scar" of local complement activation in various kidney and skin diseases. Immunobiol. 170, 74 (1985).

62. RAUTERBERG, E. W:, RAUTERBERG, A. D.: Immundiagnostik der Myositiden. Akt. Dermatol. 17, 155-161 (1991).

63. ANDERSON, P., MORIMOTO, C., BREITMEYER, B., SCHLOSSMAN, S. F.: Regulatory interactions between members of the immunoglobulin superfamily. Immunol. Today 9, 199-203 (1988).

64. VON BOEHMER, H.: Developmental biology of $T$ cells in T cèll-receptor transgenic mice. Annu. Rev. Immunol. 8, 531-556 (1990).

65. VON BOEHMER, H, KISIELOW, P.: Self-nonself discrimination by T cells. Science 248, 1369-1373 (1990)

66. ROTHER, K.: Immunologie heute: Stellenwert in der Klinik. Gelbe Hefte 25, 139-151 (1985).

67. SHOENFELD, Y., ISENBERG, D. A.: The moseic of autoimmunity. Immunol. Today 10, 123-128 (1989).

\section{Anschrift des Verfassers:}

Prof. Dr. med. Ernst Wilhard Rauterberg Medizinische Laboratorien der Deutschen Klinik für Diagnostik

Aukammallee 33

6200 Wiesbaden

\section{Separate the Trees from the Forest}

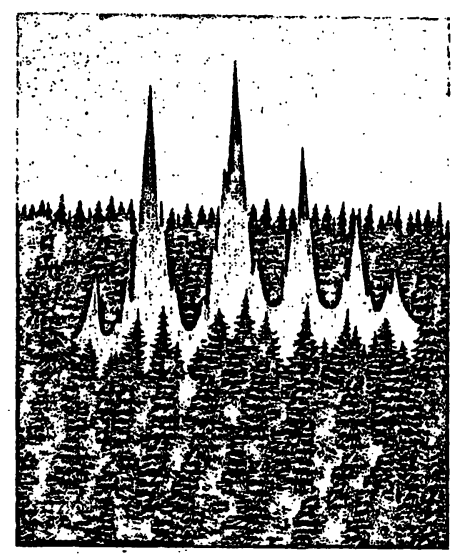

\section{... mit HPLC-Geräten und HPLC-Kits von BIO-RAD}

\section{Komplette Testpackungen:}

\section{O Urin:}

- Catecholamine

- Metanephrine

- VMS

- HVS

- HIES

- Hydroxyprolin

- VMS/HVS Screen

\section{- Plasma:}

- Catecholamine

- Benzodiazepine

- Tricyclische Antidepressiva

\section{Vollblut:}

- Eyclosporin

- Glykierte Hämoglobine

- $\mathrm{HbA}_{2}$ und $\mathrm{Hb}$-Varianten

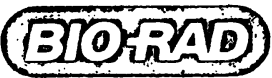

BIO-RAD Laboratories GmbH Diagnostica

Heidemannstr. 164

D-8000 München 45

Tel. (0 89) 31884140

Fax (089) 31884100 


\title{
Praktische Hinweise zur Anwendung der Durchflußzytometrie für die immunologische Leukämiediagnostik
}

\author{
Practical Approach on Flow Cytometric Immunodiagnosis of Leukemia \\ L. Schafur, K. Malberg \\ Abtoilung für Medizinische Immunologio der Medizinischen Akademie Erfurt (Leiter: Prof. Dr. med. habil. K. Malberg)
}

\section{Zusammenfassung:}

Bei der Bestimmung von Oberflächenantigenen auf Zellen ist die durchflußzytometrische Analyse zur Methode der Wahl geworden. Über Möglichkeiten und Grenzen in der routinemäßigen Anwendung unter besonderer Berücksichtigung der Leukämiediagnostik wird in dieser Arbeit berichtet.

\section{Schlüsselwörter:}

Durchflußzytometrie - immunologische Leukämiediagnostik

\section{Summary:}

The method of choice in estimation of cell surface antigens is flow cytometry analysis. The aim of the present study is to inform about the possibilities and limitations of this method, especially in immunodiagnosis"of leukemia.

\section{Keywords:}

Flow cytometry - immunological diagnosis of leukemia

\section{Einleitung}

Mit Hilfe der Durchflußzytometrie können, ähnlich wie bei der Fluoreszenzmikroskopie, Zellpopulationen mittels Markierung durch fluorochromierte monoklonale Antikörper identifiziert und quantifiziert werden. Bei beiden Methoden werden die Antikörper direkt oder indirekt mit Fluoreszenzfarbstoffen markiert und somit sichtbar gemacht. Der Vorteil der Durchflußzytometrie liegt in der wesentlich höheren untersuchten Zellzahl sowie in der weitgehenden Ausschaltung des subjektiven Faktors bei der Auswertung. Zudem ist der Arbeitsaufwand deutlich geringer. Auch mit durchflußzytometrischen Methoden ist es möglich, Aussagen über Größe und Granularität der Zellen zu treffen und somit eine Zuordnung der ermittelten Werte zu einzelnen Zellpopulationen vorzunehmen.

\section{Material und Methoden}

Zur Untersuchung gelangte heparinisiertes Venenblut von Patienten, bei denen die Diagnose einer Leukämie bereits morphologisch und zytochemisch gesichert worden war. Zur Aufbereitung von Blutproben für die Durchflußzytometrie gibt es verschiedene Möglichkeiten $(1,3,4)$ :

1. Isolierung der mononukleären Zellen durch Zentrifugation über einen Dichtegradienten (z. B. FikollNisotrast).

2. Vollblutmethode mit Lyse der Erythrozyten, z. B. durch Ameisensäure.

Beide Möglichkeiten wurden von uns angewandt.
Die verwendeten monoklonalen Antikörper (Coulter Electronics $\mathrm{GmbH}$, Krefeld) waren nur zum Teil direkt markiert. Bei den unmarkierten Antikörpern wurde die Markierung in einem zweiten Arbeitsschritt mit Fluoreszeinmarkiertem Ziege-anti-Maus-Serum (Sifin, Berlin) vorgenommen. Die Auswertung erfolgt mit dem EPICS-Profile I-System (Coulter Electronics $\mathrm{GmbH}$, Krefeld).

\section{Prinzip der Durchflußzytometrie}

Nach dem Ansaugen der präparierten Zellsuspension werden die Zellen einzeln hintereinander angeordnet. Dies geschieht, indem sie in einen bestehenden Flüssigkeitsstrom gepreßt werden. Damit ist gewährleistet, daß jeweils nur eine Zelle den Laserstrahl passiert. Bei dieser Passage durch den Laserstrahl entstehen Streulicht- und Fluoreszenzimpulse. Das entstehende Vorwärtsstreulicht ist ein Maß für die Zellgröße, das Seitwärtsstreulicht ein Maß für die Granularität einer Zelle. Mit Hilfe der Darstellung dieser beiden Parameter in einem Histogramm ist die. Unterscheidung von Lymphozyten, Monozyten und Granulozyten aus einer Voliblutprobe möglich (Abb. 1). Die Auswertung der ebenfalls entstehenden Fluoreszenzimpulse erfolgt mit Hilfe von Filtersystemen, was eine Unterscheidung zwischen roten und grünen Impulsen und somit die Doppelmarkierung von Zellen ermöglicht. Die Intensität der Fluoreszenz wird als Maß für die Antigendichte auf den Zellen ebenfalls registriert. Mit Hilfe von beliebig formbaren elektronischen Fenstern, sogenannten Bitmaps, kann die interessierende Zellpopulation eingegrenzt und isoliert ausgewertet werden. So 
wird eine differenzierte Beurteilung einzelner Populationen möglich (5).

\section{Beispiele und Ergebnisse}

Die Identifizierung der leukämischen Zellpopulation innerhalb der Gesamtleukozyten gestaltet sich von Patient zu Patient verschieden. Nicht immer unterscheiden sich die malignen Zellen in Größe und/oder Granularität so eindeutig von den gesunden Zellen, daß sich ein deutliches Areal im Streubild (Vorwärts- gegen Seitwärtsstreulicht) abgrenzt. Ein Beispiel für gute Auswertbarkeit zeigen Abb. 2 und 3. Innerhalb der Lymphozyten stellen sich im Streubild 2 Populationen dar, die mit getrennten Bitmaps erfaßt (Abb. 2) und isoliert ausgewertet wurden (Abb. 3). Abb. 3a entspricht Bitmap 1 und enthält $8 \%$ BZellen, was einem Normalbefund entspricht. Abb. 3b entspricht Bitmap 2 und enthält zu $93 \%$ B-Zellen, dürfte also die Tumorzellpopulation darstellen. Besonders dann, wenn die malignen Zellen morphologisch uneinheitlich sind, ergibt sich eine bandförmige Verteilung im Streubild mit Überlagerung der gesunden Zellpopulation. In Abb. 4 ist ein Beispiel hierzu dargestellt. Die Lymphozyten (Fläche 1) nehmen einen breiteren Raum im Vorwärtsstreulicht ein als bei gesunden Personen. Eine klare Differenzierung von gesunden und Tumorzellen war bei diesem Patienten nicht möglich. Ein bei Leukämie häufig auftretendes Phänomen ist eine niedrige Antigendichte,

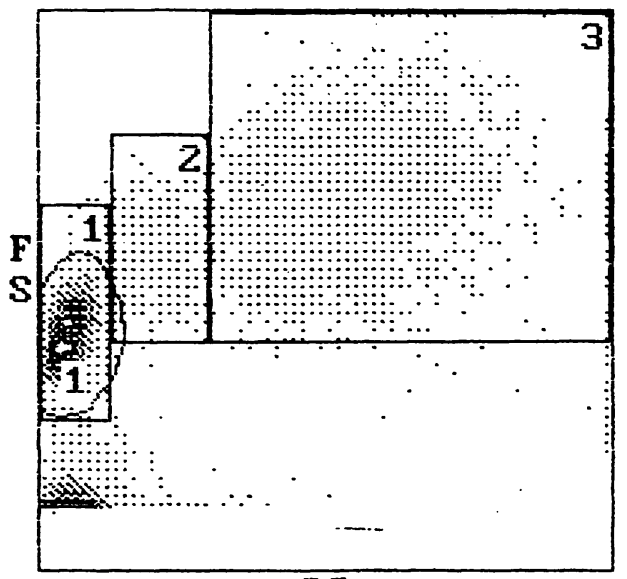

SS

\begin{tabular}{rrrrrrrr}
\multicolumn{1}{c}{ MIN MAX } & \multicolumn{2}{c}{ COUNT PERCENT } & MEAN & \multicolumn{2}{c}{ SD \% HPCV } \\
\hline $1 \times$ & 0 & 7 & 5096 & 37.2 & 3.0 & 1.8 & 94.8 \\
$\mathrm{Y}$ & 17 & 41 & & & 26.9 & 4.0 & 15.3 \\
$2 \mathrm{X}$ & 8 & 18 & 997 & 7.3 & 12.4 & 3.0 & \\
$\mathrm{Y}$ & 26 & 49 & & $\ldots$ & 36.0 & 4.6 & 11.9 \\
$3 \times$ & 19 & 63 & 4910 & 35.8 & 34.9 & 9.2 & 24.0 \\
$\mathrm{Y}$ & 26 & 63 & & & 42.5 & 7.5 & 19.5
\end{tabular}

Abb. 1: Streulicht-Histogramm einer Venenblutprobe nach Vollblut-Lyse

SS (Side Scatter) = Seitwärtsstreulicht als Maß für die Granularität der Zellen

FS (Forward Scatter) = Vorwärtsstreulicht als Maß für die Zellgröße

Flâche 1: Lymphozyten, Fläche 2: Monozyten, Fläche 3: Granulozyten

Die prozentualen Anteile der Zellen innerhalb der einzelnen Flächen in bezug auf die Gesamtpopulation sind der Tabelle zu entnehmen. Die Population unten links im Histogramm entspricht Zelltrümmern. d. h., Antigene, die auf Normalzellen in gut nachweisbarer Dichte vorkommen, sind auf Leukämiezellen oft nur spärlich vorhanden. Dadurch können nur geringe Fluoreszenzintensitäten nachgewiesen werden, welche sich dann mit der immer vorhandenen unspezifischen Reaktion überlagern. Diese unspezifische Reaktion setzt sich zusammen aus der Eigenfluoreszenz der Zellen und einer unspezifischen Reaktion mit dem primären und/oder dem sekundären Antikörper. Besonders deutlich tritt diese Erscheinung zutage, wenn man mit der Vollblutmethode und indirekter Markierungstechnik arbeitet, denn hierbei ist die unspezifische Reaktion besonders ausgeprägt. In einem solchen Fall empfiehlt sich die aufwendigere Dichtegradienten-Trennung der Leukozyten. Bei dieser Methode sind bei der Markierung Wasch-Schritte möglich und eine Alteration der Oberflächenantigene durch das Erythrozyten-Lyse-Medium entfällt ebenfalls. Abb. 5 zeigt einen Vergleich der bei indirekter Markierungstechnik üblichen Kontrolle zum Nachweis der unspezifischen Reaktion nach verschiedenen Aufarbeitungsmethoden. Hierbei wird nur der Sekundärantikörper ohne Primärantikörper zur Markierung der Zellen verwendet, eine spezifische Reaktion findet also normalerweise nicht statt. Die unspezifische Reaktion ist bei Aufarbeitung der Probe mittels Lysetechnik wesentlich ausgeprägter. Andererseits besteht bei der Dichtegradientenzentrifugation die Gefahr selektiver Zellverluste. Die Blutzellen werden bei dieser Methode nach ihrer Dichte getrennt. Monozyten und Lymphozyten haben eine geringere

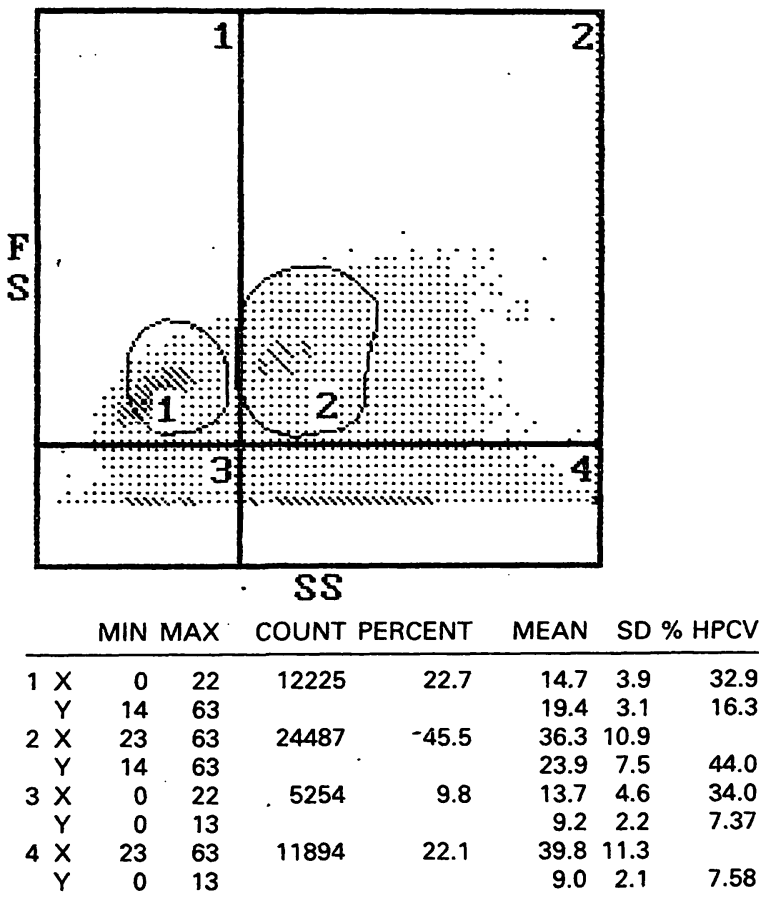

Abb. 2: Strey/icht-Histogramm der peripheren mononukleären Zellen eines Patienten mit einem niedrigmalignen Non-HodgkinLymphom (nach Dichtegradientenzentrifugation)

Fläche 1: Lymphozyten, Fläche 2: maligne Lymphozyten, Monozyten und einige Granulozyten, Flächen 3 und 4: Zelitrümmer 
3 a

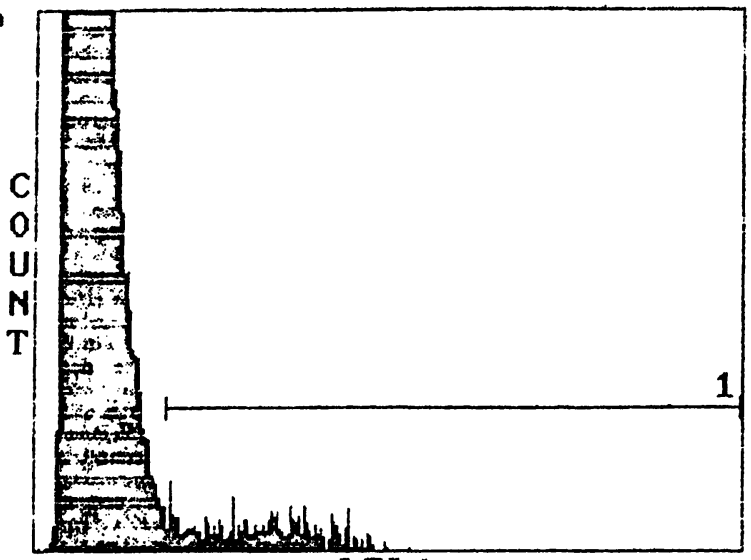

LFL 1

MIN MAX COUNT PERCENT MEAN SD \% HPCV

$\begin{array}{llllllll}1 & 3.640 & 1023 . & 713 & 8.0 & 9.409 & 1.863 & 1.99\end{array}$

3b

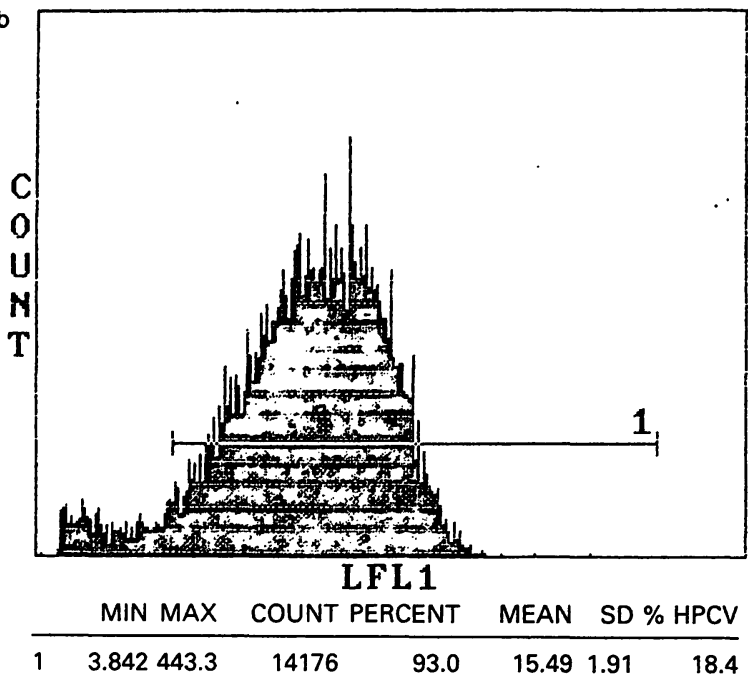

Abb. 3: Markierung der Zellen aus Abbildung 2 mit einem FITCmarkierten Antikörper gegen das B-Zell-Antigen CD72

LFL 1: logarithmische Darstellung der Fluoreszenzintensität 3a: Fluoreszenz der Zellen aus Bitmap 1 der Abbildung 2

3b: Fluoreszenz der Zellen aus Bitmap 2 der Abbildung 2

Dichte als Granulozyten und Erythrozyten. Letztere werden abzentrifugiert, während die mononukleären Zellen oberhalb des Gradienten verbleiben (1). Bei Leukämiezellen kann die Dichte und damit das Verhalten bei der Dichtegradientenzentrifugation verändert sein. Hier kann eine nach der Vollblutmethode präparierte Probe zum Vergleich des Streubildes herangezogen werden. Der Verlust relevanter Zellpopulationen ist dann sichtbar. Abb. 6a zeigt das Streubild eines Normalblutes nach Lysetechnik.

Abb. 5: Vergleich der bei indirekter Markierungstechnik üblichen Kontrolle (Markierung der Zellen mit dem Sekundärantikörper ohne Primärantikörper) zum Nachweis der unspezifischen Reaktion bei unterschiedlicher Aufarbeitungstechnik.

\section{5a: Lysetechnik}

5b: Dichtegradientenzentrifugation mit einem Waschvorgang nach der Markierung.

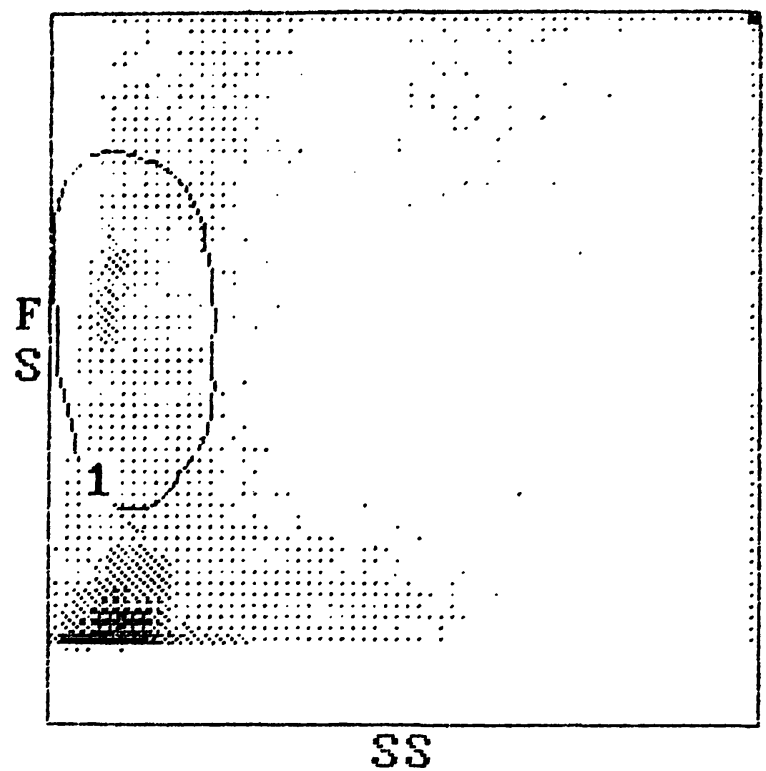

Abb. 4: Streulicht-Histogramm der peripheren mononukleären Zellen eines Patienten mit niedrigmalignem Non-Hodgkin-Lymphom (nach Dichtegradientenzentrifugation)
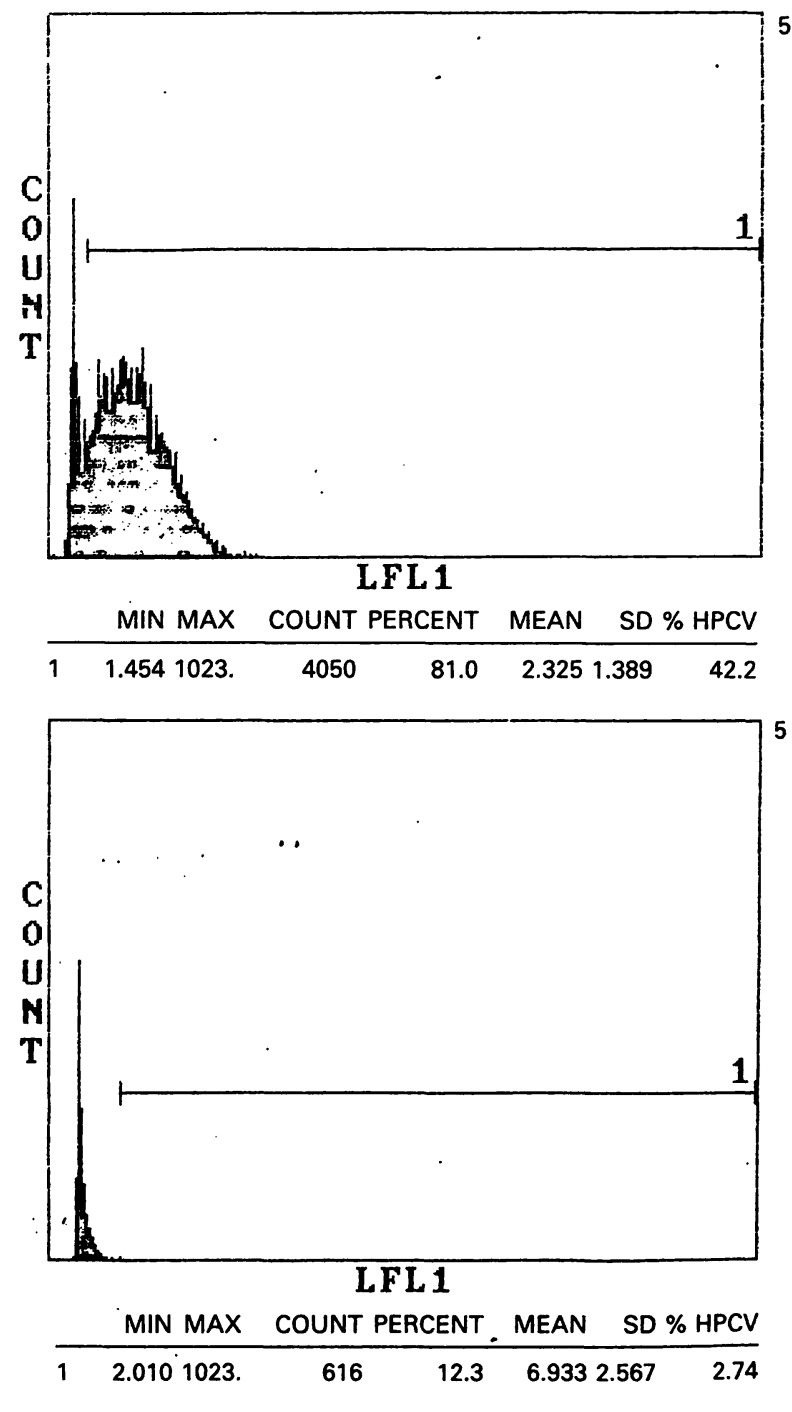


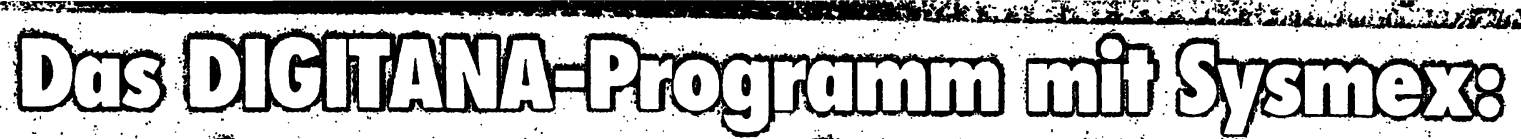

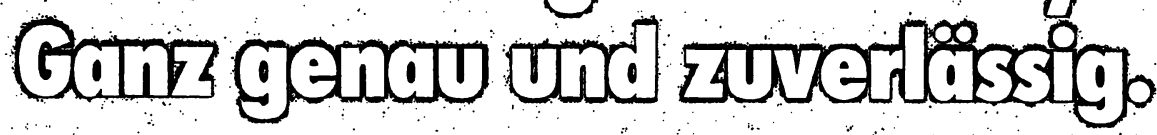

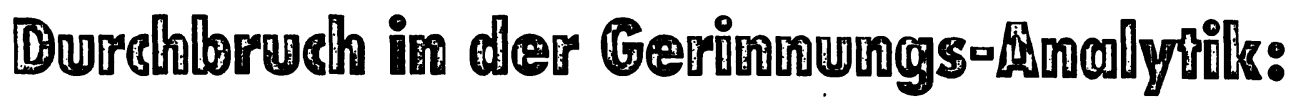

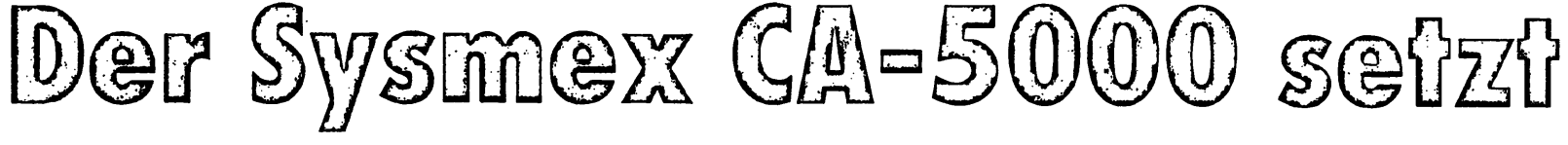

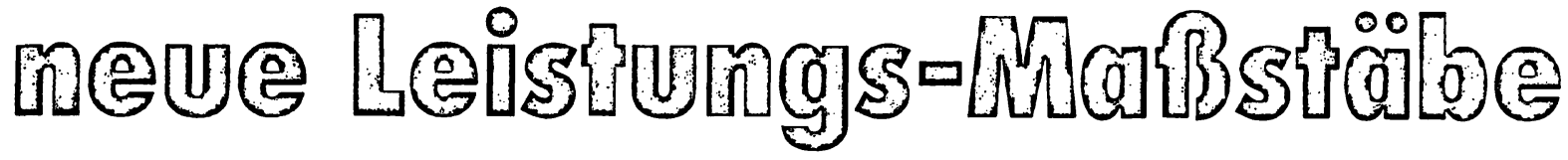

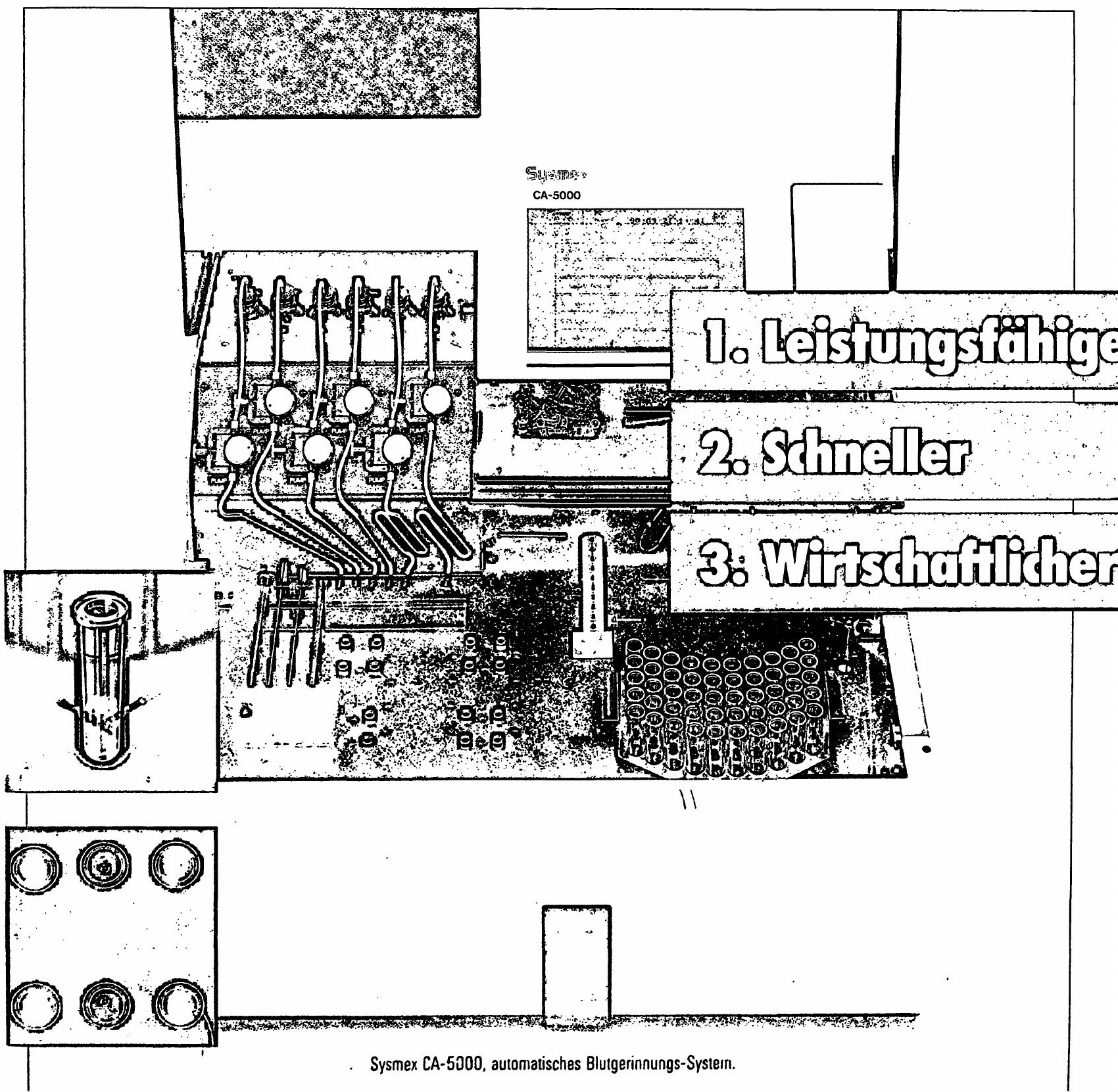




\section{STEmes Ch=EOCOOB

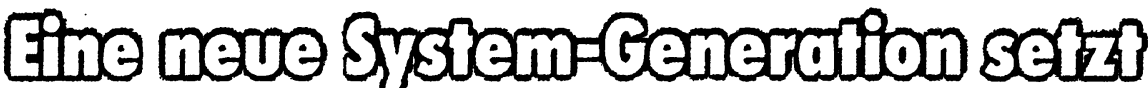

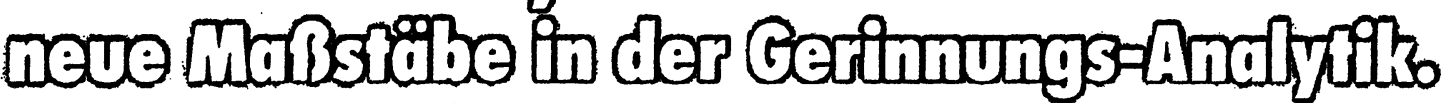

Mit dem Sysmex CA - 5000 ist erstmals ein leistungsfähiger, voll mechanisierter Mehrkanal-Analysator für die häufigsten Gerinnungs-Tests verfügbar,

O der mehrere Kanäle besitzt,

,offen“ für alle Reagenzien ist,

O probenselektiv und schnell arbeitet.

Das CA - 5000 System ist damit erstmals in der Lage, die Gerinnungs-Routine der großen Serien rationell abzuarbeiten.

Gleichzeitig, um den Bedürfnissen der Notfall- und Bereitschaftsanalytik zu entsprechen, erlaubt eine spezielle Entnahmestelle die separate Zufuhr von Plasmen, die mit Vorrang vor der laufenden Serie abgearbeitet werden.

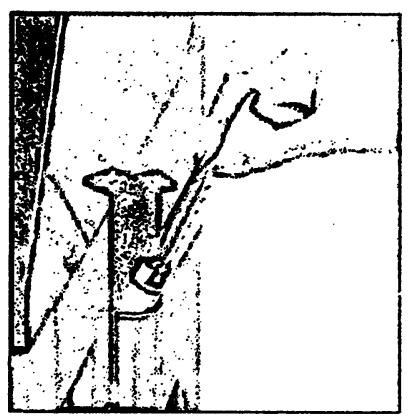

Einsetzen einer Notfallprobe

\section{Leisfungsfö̈higiger}

Der CA - 5000 bestimmt insgesamt 13 Parameter:

- 5 Globaltests (PT, APT, Fibrinogen, TT und HPT) können probenselektiv abgearbeitet werden.

- Hinzu kommen die 8 Einzelfaktoren des exogenen und endogenen Systems (II, V, VII, VIII, IX, X, XI und XII).

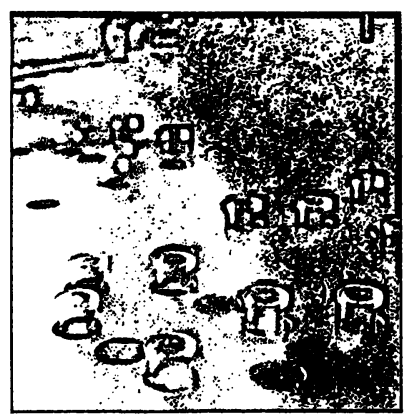

Proben in Inkubations- und Meßstellen

\section{Sehmeller}

Mit 16 Meßstellen und 24 Inkubationsstellen bewältigt der CA - 5000

- 30 Proben/Std. bei 5 Parametern

- 55 Proben/Std. bei 3 Parametern

- 120 Proben/Std. bei 1 Parameter

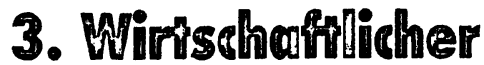

Die herausragende Wirtschaftlichkeit des Systems resultiert aus seiner Fähigkeit,

O die Gerinnungs-Routine der großen Serie vollmechanisiert, also personalsparend, abzuarbeiten,

- mit drastisch reduzierten Reagenzvolumina arbeiten zu können, (für die PT-Bestimmung sind nur noch $100 \mu$ I PT-Reagenz erforderlich, für die APTT-Bestimmung werden nur noch

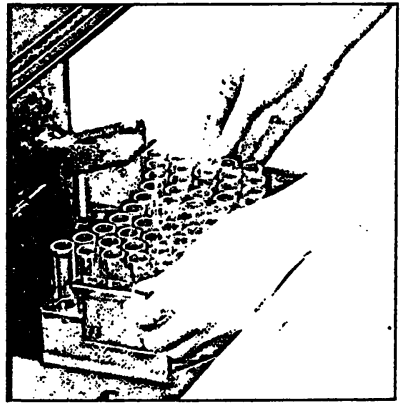

Rack bestückt mit Primärröhrchen $50 \mu \mathrm{PTT}$-Reagenz und $50 \mu \mathrm{C} \mathrm{CaCl} 2$ benötigt und für die Fibrinogen-Bestimmung nur noch $50 \mu \mathrm{l}$ Thrombin)

- den Einsatz von Primär-Röhrchen zu erlauben (die zentrifugierte Gerinnungsprobe kann direkt zur Proben-Pipettierung eingegeben werden). 
Alle Leukozytenpopulationen sind in der tatsächlichen Relation vorhanden. Abb. $6 \mathrm{~b}$ zeigt die Leukozyten nach der Dichtegradientenzentrifugation. Die Granulozyten sind deutlich reduziert, wodurch sich der Anteil der mononukleären Zellen beträchtlich erhöht. In Fläche 1, welche

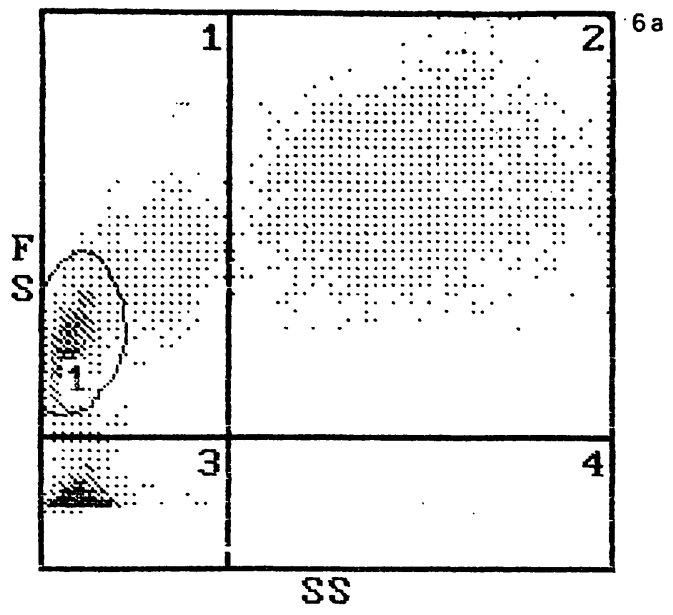

\begin{tabular}{|c|c|c|c|c|c|c|c|}
\hline \multirow[b]{2}{*}{$1 x$} & MIN & $\operatorname{MAX}$ & \multicolumn{2}{|c|}{ COUNT PERCENT } & \multirow{2}{*}{$\begin{array}{r}\text { MEAN } \\
5.1\end{array}$} & \multicolumn{2}{|c|}{ SD \% HPCV } \\
\hline & 0 & 20 & 6517 & 30.6 & & 4.6 & 56.9 \\
\hline$Y$ & 15 & 63 & & & 27.3 & 6.4 & 19.7 \\
\hline $2 x$ & 21 & 63 & 6170 & 29.0 & 41.5 & 10.1 & 25.2 \\
\hline$Y$ & 15 & 63 & & & 43.1 & 7.7 & 15.7 \\
\hline $3 x$ & 0 & 20 & 8557 & 40.2 & 3.7 & 2.0 & 43.7 \\
\hline$Y$ & 0 & 14 & & & 7.6 & 1.3 & 6.67 \\
\hline $4 x$ & 21 & 63 & 46 & 0.2 & 33.4 & 10.2 & 5.42 \\
\hline$Y$ & 0 & 14 & & & 9.8 & 2.3 & 9.10 \\
\hline
\end{tabular}

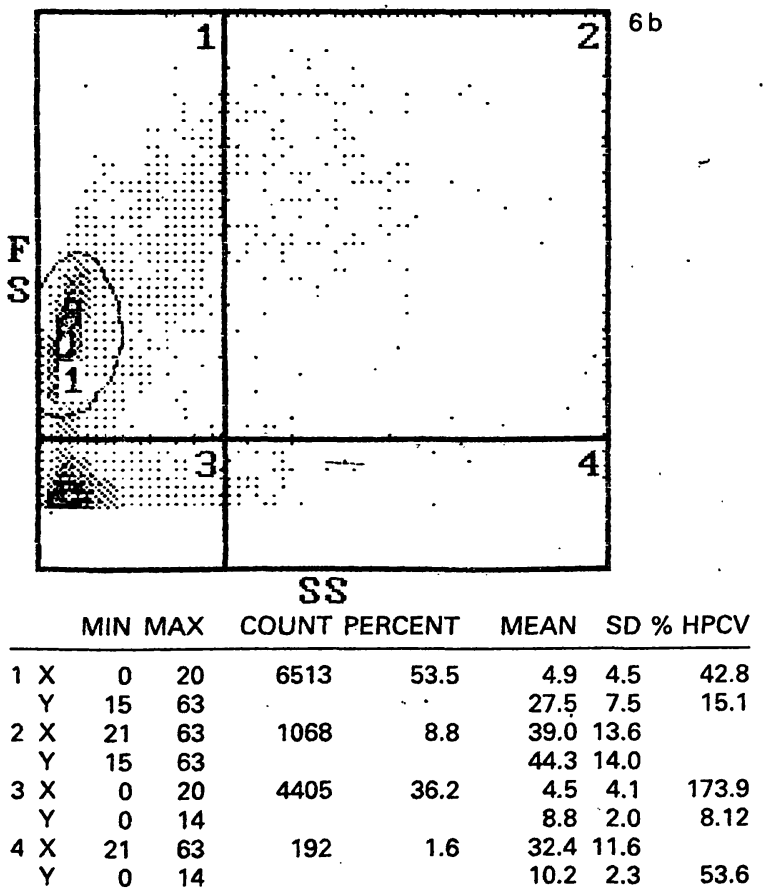

Abb. 6: Vergleich der Streubild-Histogramme des peripheren Blutes eines Gesunden nach verschiedenen Präparationsmethoden.

6a: Lysetechnik

6b: Dichtegradientenzentrifugation

Fläche 1: mononukleäre Zellen

Fläche 2: Granulozyten

Flächen 3 und 4: Zelltrümmer. diese Zellen enthält, befinden sich in Abb. 6 a $30,6 \%$ der Zellen, in Abb. 6b dagegen 53,0\%. Die Antikörperreaktion wird von der Präparationsmethode nicht beeinflußt. Abb. 7 zeigt einen Vergleich der Reaktion mit einem AntiB-Zell-Antikörper in der Lymphozytenpopulation nach verschiedenen Präparationsmethoden. Es sind $13,4 \%$ (Dichtegradient) bzw. 14,3\% (Lyse) der Zellen markiert, was einem identischen Befund entspricht.

\section{Schlußfolgerungen}

Die Bestimmung der Oberflächenmarker mit Hilfe der Durchflußzytometrie ist eine wertvolle Methode für die immunologische Leukämiediagnostik. Die Wertigkeit der erhaltenen Befunde kann bei einzelnen Patienten unterschiedlich sein in Abhängigkeit sowohl von der Antigendichte als auch von der Morphologie der malignen Zel-
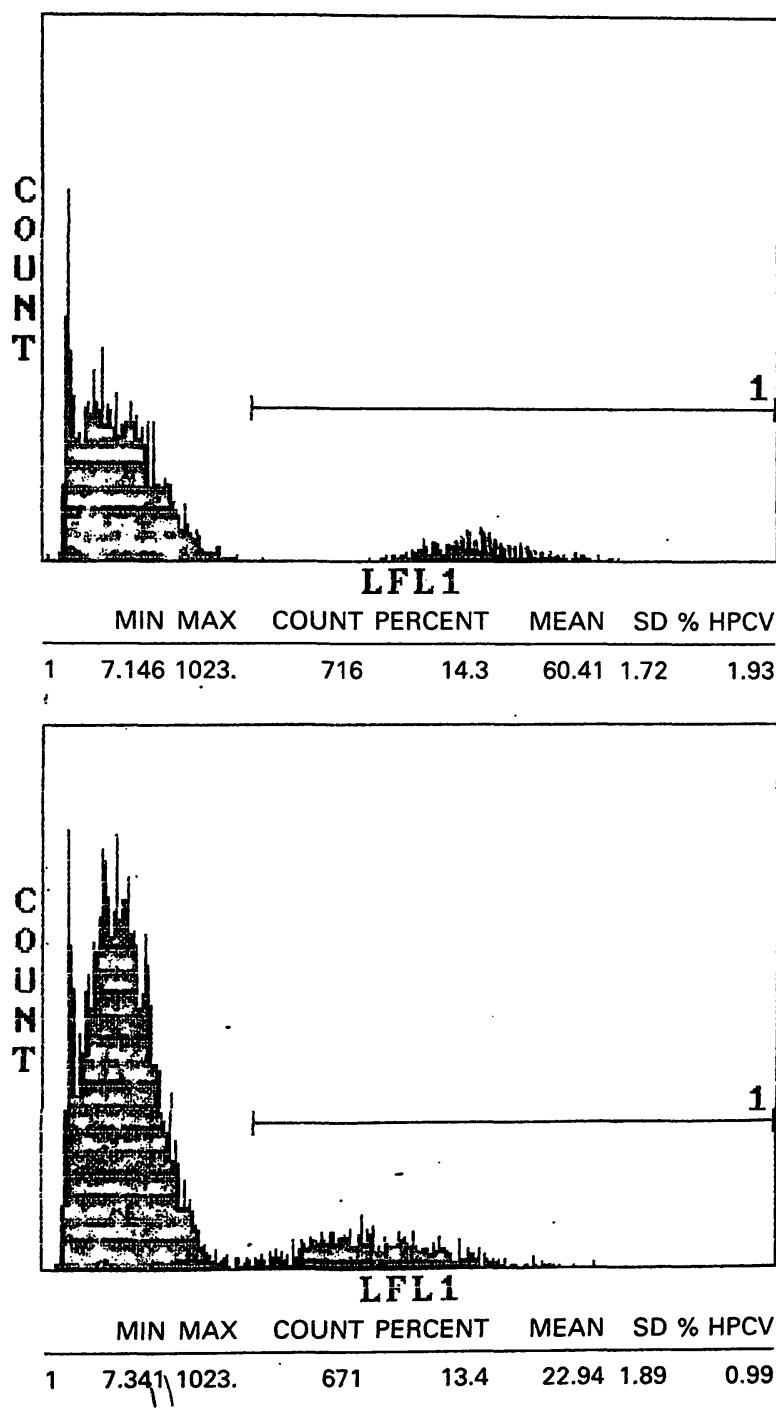

Abb. 7: Vergleich der Antikörperreaktion (Antikörper gegen das $B$-Zell-Ag CD20) innerhalb der Lymphozytenpopulationen aus Abbildung $\dot{6}$.

7a: Reaktion der Zellen innerhalb des Bitmaps in Abbildung 6a (Lysetechnik)

7b: Reaktion der Zellen innerhalb des Bitmaps in Abbildung $6 b$ (Dichtegradientenzentrifugation)

LFL1: logarithmische Darstellung der Fluoreszenzintensität. 


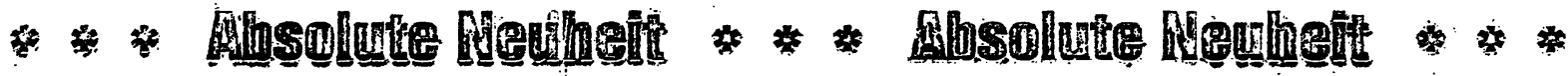

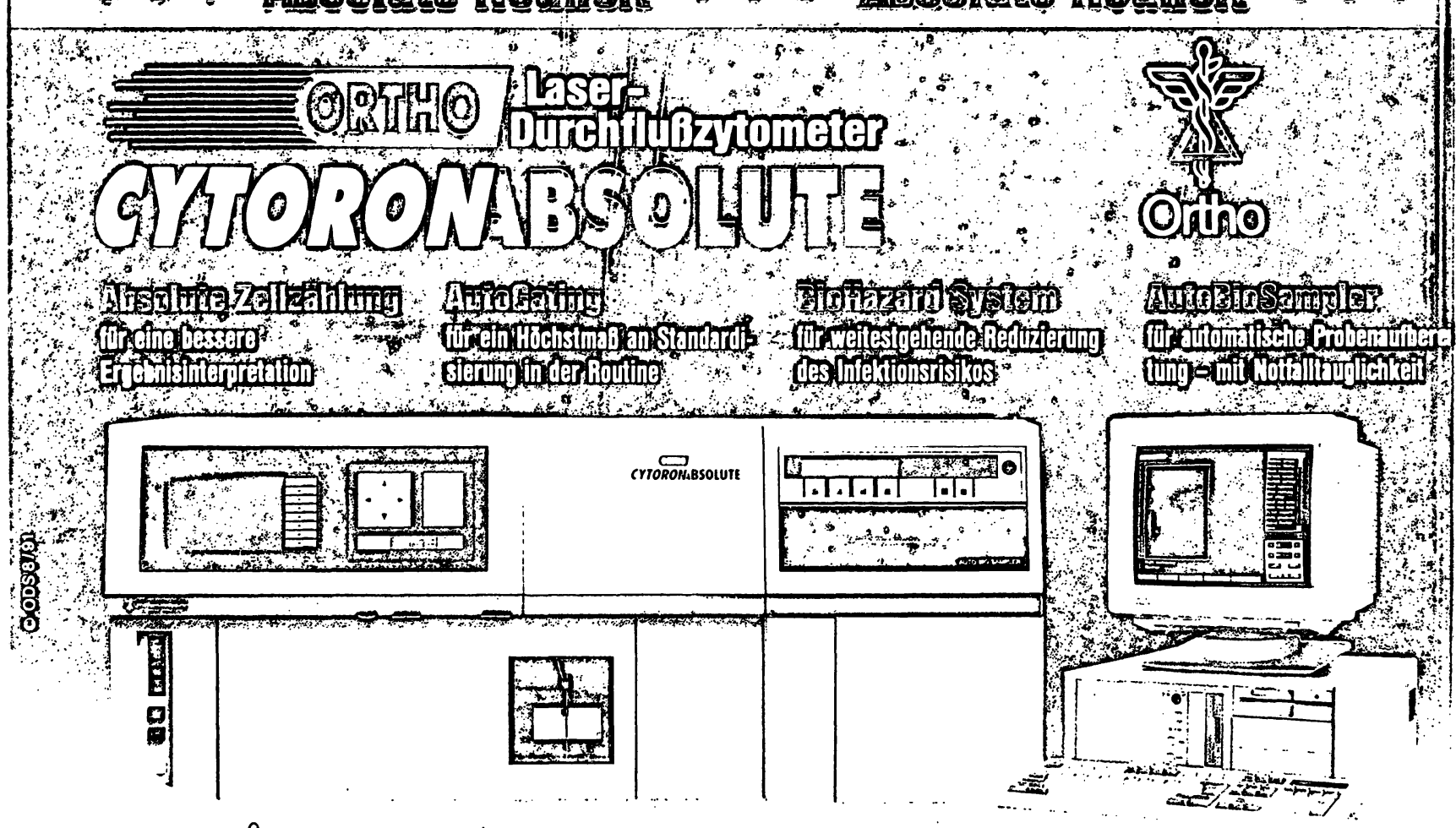




\title{
Empfehlungen zur Vorgehensweise bei der Untersuchung auf Toxoplasma-Antikörper in der Schwangeren- und der Kinder-Vorsorge
}

\section{Recommendations about proceedings for Toxoplasma antibody screening} in mother and child care

\section{K. Janitschke*}

Robert-Koch-Institut des Bundesgesundheitsamtes, Berlin

\begin{abstract}
Zusammenfassung:
Eine Kommission des Bundesgesundheitsamtes empfiehlt die Untersuchung aller Schwangeren und der überwachungsbedürftigen Kinder auf Toxoplasma-Antikörper. Dazu werden Richtlinien für die Auswahl von Testmethoden und dẹren Anwendung gegeben (Tab. 1-3). Besonderer Wert ist dabei auf die Qualitätssicherung zu legen.
\end{abstract}

Schlüsselwörter:

Toxoplasmose - Serodiagnostik - Schwangerenvorsorge - Kindervorsorge - Qualitätssicherung

\section{Summary:}

An advisory board of the Federal Health Office recommends the screening for Toxoplasma antibodies in all pregnant women and children, which need to be watched. Lines of directions are given for the selection of methods and their applications (tab. 1-3). Great importance has to be attached on quality assurance.

Keywords:

Toxoplasmosis - serodiagnosis - mother care - child care - quality assurance

\section{Einleitung}

Nach den derzeit geltenden Mutterschafts-Richtlinien (geänderte Fassung vom 12.1. 1989) gehören zur Betreuung der Schwangeren serologische Untersuchungen auf Toxoplasmose bei begründetem Verdacht. Nur in wenigen FälIen verläuft jedoch die Infektion mit klinischen Erscheinungen. Ein Verdacht ist daher fast ausschließlich nur epidemiologisch zu begründen. Infektionsmöglichkeiten bestehen bei der Zubereitung rohen Fleisches, dessen Verzehr, auch im halbgaren Zustand, Kontakt mit Erdboden, der Toxoplasma-Oozysten enthalten kann, und Aufnahme eventuell damit kontaminierten Rohgemüses. Eine Risikogruppe ist daher nicht zu definieren. Für alle Personen besteht ein Risiko, auch wenn man es vorbeugend vermindern kann. Daher empfiehlt das Bundesgesundheitsamt, daß sich grundsätzlich alle Frauen kurz vor oder möglichst früh in einer Schwangerschaft auf Toxoplasma-Antikörper untersuchen lassen. Nach den zur Zeit gültigen Mutterschafts-Richtlinien hat der konsultierte Arzt zu entscheiden, ob er alle oder nur einzelne Frauen serologisch prüfen läßt. Gibt er eine serologische Untersuchung in Auftrag, so haben die Kassen die Kosten zu tragen. Mit welchen Methoden dabei vorgegangen werden sollte, ist von der Kommission des Bundesgesundheitsamtes "Toxoplasmose und Schwangerschaft" erarbeitet worden und wird hier mitgeteilt.

* als Vorsitzender der Beratenden Kommission des Bundesgesundheitsamtes "Toxoplasmose und Schwangerschaft".
Ziel ider Untersuchungen ist die frühzeitige Erkennung und Behandlung der Erstinfektion, und damit ist auch die gesundheitliche Überwachung der von diesen Müttern geborenen Kinder eingeschlossen. Das ist nach den geltenden Kinder-Richtlinien (geänderte Fassung vom 3.7. 1987) möglich, obwohl die pränatale Toxoplasma-Infektion dort nicht wörtlich aufgeführt ist. Auch für die serologische Untersuchung dieser Kinder wird die von der o. g. Kommission empfohlene Vorgehensweise vorgestellt.

\section{Untersuchungen im Rahmen der Kinderwunsch- und der Schwangeren-Sprechstunde}

Nach eingehender Prüfung verschiedener Möglichkeiten hat sich aufgrund wissenschaftlicher, labortechnischer und finanzieller Abwägung eine 3-Stufen-Diagnostik als optimal erwiesen (s. Tab. 1, auch bezüglich der Abkürzungen). Hinsichtlich der anwendbaren kommerziellen Produkte werdeip |keine Angaben gemacht. Hierzu wird auf die einschlägigen Publikationen verwiesen, und es sind eigene Erfahrungen zu sammeln.

Im einzelnen wird die folgende Vorgehensweise empfohlen (s. auch Tab. 2):

Ein Toxoplasma-Antikörper-Suchtest (mittels DA, IIF oder SFT) sollte möglichst schon vor einer geplanten Schwangerschaft vorgenommen werden, weil dadurch eine Interpretation des Befundes leichter möglich ist als während 
Tab. 1: Methoden der 3-Stufen-Diagnostik zum Nachweis von Toxoplasma-Antikörpern im Rahmen der Kinderwunsch- und der Schwangeren-Sprechstunde

\section{Toxoplasma-Antikörper-Suchtest (qualitativ)}

Dazu sind Teste zu verwenden, bei denen Antikörper gegen Membranantigene nachgewiesen werden.

1. Direkte Agglutination (DA) oder

2. Indirekter Immunfluoreszenztest (IIF) (entsprechend den Verfahrensrichtlinien des Bundesgesundheitsamtes - Bundesgesundhbl. 31 (1988) 408, 32 (1989) 552-553), positiv = 1:16 oder

3. Sabin-Feldman-Test (SFT) (entsprechend den Verfahrensrichtlinien des Bundesgesundheitsamtes - Bundesgesundhbl. 32 (1989) 553-555), positiv $=1: 16$

II. Toxoplasma-IgM-Antikörper-Test (quantitativ)

1. Enzymimmunoassay (EIA-IgM) oder

2. Immunosorbent Agglutination Assay (ISAGA)

III. Toxoplasma-Abklärungstest (quantitativ)

1. Indirekter Immunfluoreszenztest s. I 2 (Titerstufen 1:16, 1:64 usw.)

oder

2. Sabin-Feldman-Test s. I 3 (Titerstufen 1:16, 1:64 usw.)

einer Gravidität und darüber hinaus Kosten eingespart werden können. Wurden bei dieser Untersuchung Toxoplasma-Antikörper nachgewiesen, so erübrigen sich weitere Untersuchungen während der Schwangerschaft. Wird ein Suchtest erstmalig während einer Frühschwangerschaft durchgeführt und werden mit diesem Test keine Toxoplasmaantikörper nachgewiesen, so sind weitere Suchteste im Verlauf der Schwangerschaft im Abstand von 8 bis 12 Wochen vorzunehmen. Im Falle einer Serokonversion hat eine Erstinfektion stattgefunden. Werden bei der Erstuntersuchung Antikörper festgestellt, so ist folgendermaßen zu verfahren:
Mit derselben Serumprobe ist ein Toxoplasma-lgM-Antikörper-Test (mittels EIA-IgM oder ISAGA) vorzunehmen. Werden IgM-Antikörper nicht festgestellt, so erübrigen sich weitere Untersuchungen während der Schwangerschaft. Gelingt der Nachweis von IgM-Antikörpern, so ist wie folgt zu verfahren:

Mit derselben Serumprobe ist ein Toxoplasma-Abklärungstest (mittels IIF oder SFT) vorzunehmen. Bei einem Titer von 1:256 oder darunter ist eine Erstinfektion nicht nachweisbar. Beträgt der Titer 1:1024 und lag im Toxoplasma-IgM-Antikörper-Test ein hoher Wert (s. Diskussion) vor, so kann eine Erstinfektion bestehen. Zur Klärung ist 8 bis 10 Tage nach der ersten Blutprobe eine zweite zu entnehmen. Ist der Titer auf mindestens 1:4096 angestiegen, so handelt es sich um eine Risikoschwangerschaft. Sie liegt auch dann vor, wenn dieser Titer bereits bei der ersten Blutprobe festgestellt wird.

Bei der Geburt ist das Blut der Mutter und das des Kindes auf Tóxoplasma-lgM-Antikörper (mittels EIA-IgM oder ISAGA) und Toxoplasma-Antikörper (mittels IIF oder SFT) zu untersuchen. Werden Toxoplasma-IgM-Antikörper übereinstimmend im Nabelschnur- und peripheren Blut des Kindes nachgewiesen, so ist von einer pränatalen Infektion auszugehen. Bei negativem Toxoplasma. IgM-Antikörperbefund und einem IIF- oder SFT-Titer von mindestens 1:1024 gilt das Kind nach den folgenden Empfehlungen trotzdem als überwachungsbedürftig.

\section{Untersuchungen im Rahmen der Kinder-Vorsorge}

Für die Untersuchungen auf Toxoplasma-Antikörper sind die Zeitpunkte durch die Kinder-Richtlinien (U3 bis U5) vorgegeben. Die dabei angewandten serologischen Methoden sind der EIA-IgM oder der ISAGA für IgM-Antikör. per bzw. der IIF oder SFT für Gesamtantikörper (Tab. 3).

Bilden sich im Verlauf der Früherkennungsuntersuchungen (U3 bis U5) Toxoplasma-IgM-Antikörper, so ist von einer pränatalen Infektion auszugehen. Das kann auch angenommen werden; wenn keine Toxoplasma-IgM-Anti-

Tab. 2: Vorgehensweise bei der Serodiagnostik der Toxoplasma-Infektion im Rahmen der Kinderwunsch- und der SchwangerenSprechstunde

(Vorschlag der Kommission des Bundesgesundheitsamtes "Toxoplasmose und Schwangerschaft")

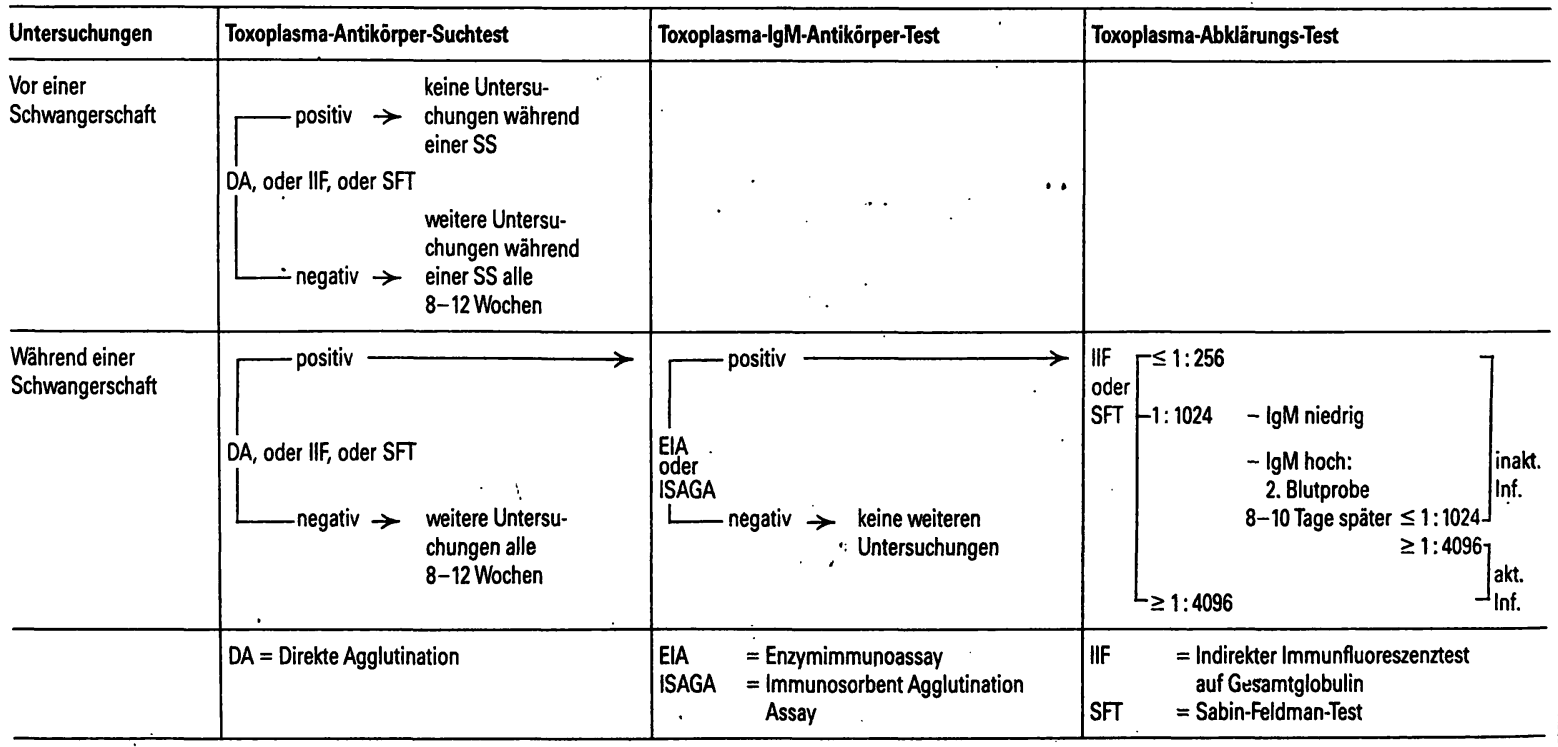


Tab. 3: Vorgehensweise bei der Serodiagnostik der pränatalen Toxoplasma-Infektion im Rahmen der Schwangeren-und Kindervorsorge

(Vorschlag der Kommission des Bundesgesundheitsamtes "Toxoplasmose und Schwangerschaft")

\begin{tabular}{|c|c|c|c|c|}
\hline \multirow[b]{2}{*}{ Untersuchung } & \multicolumn{2}{|c|}{ Antikörperteste } & \multicolumn{2}{|c|}{ pränatale Infektion } \\
\hline & $\begin{array}{l}\text { ElA-IgM } \\
\text { oder } \\
\text { ISAGA }\end{array}$ & $\begin{array}{l}\text { IIF } \\
\text { oder } \\
\text { SFT }\end{array}$ & nein & ja \\
\hline $\begin{array}{l}\text { U } 1 \\
\text { (1. Tag p. p.) } \\
\text { (Nabelschnur- und } \\
\text { peripheres Blut) }\end{array}$ & $\begin{array}{l}\text { pos. } \\
\text { neg. }\end{array}$ & $\begin{aligned} \geq & 1: 4096 \\
\geq & 1: 256 \\
& 1: 1024 \\
& \downarrow\end{aligned}$ & $\mathbf{x}$ & $\begin{array}{l}x \\
x\end{array}$ \\
\hline $\begin{array}{l}\text { U } 3 \\
\text { (4. }-6 \text {. Wo. p. p.) }\end{array}$ & $\begin{array}{l}\text { pos. } \\
\text { neg. }\end{array}$ & $\begin{aligned} \geq 1: 4096 \\
\leq 1: 256 \\
1: 1024 \\
\quad \downarrow\end{aligned}$ & $x$ & $\begin{array}{l}x \\
x\end{array}$ \\
\hline $\begin{array}{l}\text { U } 4 \\
\text { (3. }-4 \text {. Mo. p. p.) }\end{array}$ & $\begin{array}{l}\text { pos. } \\
\text { neg. }\end{array}$ & $\begin{array}{l}\geq 1: 4096 \\
\leq 1: 256 \\
1: 1024 \\
\quad \downarrow\end{array}$ & $x$ & $\begin{array}{l}x \\
x\end{array}$ \\
\hline $\begin{array}{l}\cup 5 \\
\text { (5.-6. Mo. p. p.) }\end{array}$ & $\begin{array}{l}\text { pos. } \\
\text { neg. }\end{array}$ & $\begin{array}{l}\leq 1: 256 \\
\geq 1: 1024\end{array}$ & $x$ & $\begin{array}{l}x \\
x\end{array}$ \\
\hline
\end{tabular}

\section{EIA = Enzymimmunoassay}

IIF = Indirekter Immunfluoreszenztest auf Gesamtglobulin

ISAGA = Immunsorbent Agglutination Assay

SFT = Sabin-Feldman-Test

körper auftreten, aber der IIF- oder SFT-Titer bis zur U5 bei mindestens 1: 1024 persistiert oder ansteigt.

\section{Qualitätssicherung}

Die Ergebnisse serologischer Untersuchungen auf Toxoplasma-Antikörper bei Schwangeren können schwerwiegende Entscheidungen nach sich ziehen. Daher ist die Sicherung der Qualität der Antikörpernachweise unabdingbare Voraussetzung, diese Teste überhaupt vornehmen zu können. Die derzeitige Situation ist nicht befriedigend. Keines der ca. 70 kommerziellen Produkte ist zulassungspflichtig, und es besteht für die ca. 800 Laboratorien, die entsprechende Untersuchungen vornehmen, keine Pflicht zur Teilnahme an Ringversuchen zur Qualitätssicherung. Die o. g. Kommission schlägt daher eine Registrier- und Prüfungspflicht für die einschlägigen kommerziellen Produkte vor. Damit wäre auch eine wesentliche Voraussetzung aus dem Bundesausschuß Ärzte und Krankenkassen erfüllt, um die Diskussion zur Erweiterung der Mutterschafts-Richtlinien hinsichtlich der Untersuchung aller Schwangeren auf Toxoplasma-Antikörper wieder aufzunehmen (3). Mit einer Zulassungspflicht wäre die derzeit einzige Möglichkeit gegeben, deren Anzahl auf die geeigneten Präparate zu beschränken. Dennoch wird empfohlen, die in der Tabelle 1 genannten Methoden und die in den Tabellen 2 und 3 dargestellten Vorgehensweisen anzuwenden.

Die wesentlichste Möglichkeit zur Qualitätssicherung der serologischen Untersuchungen ist die Teilnahme an Ringversuchen. Damit kann gesichert werden, daß geeignete
Produkte verwendet und die Teste korrekt vorgenommen werden. Seit 6 Jahren laufen zweimal jährlich diese Ringversuche (Parasitenimmunologie I) auf freiwilliger Basis, organisiert durch das Institut für Standardisierung und Dokumentation in der Medizin (INSTAND). Bei der Auswertung der Ergebnisse wird größter Wert darauf gelegt, den Laboratorien bei der Verbesserung der Qualität der Untersuchungen behilflich zu sein. Dazu steht auch ein Kalibrationsserum Toxoplasmose zur Verfügung, das vom Institut für Medizinische Parasitologie der Universität Bonn abgègeben wird.

Zur Ausführung der Richtlinien der Bundesärztekammer . zur Qualitätssicherung in medizinischen Laboratorien werden derzeit Richtlinien für die Pflichtteilnahme an Ringversuchen auch in der Toxoplasmose-Serologie vorbereitet.

\section{Schlußbemerkungen}

Bei den hiermit gegebenen Empfehlungen zur Vorgehensweise bei der Untersuchung auf Toxoplasma-Antikörper im Rahmen der Schwangeren- und Kindervorsorge kann es sich nur um Richtlinien handeln. Kein noch so detailliert ausgearbeitetes Untersuchungsschema kann alle Eventualitäten vorsehen. In Einzelfällen sind weitergehende Untersuchungen vorzunehmen. Die Empfehlungen basieren auf dem aktuellen Wissensstand. Sie müssen daher zu gegebener Zeit neueren Entwicklungen angepaßt werden. Derzeit wird untersucht, inwieweit $\mathrm{Me}$ thoden zum Nachweis von Toxoplasma-IgA-Antikörpern zu einer Verbesserung der Diagnostik beitragen können.

Schließlich wird noch auf Literatur hingewiesen, die die hier dargestellten Empfehlungen untermauert bzw. weitere Informationen vermittelt.

Schrifttum:

1. ASPOCK, H. FLAMM, H. PICHER, O.: Die Toxoplasmose-Überwachung während der Schwahgerschaft - 10 Jahre Erfahrungen in Osterreich. Mitt. Osterr. Ges. Tropenmed. Parasit. 8, 105-113 (1986).

2. DESMONTS, G.: Toxoplasmosis in France. Asean J. Clin. Sc. 7, 89-109 (1987).

3. EFFERT, E., KRIMMEL, L.: Neue Aspekte in der gesetzlichen Mutterschaftsvorsorge. Dtsch. Árztebl. 87, B 1938-1940 (1990).

4. FRIESE, K.: Toxoplasmose-Test bei Graviden sollte obligat sein. Ärzte-Ztg. 11.9. 1990. 5. HENDERSON, J. B., BEATTIE, C. P., HALE, E. G., WRIGHT, T.: The evaluation of new services: possibilities for preventing congenital toxoplasmosis. Int. J. Epidem. 13, 65-72 (1984).

6. JANITSCHKE, K. BUSCH, W, KELLERSHOFEN, C.: Untersuchungen zur Anwendbarkeit der direkten Aglutination zur Toxoplasmoseüberwachung im Rahmen der Mutterkeit der direkten Agglutination zur Toxoplasmo
schaftsvorsorge. Imm. Inf. 16, 189-191 (1988).

schaftsvorsorge. Imm. Inf. 16, 189-191 (1988). 7. MAAS, G., GIESING, M.: Toxoplasma-Infektion. Un

8. PROMPELER, H. J., PETERSON, E. E.: Toxoplasmose-Diagnostik in der Schwangerschaft. Geburtsh. Frauenheilk. 49, 642-648 (1989).

9. SANDER, J., NIEHAUS, C.: Häufigkeit der Toxoplasmose-Erstinfektionen bei Schwangeren. Dtsch. Med. Wschr. 108, 455-457 (1983).

10. SANDOW, D. Hochrechnung zur Häufigkeit von primär toxoplasmainfizierten 10. SANDOW, D.: Hochrech

11. STURCHLER Donnatalen Toxoplasmosen. R. Bie konnatale Toxoplasmose in der 11. STURCHLER, D., BERGER, R., JUST, M.: Die
Schweiz. Schweiz. Med. Wschr. 117, 161-167 (1987).

Schweiz. Schweiz. Med. Wschr. 117, 161-167 (1987). 12. WERNER, H., JANITSCHKE, K.: Serodiagnostik der Toxoplasmose. Aktuelle Pro-
bleme unter besonderer Berücksichtigung der Schwangerenvorsorge. Kassenarzt 38, 40-45 (1985).

13. WILSON, C. B., REMINGTON, J. S.: What can be done to prevent congenital toxoplasmosis. Amer. J. Obst. Gyn. 138, 357-363 (1980).

Bei der Ausarbeitung der Empfehlungen waren folgende Mitglieder der BGA-Kommission "Toxoplasmose und Schwangerschaft" beteiligt: AspöckWien, Brade/Erlangen, Friese/Mannheim, Seitz/Bonn, Tietze/Berlin, Werner/Berlin.

\section{Anschrift des Verfassers:}

Dr. K. Janitschke

Direktor und Professor

Robert Koch-Institut des Bundesgesundheitsamtes

Nordufer 20

1000 Berlin 65 


\title{
Arzneimittel und Laborwerte: Stand 1991
}

\section{Drugs and Laboratory Results 1991}

\author{
P. Hagemann \\ Zentrallaboratorium, Kantonsspital Münsterlingon
}

\section{Zusammenfassung:}

Ziel: Die Übersicht will auf die Bedeutung von Arzneimittelstörungen bei der Interpretation von Laborwerten hinweisen und den Blick auf die am häufigsten beteiligten Arzneimittelgruppen fokussieren.

Quellen: Die Zusammenstellung stützt sich hauptsächlich auf die Bücher von Tryding und Roos (1989), Salway (1990) und Young (1990) sowie neuere Originalliteratur. Sie beschränkt sich auf klinisch relevante Störungen am Menschen.

Selektion: Als "klinisch relevant” wurden in der Regel solche Störungen aufgefaßt, die bei > 1-5\% der behandelten Patienten auftraten und bei Weiterführung der Medikation persistierten.

Synthese: Arzneimittelbedingte Störungen von Laborwerten sind überwiegend In-vivo-Nebenwirkungen. Sie werden hauptsächlich durch Arzneimittel aus folgenden Hauptgruppen der Roten Liste verursacht: Analgetika/Antirheumatika, Antiarrhythmika, Antibiotika, Antiepileptika, Antihypertonika, Sexualhormone und ihre Hemmstoffe sowie Zytostatika und Metastasenhemmer. Die betroffenen Arbeitsgebiete des Laboratoriums sind in erster Linie die Bestimmung von Metaboliten und Hormonen und die Zählung der Blutzellen.

Schlußfolgerungen: Insbesondere bei neuen Arzneimitteln sind mögliche Störungen prospektiv und interdisziplinär aufzuklären. Unter Einsatz geeigneter Informatikmittel ist der Anwender adäquat zu dokumentieren.

\section{Schlüsselwörter:}

Arzneimittelstörung - In-vivo-Nebenwirkung - Präanalytik

\section{Summary:}

Objective: The review focusses on the importance of drug interferences and drug effects in the interpretation of laboratory results. It emphasizes those drug groups which are most often causing problems.

Data sources: The review is primarily based on the books by Tryding and Roos (1989), Salway (1990), and Young (1990), as well as on more recent original articles. It is limited on clinically relevant effects on humans.

Selection: Effects were usually considered "clinically relevant" if > 1-5\% of treated patients were affected and the interference persisted under ongoing treatment.

Data synthesis: Drug induced interferences and drug effects on laboratory results are mostly biological effects. They are mainly due to drugs belonging to the following groups of the German "Red list": Analgetics/ antirheumatics, antiarrhythmics, antibiotics, anticonvulsants, antihypertonics, sexual hormones and their inhibitors, and cytostatics and metastasis inhibitors. The fields of laboratory work mostly concerned are determination of metabolites and hormones as well as blood cell counting.

Conclusions: Especially in new drugs potential drug interferences and drug effects should be evaluated prospectively and interdisciplinarily. The user should be documented adequately.

\section{Keywords:}

Drug interference - drug effect - biological effect - preanalytical problems

\section{Einführung}

Im Spannungsfeld rund um Arzneimittel geht es primär um die Wirkung. Die Diskussion um Nebenwirkungen droht gelegentlich diese Tatsache zu verschleiern. Schwer zu überblicken sind auch Interaktionen von Arzneimitteln untereinander. Schließlich beeinflussen Arzneimittel mit dem Stoffwechsel des Patienten auch Meßgrößen des Laboratoriums (Abb. 1). Das ist unerwartet, unerwünscht und wird oft kurzerhand als "Laborfehler" abgetan. Nur in wenigen Institutionen werden derartige Störungen in interdisziplinärer Zusammenarbeit von Arzt, Klinischem Pharmakologen und Klinischem Chemiker korrekt abgeklärt.

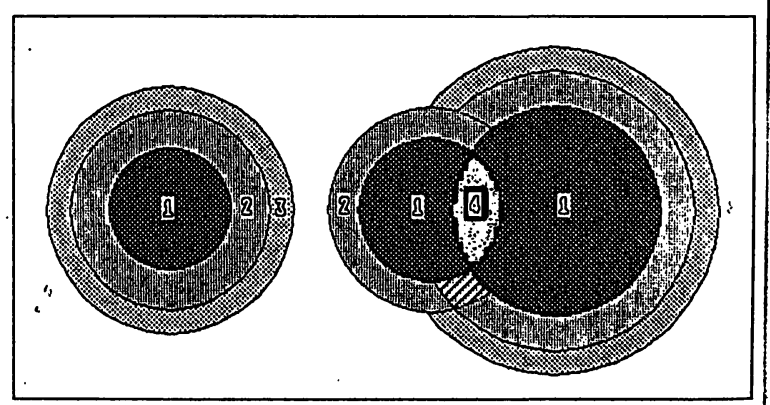

Abb. 1: Wirkungen (1), Nebenwirkungen (2), gestörte Laborwerte (3) und Interaktionen (4) von Arzneimitteln. 


\section{Hämatologie-Systeme in der Praxis:}

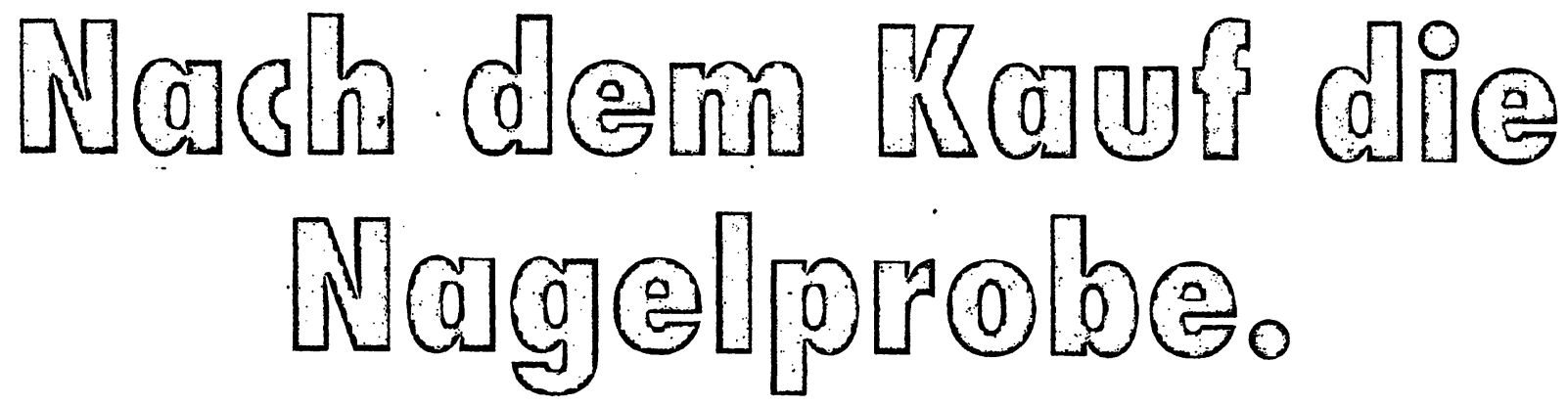

Hämatologie-Systeme sind keine Maschinen, die - einmal am Netz - praktisch wartungsfrei und unbeaufsichtigt arbeiten können. Es sind vielmehr komplexe Meßsysteme, die von Fachleuten bedient und von Fachleuten versorgt und gewartet werden müssen.

Darum endet auch eine Geschäftsbeziehung nicht mit dem Kauf eines Systems. Ganz im Gegenteil:

Hämatologie-Anwender wissen, daß sich die Qualität der Geschäftsbeziehung (und damit die Richtigkeit der Kaufentscheidung) erst nach dem Kauf erweist.

Stellen Sie daher rechtzeitig, d.h. vor dem Kauf, sicher, daß Sie danach nicht allein gelassen werden. Lassen Sie sich ein perfektes und bewährtes Service-System nachweisen, das Sie weder heute noch nach Jahren im Stich läßt.

Das ist Ihr gutes Recht. Fordern Sie es ein!

\section{Für die DIGITANA isf diese Forderung Verpflichfung.}

- Mit dem Angebot von Sysmex Hämatologie-Systemen, deren Genauigkeit, Zuverlässigkeit und einfache Bedienung weltweit Maßstäbe gesetzt hat.

- Mit einem lückenlosen Angebot vom Basisgerät (Ery, Leuko, $\mathrm{Hb} /$ bis hin zum Differenzier-Automaten und Flow-Zytometer.

- Mit einem dichten Netz von Service- und Beratungszentren in Deutschland und der Schweiz.

- Mit einem Stab von System-Beratern, die - aus der Praxis kommend - Innen individuell beistehen und Sie streng praxisorientiert (nicht provisionsorientiert) informieren und beraten.

- Mit einer wissenschaftlichen Leitung, die Mitarbeiterschulung, Anwenderkurse und Weiterbildung anbietet und in engem Kontakt mit Standesorganisationen und medizinischen Fachgesellschaften Trends der Hämatologie mitbestimmt.

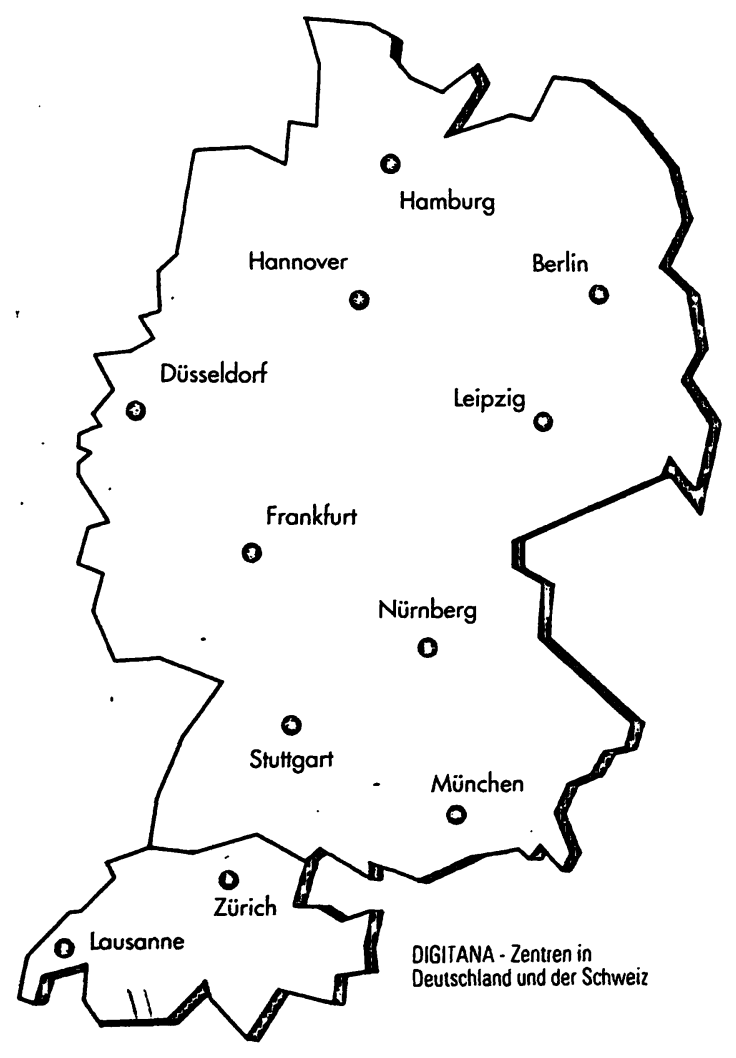

\section{Damif beste Sysfeme auch in der Praxis Bestes leisten.}

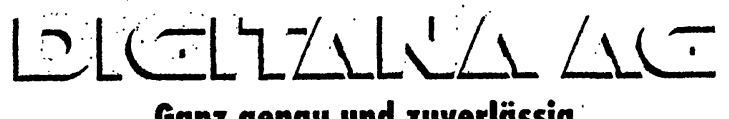

\section{Ganz genau und zuverlässig:}

D. 2000 Hamburg 76 . Weidestraße 118 b - Tel.: $040 / 2707050$ $\mathrm{CH}-8810$ Horgen 'Burghialdenstraße 11. Tel:: $01 / 7256191$ 


\section{Lassen Sie es}

$\mathrm{nicht} \mathrm{zum}$

Finanzchaos

$\mathrm{k}$ o $\mathrm{mm}$ e $\mathrm{n}$ !

Hand auf's Herz: Viele Ärtte lahen ihre Finanzen nicht im Griff - kein Wunder bei der knappen Zeit und den sich ständig verschärfenden Rahmenbedingungen.Überschuldung, Liquiditätsengpässe, unangemessene Investitionen, fehlende Personalplanung, Anlageflops usw.

Was passiert, wenn die Bank Ihnen den Hahn zudreht?!

Nicht auszudenken...

Deshalb, bevor es zu spät ist: Sichern Sie Ihre Zukunft mit CombiPlan, der Finaniprophylaxe des Arztes.

Endlich Klarheit über: Liquidität, Umsätze, Kosten, Gewinne, Fallzahlen, Fallwerte, Personal, Investitionen, Steuern

\section{Das System:}

edles Vollindleder bordeaux handliches Taschenformat $(15 \mathrm{~cm} \times 11 \mathrm{~cm})$,

Einsteckfach mitSolar-Tasschenrechner in Scheckkattenformat, übersichtliches Brevier, Finanzplan, gefaltet nicht größer als ein Taschenkalender.

\section{Die Leistung:}

Totalinformation über edes Quartal, Jahresübersicht 1991,1992 und 1993,

\section{COMBİ $\overline{\text { CLAN }^{\circledR}}$}

lierlag hirchheim + (o) (mmbH.

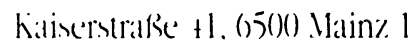

Transparenz für jeweils drei Jahre, geringer Zeitaufwand

Auf kleinstem Raumund in logischer Reihenfolge wird dem Arzt ein Informationssystem geboten das zu transparenten Zallenmaterial fühit und in idealer Weise die Informatoonen des Steuerbernters oder sogar der elgenen EDV ergänzt:

Bitte senden Sie mir Finanzplaner CombiPlan von G. Frielingsdorf im eleganten Lederetui, mit Solar-Taschenrechner und Brevier, für clie Vergleichsjahre 1991, 1992 und 1993, zum Preis von 148,- DM, ISBN 3-87409-181-3.

NAME:

STRASSE:

PLZ/ORT: 
Störungen von Laborwerten durch Arzneimittel waren als Spezialfall von Nebenwirkungen traditionell eine Domäne der Klinischen Pharmazeutik. In der entsprechenden Literatur nahm die Bedeutung dieses Wissenszweiges indessen in letzter Zeit sukzessive ab: Selbst ein renommiertes Werk wie Meyler's Side Effects of Drugs (4) behandelt Störungen von Laborwerten durch Arzneimittel nur am Rande, berücksichtigt 'fast ausschließlich hämatologische Parameter und beurteilt sie zudem gelegentlich in bezug auf überholte Labormethoden ( $z$. B. Aschheim-Zondek-Test für hCG). Ähnliches gilt vom "Goodman Gilman" (6). Im Lehrbuch von Hansten (9) ist ab der 5. Auflage (1985) der zweite Hauptteil „Drug Effects" überhaupt weggelassen. Es obliegt somit dem Klinischen Chemiker, in diesem Bereich der Präanalytik das Terrain zu entminen, zumal die Impräzision der verfügbaren Methoden immer geringer, somit gestörte Resultate immer offenkundiger werden.

Nach Vorarbeiten aus den sechziger Jahren legten Young et al. 1975 eine erste umfassende Zusammenstellung von Meßgrößen vor, die durch Arźneimittel gestört werden. Sonntag (1985) sowie Siest und Galteau (1988) publizierten erste systematische Untersuchungen auf der Basis therapeutischer Dosen. Die letzten Aufdatierungen der grundlegenden Tabellenwerke sind neueren Datums: Tryding und Roos 1989, Salway 1990, Young 1990. Stets handelt es sich freilich im wesentlichen um eindimensionale Listen. Sie beantworten grundsätzlich nicht die Frage nach der Relevanz der mitgeteilten Effekte. Zweifellos sind einzelne Störungen von Laborwerten durch Arzneimittel Hinweise auf ernste und schwerwiegende Komplikationen, andere aber keineswegs. Manche können durch entsprechende Vorsichitsmaßnahmen vermieden, sehr viele für alle klinisch-praktischen Zwecke ignoriert werden.

Arzneimittel stören Laborresultate als Einflußgrößen (in vivo) und/oder als Störfaktoren (in vitro, Abb. 2). Standen früher Störungen der Analytik im Vordergrund (Trübungen, falsch-erhöhte Meßwerte bei Anwendung unspezifischer Methoden etc.), so hat sich heute das Schwergewicht auf tatsächliche Verschiebungen im Stoffwechsel durch immer potentere Arzneimittel verschoben: Einflußgrößen dominieren über Störfaktoren. Darüber hinaus können gestörte, "falsche” Laborresultate natürlich Anzeichen ernsthafter Arzneimittelnebenwirkungen sein.

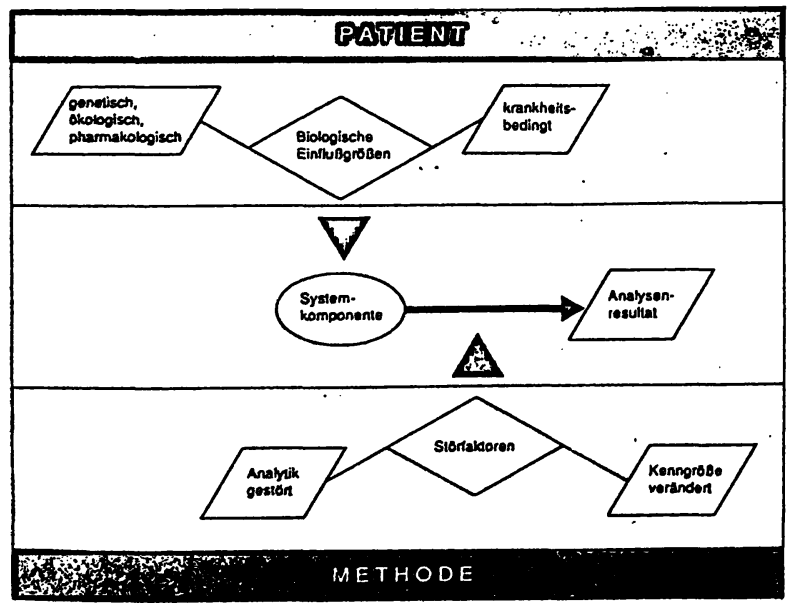

Abb. 2: Einflußgrößen und Störfaktoren auf der Achse von der Systemkomponente zum Analysenresultat (verändert nach [12]).

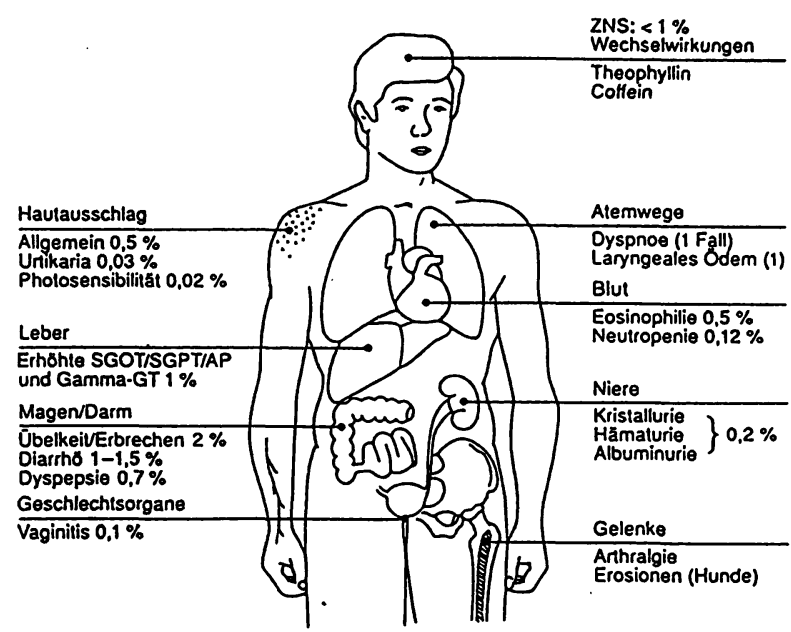

Abb. 3: Nebenwirkungen von Ciprofloxacin: Gesamthäufigkeit 10,2\%, signifikante Nebenwirkungen 5,6\% (Daten aus [17]).
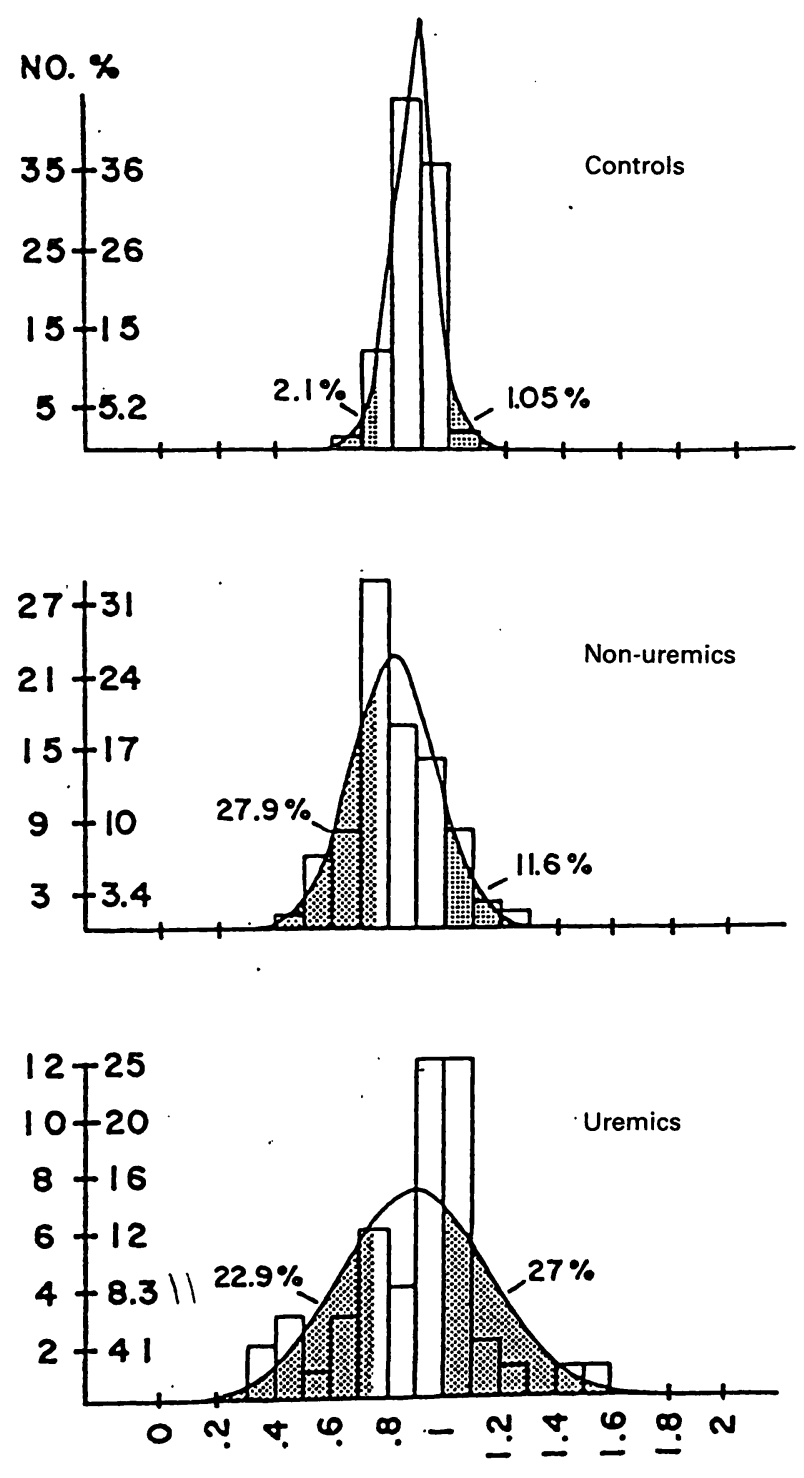

$\mathrm{mmol} / \mathrm{L}$

Abb. 4: S-Magnesium bei urämischen und nichturämischen Patienten unter Digoxin, verglichen mit einer Konitrollgruppe (22). 
Um Mißverständnisse zu vermeiden, ist in einzelnen Fällen die Matrix einer Meßgröße mit den durch die IFCC bzw. die IUPAC empfohlenen Abkürzungen angegeben: $B$ $=$ Blut, $S=$ Serum, $F=$ Stuhl, $U=$ Urin (24).

\section{Ein Fallbeispiel}

Ciprofloxacin ist ein neueres 4-Chinolon, ein Antibiotikum, das die bakterielle DNA-Gyrase blockiert. Vor der Registration 1987 wurden die Nebenwirkungen an einer Stichprobe von 8861 Probanden erfaßt (17). Bei insgesamt 902 der Patienten (10,2\%) waren irgendwelche Nebenwirkungen zu verzeichnen, freilich bei der Hälfte nur leichte und vorübergehende (Abb. 3). Die meisten Störungen von Laborwerten fallen in diese Kategorie, z. B. der vorübergehende Abfall der Leukozyten im Blut oder die Eosinophilie. Am häufigsten wurden erhöhte Aktivitäten der Leberenzyme gemessen, freilich in keinem Fall als Ausdruck einer irreversiblen Hepatotoxizität. In drei Fällen trat eine Kristallurie auf, ohnehin keine relevante Meßgröße des Laboratoriums. Zwei Patienten litten gleichzeitig an einer Niereninsuffizienz, in mehreren Fällen lag eine gleichzeitige Therapie mit Theophyllin vor, so daß keine eindeutige Kausalbeziehung hergestellt werden konnte. Unter den insgesamt 54 ernsthaften Nebenwirkungen waren in fünf Fällen Laborparameter betroffen, nämlich je ein Fall von Acidose, erhöhter Alkalischier Phosphatase, Hypercalcämie, Leukocytose und Hämolyse. Fazit im „Arzneimittel-Kompendium” als "Einflüsse auf Laborwerte: Besonders bei Patienten mit vorgeschädigter Leber kann es zu einem vorübergehenden Anstieg der Transaminasen und der alkalischen Phosphatase kommen; vorübergehender Anstieg von Harnstoff, Kreatinin und Bilirubin im Serum. Eosinophilie, Leukozytopenie, Leukozytose, Anämie".

\section{Mechanismen der Laborwertstörung}

Im Bereich der Einflußgrößen kann eine Störung der Homoeostase vorliegen: So beeinträchtigt Digoxin die Kontrolle über den Magnesiumspiegel im Serum, so daß eine breitere Streuung der Meßresultate beobachtet wird (22). Insbesondere bei urämischen Patienten treten ca. 10 mal mehr Hypomagnesiämien, aber auch 20 mal mehr Hypermagnesiämien auf als in der Kontrollgruppe (Abb. 4).

Die Mehrzahl der Störungen kann indessen klar einer Erhöhung bzw. Senkung des Meßresultates zugeordnet werden (8). Eine erste Gruppe betrifft durch Arzneimittel verursachte Organschäden:

- Unter dem Diureticum Furosemid wird oft ein Anstieg der S-Amylase gemessen, weil das Medikament eine Pankreatitis verursacht.

- Das Virostatikum Zidovudin ist knochenmarktoxisch; damit sinkt unter anderem die Hämoglobinkonzentration des Blutes.

Eine zweite Gruppe von Arzneimitteln verändert die Stoffwechsellage, so zum Beispiel:

- Phenytoin und andere Antiepileptica induzieren in der Leber die Synthese bestimmter Enzyme: damit steigt z. B. die gemessene Aktivität von ASAT oder insbesondere GGT.

- Acetylsalicylsäure, Cimetidin und Ranitidin hemmen die Alkoholdehydrogenase des Magens, so daß signifikant höhere Ethanolspiegel im Blut resultieren (15).
- Thiazid-Diuretica führen zu einem Anstieg der Harnsäure im Serum, weil sie durch eine Senkung der tubulären Sekretion die Ausscheidung verringern.

- Zytostatika führen bei erfolgreicher Therapie zu Einschmelzen von Organen mit massivem Zellzerfall und Freisetzung von Nukleotiden, wodurch der Harnsäurespiegel im Serum steigt.

- S-Albumin ist unter Infusionstherapie mit Dextranen häufig tief, weil das Polysaccharid eine Hämodilution bewirkt.

In einer dritten Gruppe sind es spezifische Eigenschaften des Arzneimittels selbst, welche zu Störungen führen:

- Unter dem Antikonvulsivum Valproat kann der Urinnachweis von Ketonen falsch-positiv ausfallen, weil das Arzneimittel teilweise in Ketonform ausgeschieden wird.

- Wird Penicillin als Kaliumsalz verabreicht, können in Serum und Urin erhöhte Kaliumkonzentrationen auftreten, weil 1 Mio. Einheiten 1,7 mmol/l Kalium enthält.

In einer vierten Gruppe schließlich können Rezeptoreffekte zusammengefaßt werden:

- Das Analgeticum Acetylsalicylsäure konkurriert z. B. mit Thyroxin um Bindungsstellen und führt so zu einer Erniedrigung der im Serum gemessenen Thyroxinwerte.

\section{Als Störfaktoren können in Frage kommen:}

- Verfärbungen, welche zu unspezifisch erhöhten Meßwerten bei spektrometrischen Methoden führen.

- Hemmung enzymatischer Methoden durch gewisse Arzneimittel.

- Kreuzreaktionen bei Immunotests, welche in dem Maße häufiger beobachtet werden, in dem derartige Verfahren breiter angewendet werden.

Stets ist zu beachten, daß unter Einflußgrößen objektiv richtige Meßresultate entstehen, die jedoch klinisch - im Sinne der Fragestellung - als unglaubwürdig abgelehnt werden. Störfaktoren- dagegen führen zu objektiv falschen Resultaten.

\section{Umgang mit gestörten Laborwerten}

In der praktischen Arbeit mit den verfügbaren Daten geht es in erster Linie um die Evaluation von Randbedingungen:

- Die Häufigkeit der beobachteten Störungen ist außerordentlich unterschiedlich: Am einen Ende der Skala finden sich z. B.'áplastische Anämien unter Phenylbutazon bei einem von 300000 behandelten Patienten (14), am anderen signifikante Verschiebungen der Referenzintervalle bestimmter Parameter bei Frauen unter Antikonzeptiva (Abb. 5).

- Der Schweregrad reicht von passageren allergischen Reaktionen, welche auch bei Fortdauer der Behandlung verschwinden, bis zu Todesfällen, welche den Rückzug eines Medikaments zur Folge haben könneń. Zytostatika zum Beispiel führen zwangsläufig zu eiırer Knochenmarksdepression; deren Ausmaß ist indessen je nach Präparat durchaus unterschiedlich, auch sind die einzelnen Zellinien verschieden stark betroffen.

- Chinin kann zu einer intravaskulären Hämolyse und damit unter anderem zu niedrigen Hämoglobinkonzentrationen im Blut führen, aber nur bei Patienten mit Glu- 


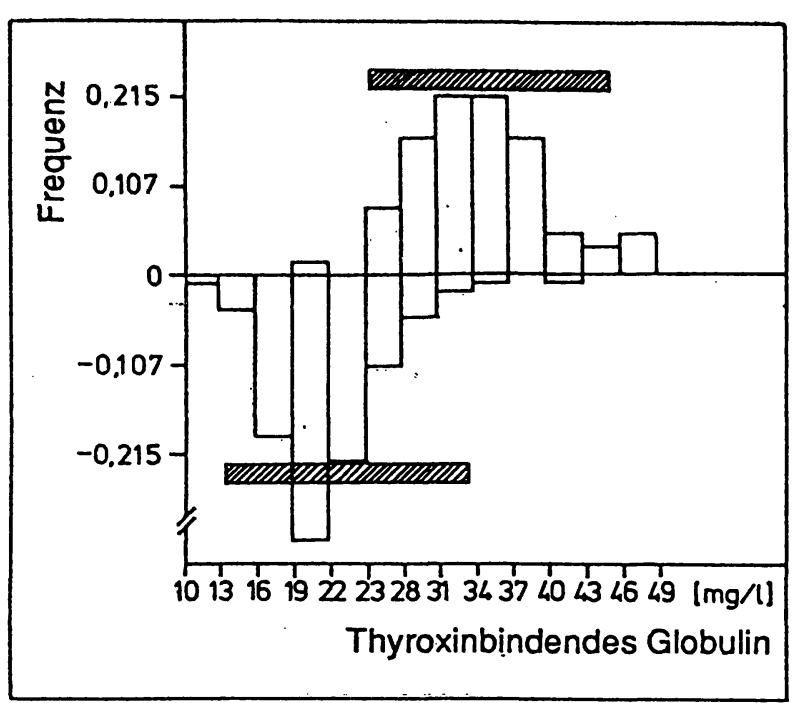

Abb. 5: Thyroxinbindendes Globulin bei jungen Frauen: Oberes Histogramm Probandinnen mit, unteres Histogramm ohne orale Antikonzeption (aus [11]).

cose-6-phosphatdehydrogenase-Mangel. Diese hereditäre Enzymopathie wird bei $15 \%$ der Schwarzen in den USA, bei $11 \%$ sephardischer Juden, aber nur sehr selten in der schweizerischen Bevölkerung angetroffen. Damit wird klar, daß es nicht zuletzt von der Geografie abhängt, ob eine Einflußgröße häufig oder selten angetroffen wird. Als zweites Beispiel einer ArzneimittelStörung, die nur beim Vorliegen einer konstitutionellen Anomalie manifest wird, sei hier die Sulfonamid-Hämolyse bei Patienten mit Hämoglobin Zürich erwähnt, wie sie von $W$. Hitzig vor 30 Jahren bei einem damals knapp dreijährigen Mädchen beschrieben worden ist (10): Die Heinzschen Innenkörper in den Erythrozyten (Supravitalfärbung mit Brillantkresylblau) bestehen aus $\mathrm{Hb}$ Zürich (unstabile Variante mit Punktmutation im $\beta$-Globin: arg statt his in Position 63) und werden ausgestoßen, wobei es zur Hämolyse kommt.
- Die Rolle des Geschlechts wurde bereits oben gestreift: Bei Männern fehlen naturgemäß Interpretationsprobleme unter Antikonzeptiva.

- Und das Stichwort etwas ausgeweitet: Geschlecht und Gesellschaft: Mifepriston (ehemals RU 486, [19]), ein Progesteron-Antagonist und damit Menstruationsauslöser, also eine „Pille danach", wurde bisher einzig auf dem französischen. Markt eingeführt; bereits werden dort etwa ein Drittel aller Abbrüche von unerwünschten Schwangerschaften damit durchgeführt. In Schweden, Großbritannien und den Niederlanden steht die Einführung bevor. In den USA hat die Diskussion in Fachkreisen und der Öffentlichkeit eben erst begonnen, wobei deren Dauer von Experten auf ca. 5 Jahre geschätzt wird.

- Unter dem Aspekt der Gebräuchlichkeit von Arzneimitteln lassen sich zwei Kategorien unterscheiden: Die Dauerbrenner und die neuen Hits. Im Laufe der langen Karriere von Acetylsalicylsäure (Einführung 1899, im weitesten Sinne aber auch heute noch gut für einen Nobelpreis [J. R. Vane 1982, Prostaglandine]) wurden eine ganze Reihe von gestörten Laborparametern registriert: Sie reichen von der falsch-negativen U-Glucose über erniedrigte Thrombozyten und falsch-positives Hämoglobin im Stuhl bis zum erhöhten Theophyllin (Ektachem). Bei einem Verbrauch von 16000 t Aspirin pro Jahr allein in den USA (23) steigt eben auch die Zahl der festgestellten Störungen. Eine ähnlich lange Liste von Störungen hat etwa Cimetidin in seinem erfolgreichen Jahrzehnt akkumuliert.

- Anhand eines Fallbeispiels soll schließlich die Rolle des gleichzeitigen Konsums von Ethanol illustriert werden (Abb. 6): Ein 30jähriger Mann erschien am Mittwoch (17.2.) nach einem Wochenende mit schwerem Alkoholabusus im Ambulatorium des Denver General Hospital und klagte über schwere Übelkeit und Erbrechen. Aufgrund folgender Laborresultate: ASAT 995 U/I, ALAT 630 U/I, LDH 1345 U/l, S-Bilirubin $36 \mu \mathrm{mol} / \mathrm{l}$ wurde die Diagnose einer akuten Hepatitis mit unklarer Aetiologie gestellt. Am Freitag mußte er stationär hospitalisiert werden. Es stellte sich heraus, daß der $\mathrm{Pa}$ tient seit dem Wochenende dreimal je drei ExtraStrength Tylenol-Tabletten geschluckt hatte (insgesamt
Abb. 6: Paracetamol-Effekte bei vorangegangenem Alkoholabusus (Daten nach [25]).

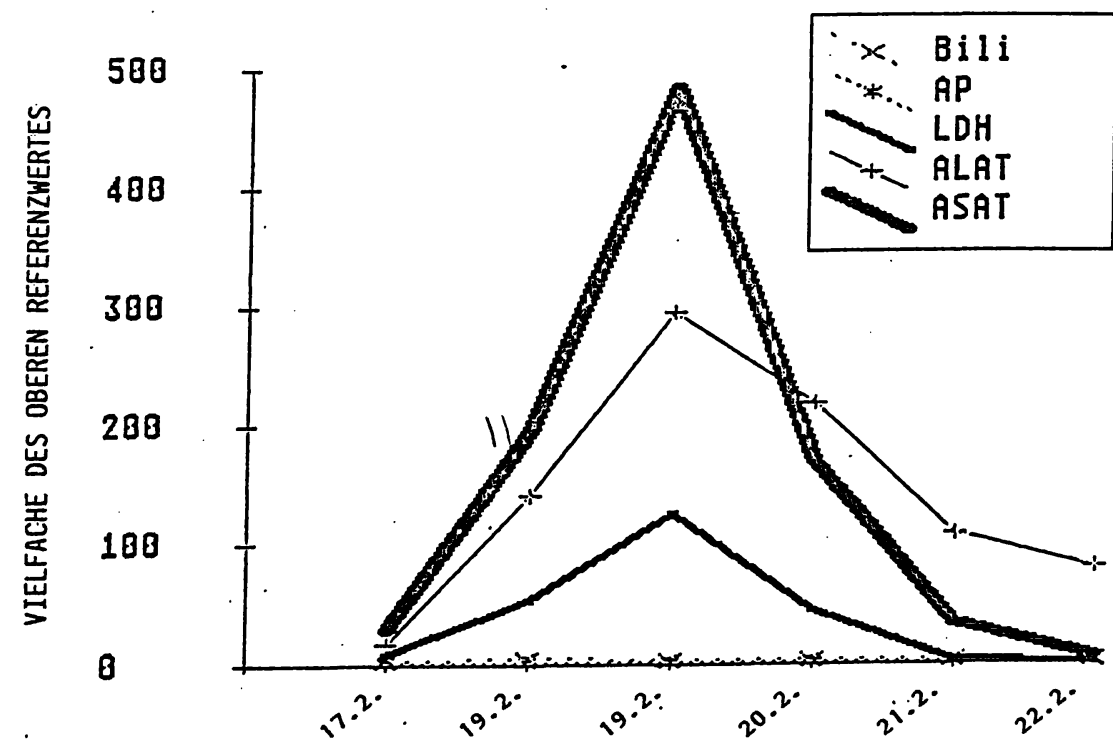

Lab.med. 15:.453 (1991) 
4,5 g Paracetamol). Der Patient wurde mit Infusionen und Vitamin $\mathrm{K}$ behandelt und am 3. Tag entlassen. Analog muß unter oraler Kontrazeption besonders dann mit Störungen gerechnet werden, wenn gleichzeitig $\mathrm{Ni}$ kotin konsumiert wird.

- Eine weitere wesentliche Komponente ist die Verfügbarkeit eines Arzneimittels: So ist z. B. Ibuprofen seit kurzem in der Schweiz nicht mehr rezeptpflichtig und in Apotheken frei erhältlich. Dieser Umstand wird zu einem Anstieg des Verbrauchs führen; gleichzeitig wird dessen anamnestische. Erfassung erschwert, da nicht rezeptpflichtige Arzneimittel für den Patienten häufig als nicht erwähnenswert gelten.

- Beobachtungen von gestörten Laborwerten sind oft mit der Anwendungsdauer von Arzneimitteln korreliert (3).

- Zum Schluß drei Beispiele zur Aktualität von Arzneimitteln: Es ist müßig, in Tabellenwerken längst obsolete Produkte (wie etwa die ursprüngliche "Pille" mit einer zehnfach höheren Estrogendosis als die heutige Micropille) mitzuschleppen. Vielmehr muß man Studien über neue Medikamente verfolgen, wie etwa über das Zidovudin oder - noch unerprobter - das 2,3-Dideoxyinosin gegen AIDS. Es gilt, die Resultate in jenen Ländern zu verfolgen, wo ein Produkt bereits auf dem Markt ist, wie etwa das Antidepressivum Fluoxetin in den USA. Und man muß den Bedeutungswandel von Substanzen verfolgen, die sich von Metaboliten zu Arzneimitteln entwickeln, wie etwa Interleukin-2.

- Zwar heute wie gesagt weniger bedeutsam, ist es durchaus variabel, inwiefern Labormethoden - in vitro - durch Arzneimittel gestört werden, abhängig von Meßprinzip, Reagentienkonzentration und Meßgerät. Ein Beispiel, das gleichzeitig das unterschiedliche Störpotential nah verwandter Arzneimittel illustriert, ist in Tabelle 1 wiedergegeben.

Tab. 1: Gestörtheit aktueller Methoden der Kreatininbestimmung durch verschiedene Cephalosporine (Daten aus [7]). Veränderungen in Prozent, Kreatininkonzentration ca. $120 \mu \mathrm{mol} / \mathrm{I}$, Cephalosporinkonzentration $1 \mathrm{~g} / \mathrm{l}$. (A) und (B) bedeuten unterschiedliche Reagenskonzentrationen

\begin{tabular}{lllccc}
\hline & \multicolumn{2}{c}{$\begin{array}{l}\text { Jaffe-Reaktion } \\
\end{array}$} & (A) & (B) & \multicolumn{3}{c}{$\begin{array}{c}\text { Enzymatische Bestimmung } \\
\text { Boehringer }\end{array}$} & Wako & Ektachem \\
\hline Cefalotin & +131 & +220 & -14 & -14 & -12 \\
Cefazolin & +42 & +87 & $<10$ & -10 & -10 \\
Cefalexin & +48 & +54 & $<10$ & $<10$ & -10 \\
Cefaclor & +160 & +156 & -34 & -22 & -15 \\
Cefradin & +73 & +52 & -16 & -10 & -12 \\
Cefuroxim & $<10$ & $<10$ & -11 & -11 & -10 \\
Cefoxitin & +262 & +673 & $<10$ & $<10$ & $<10$ \\
Cefamandol & $<10$ & $<10$ & -11 & -14 & $<10$ \\
\hline
\end{tabular}

Tab. 2: Kriterien der Datenauswahl für Abbildụng 7 und 8

\begin{tabular}{ccc} 
nicht Ratte, sondern Mensch \\
letale \\
obsolete \\
kurzzeitige \\
therapeutische Dosis \\
Eebräliachliche Arzneimittel \\
absolete & $\begin{array}{l}\text { anhaltende Effekte } \\
\text { reproduzierbare Wirkungen } \\
(1-5 \% \text { der Patienten, [21]) } \\
\text { aktuelle Labormethoden }\end{array}$ \\
\hline
\end{tabular}

\section{Standortbestimmung}

Faßt man nach folgenden Kriterien (Tab. 2) die bekannten Störungen zusammen (8), ergibt sich bei einer Gliederung nach Arzneimitteln folgendes Bild (Abb. 7):

- In 47 der insgesamt 87 Hauptgruppen der Roten Liste liegen keine klinisch signifikanten Störungen vor.

- In 20 Hauptgruppen sind je maximal 5 Störungen belegt.

- Das Gros der Störungen mit je > 30 Einträgen konzentriert sich auf die 7 Hauptgruppen Analgetika/Antirheumatika, Antiarrhythmika, Antibiotika, Antiepileptika, Antihypertonika, Sexualhormone und ihre Hemmstoffe sowie Zytostatika und Metastasenhemmer. Häufig verwendet, aber im Störpotential unterschätzt sind besonders Analgetika und Antibiotika, während z. B. bei den Zytostatika die „awareness" für arzneimittelbedingte Fehlresultate deutlich größer ist.

Bei einer Gliederung nach Fachgebieten der Laboratoriumsmedizin (Abb. 8) zeigt es sich, daß

- in der Klinischen Chemie am meisten Einflüsse auf den Intermediärstoffwechsel belegt sind. Betroffen sind in erster Linie Metabolite, hauptsächlich Lipide und Proteine. Weniger häufig sind Störungen des Elektrolytstoffwechsels, Ausdruck einer auch unter Arzneimittelwirkung intakten Homöostase. Enzyme sind in der Regel Marker einer Zellschädigung: direkte zytotoxische Arzneimittelnebenwirkungen sind bei angemessener Dosierung und Behandlungsdauer relativ selten. Bei den Hormonen ist vor allem die Schilddrüse betroffen, stets im Sinne einer In-vitro-Störung. Diese Sachlage wurde kürzlich von klinischer Seite (5) ausführlich diskutiert;

- hämatologische Nebenwirkungen in zwei klar getrennte Gruppen fallen: Entweder sind sie vorübergehender Natur und/oder klinisch ohne wesentliche Bedeutung, wenn auch in vielen Beipackzetteln auf mögliche Störungen hingewiesen wird. Oder aber können sie Anzeichen einer möglicherweise lebensbedrohlichen Schädigung des blutbildenden Systems sein;

- erst relativ wenige Arzneimittelinteraktionen im Sinne gestörter Laborwerte in der Literatur erwähnt sind. Dies mag damit zusammenhängen, daß Arzneimittelspiegel erst seit wenigen Jahren routinemäßig gemessen werden.

\section{"Falsche" Laborwerte als Indikatoren}

Wenn auch das Schwergewicht der vorliegenden Übersicht auf der durch Arzneimittel gestörten Meßgröße liegt, soll doch zum Schluß auf die umgekehrte Konstellation hingewiesen werden: den "falschen" Laborwert als Indikator einer schwerwiegenden Nebenwirkung. Dazu drei Beispiele: Beim Einsatz von Clozapin ist die Möglichkeit einer Granulozytopenie das Hauptrisiko. Es wird deshalb empfohlen (13), nur Patienten mit Leukozytenzahlen im Referenzintervall mit diesem Arzneimittel zu behandeln, die Leukozytenzahlen in den ersten 18 Wochen der Behandlung wöchentlich, später monatlich zu kontrollieren sowie jedes Infektionssymptom dem Arzt melden zu lassen. Ähnlich gilt es bei der Therapie mit Valproat eine seltene idiosynkratische Nebenwirkung, die Leberinsuffizienz, zu vermeiden. Neben generel!en Vorsichtsmaßnahmen wie Wahl einer niedrigen Dosierung, Vermeiden von 


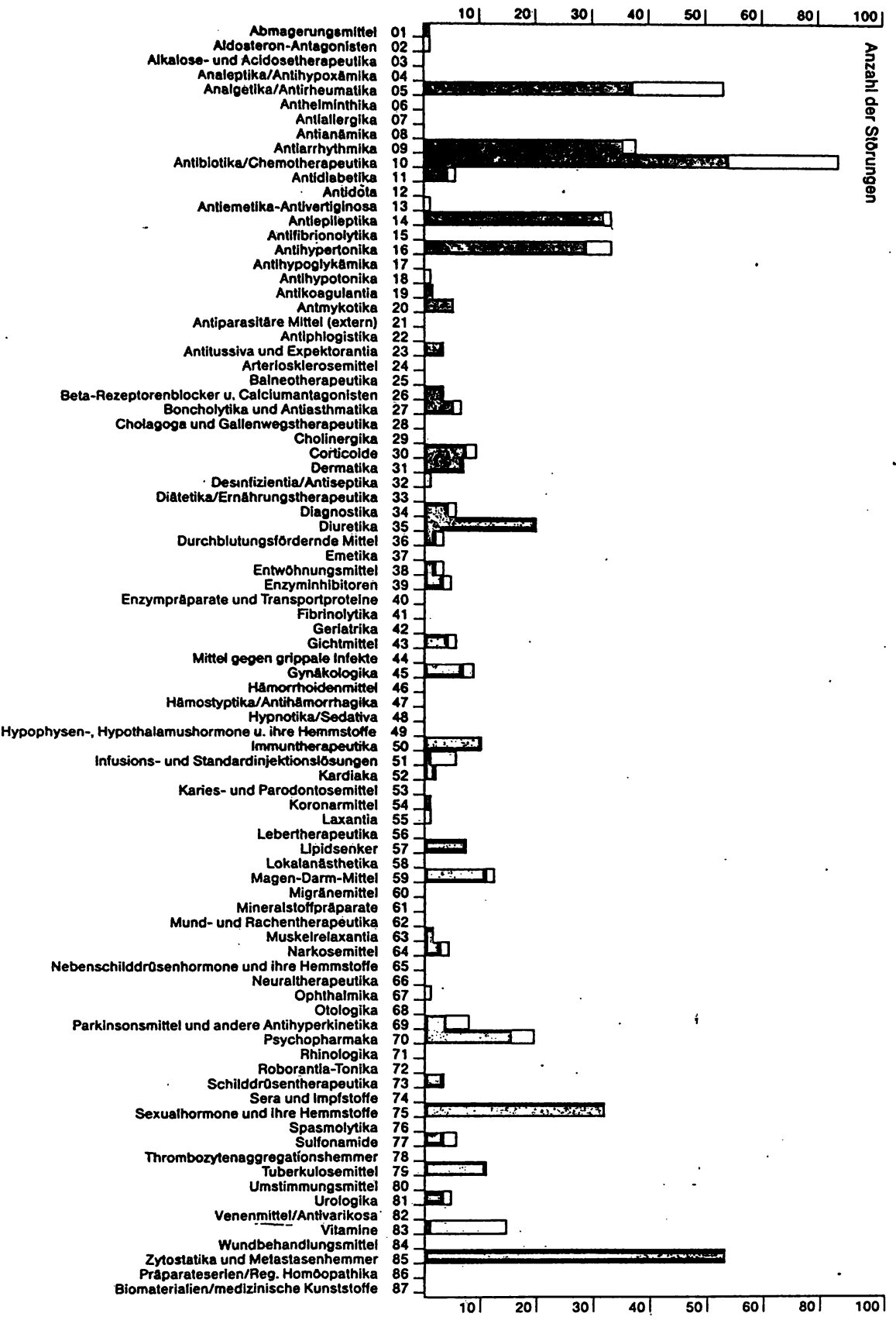

Abb. 7: Störungen von Laborwerten, gegliedert nach. Hauptgruppen der Roten Liste (aus [8]). Schwarz: In-vitro-Wirkungen, weiß: In-vivo-Wirkungen.

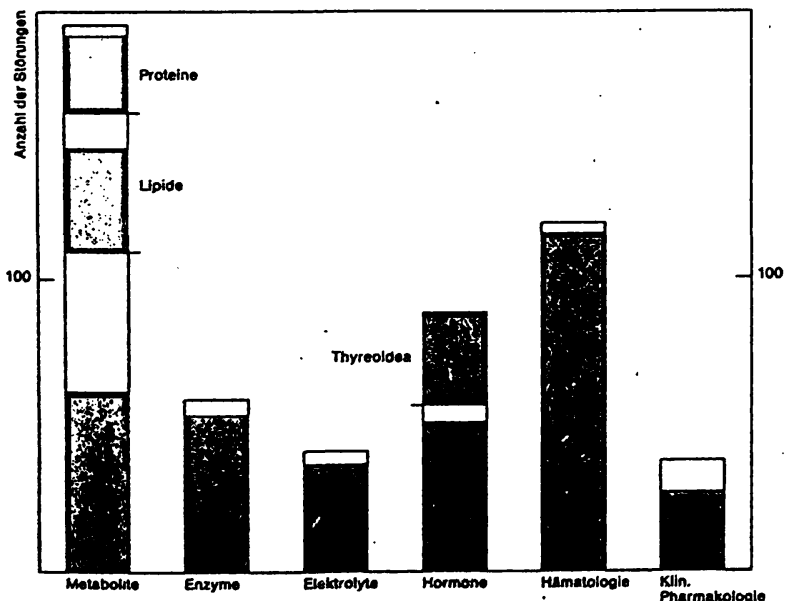

Abb. 8: Störungen durch Arzneimittel, gegliedert nach Arbeitsbereichen des Laboratoriums (aus [8]). Schwarz: In-vitro-Wirkungen, weiß: In-vivo-Wirkungen. 


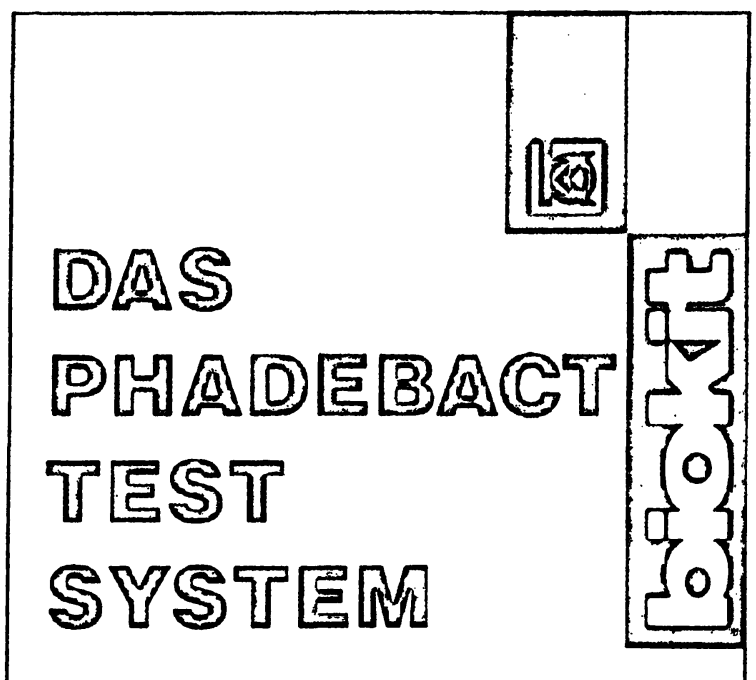

PHADEBACT Streptococcus Test

PHADEBACT CSF Test

PHADEBACT Pneumococcus Test

PHADEBACT Haemophilus Test

PHADEBACT Meningitis EIA Test

PHADEBACT Monoclonal GC Test

PHADIRECT Strep A Test

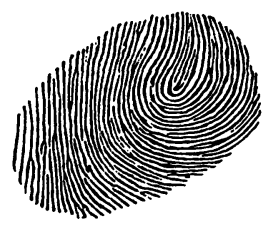

Vertrielb

BHOKDT GmbI-

Industriestraße 12

4284 Heiden

Telefon (02867) 990770

Telefax (02867) 990779
Fasten und gleichzeitiger Verabreichung von Salicylaten und potentiell hepatotoxischen Substanzen wird empfohlen (1), in den ersten 6 Therapiemonaten alle 2 bis 3 Wochen ALAT, Bilirubin, Amylase, Albumin und die Gerinnungsparameter bestimmen zu lassen. Von ganz besonderer Bedeutung schließlich ist die enge Zusammenarbeit mit dem Laboratorium zur Vermeidung zytostatikaassoziierter Toxizität (2).

Schriftum:

1. BINEK, J., HANY, A., EGLOFF, B., HEER, M.: Akute iodliche Leberinsutfizienz unter Valproinsăuretherapie. Schweiz. med. Wschr. 121, 228-233 (1991).

2. CERNY, T., BUSER, K. KISER, J., JOSS, R. A.: Prophylaktische und therapeutische Maßnahmen bei zytostatika-assoziierter Toxizităt. Schweiz. med. V/schr. 120. 1353-1362 (1990).

3. DOPPELBAUER, A, et al.: Bedeutung von Laboratoriumsbefunden bei Antiepileptika-Langzeittherapie. Disch. med. Wschr. 116, 41-47 (1991).

4. DUKES, M. N. G. (ed.): Meyler's Side Effects oi Drugs. 11th ed., Elsevier, Amsterdam (1988).

5. GERBER, H.: Abnorme Hormonwerte: Medikamente im Spiel? Schweiz. med. Wschr. 5. GERBER, H.: Abnorm

6. GOODMAN GILMAN, A., GILMAN, L S., RALL, T. W., MURAD, F. (eds).: The Pharmacological Basis of Therapeutics. 7th ed., MacMillan, New York (1985).

7. GREEN, A. J. E., et al.: Interference by Newer Cephalosporins in Current Methods for Measuring Creatinine. Clin. Chem. 36, 2139-2140 (1990).

8. HAGEMANN, P., REIMANN, I. W.: Arzneimittel und Laborwerte. Wissenschaftliche Verlagsanstak, Stuttgart (im Druck).

9. HANSTEN, P. D.: Drug Interactions. 5th ed., Lea \& Febiger, Philadelphia (1985).

10. HITZIG, W. H.: Langzeitverlauf von Krankheiten im Kindesalter. Vierteljahresschrift der Naturforschenden Gesellschaft in Zürich 135, 73-88 (1990).

11. KELLER, H.: Entscheidungshilfen zur Bewertung klinisch-chemischer Resultate. Z. med. Lab.diagn. 30, 416-424 (1989).

12. KELLER, H., GUDER, W. G., HANSERT, E., STAMM, D.: Biological Influence Factors and Interference Factors in Clinical Chemistry. J. Clin. Chem. Clin. Biochem. 23, 3-6 (1985).

13. KRUPP, P., BARNES, P.: Leponex-associated granulocytopenia: a review of the situation. Psychopharmacology 99, 118-121 (1989).

14. LUBRAN, M. M.: Hematologic Side Effects of Drugs. Ann. Clin. Lab. Sci. 19, 114-121 (1989).

15. ROINE, R., GENTRY, R. TH., HERNANDEZ-MUNOZ, R., BARANOA, E., LIEBER, CH. S.: Aspirin Increases Blood Alcohol Concentrations in Humans After Ingestion of Ethanol. JAMA 264, 2406-2408 (1990).

16. SALWAY, J. G.: Drug-Test Interactions Handbook. Chapman and Hall, London (1990).

17. SCHACHT, P., et al. Worldwide Clinical Data on Efficacy and Safety of Ciprofloxacin. Infection 16, Suppl. 1, 29-43 (1988).

18. SIEST, G., GALTEAU, M. M.: Drug Effects on Laboratory Test Results. PSG Publishing Company Inc. Littleton (1988).

19. SILVESTRE, L, DUBOIS, C., RENAULT, M., REZVANI, Y., BAUUEU, E.-E., ULMANN,

A.: Voluntary interruption of Pregnancy with Mifepristone (RU 486) and a ProstagA.: Voluntary interruption of Pregnancy with Mifepris
landin Analogue. N. Engl. J. Med. 322, 645-648 (1990).

landin Analogue. N. Engl. J. Med. 322, 645-648 (1990).
20. SONNTAG, O.: Arzneimittel-Interferenzen. G. Thieme, Stuttgart-New York (1985). 21. TRYDING, N., ROOS, K.-A. (eds.): Drug Interferences and Drug Effects in Clinica Chemistry. $5^{\text {th }}$ ed., Apoteksbolaget, Stockholm (1989).

22. VARSOU, A., PAPADIMITIOU, J. C., KOCH, TH. R., KNOBLOCK, E. C.: Occurrence of Abnormal Serum Magnesium Concentrations in Uremic and Nonuremic Patients Treated With Digoxin. Lab.Med. 21, 226-228 (1990).

23. WEISSMANN, G.: Aspirin. Sci. Amer. 264/1, 58-64 (1991).

24. WHO (ed.): The SI for the Health Professions. WHO, Geneva (1977).

24. WHO (ed.): The SI for the Health Professions. WHO, Geneva (1977).
25. WINTER, S. D., FUHRMAN, S. A.: Selected Clinical Chemistry Problems. Symposium am ASCP National Meeting. Chicago (1989).

26. YOUNG, D. S., PESTANER, L. C., GIBBERMAN, V.: Effects of Drugs on Clinical Laboratory Tests, 2 nd edition. Clin. Chem. 21, 10-432D (1975).

27. YOUNG, D. S.: Effects of Drugs on Clinical Laboratory Tests, 3rd edition. AACC Press, Washington (1990).

Anschrift des Verfassers:

Dr. P. Hagemann

Zentrallaboratorium

Kantonsspital

$\mathrm{CH}-8596$ Münsterlingen

Überarbeitete und enweiterte Fassung eines Referats an der 34. Jahrestagung der Schweizerischen Geséllschaft für Klinische Chemie am 22. 6. 1990 in Flims. 


\title{
Molecular Genetics of Porphyrias
}

\author{
Molekulare Genetik der Porphyrien
}

Yves Nordmann, Jean-Charles Deybach

From the Centre Français des Porphyries, Hôpital Louis Mourier, Colombes, France

\begin{abstract}
Summary:
Recent progress in the molecular biology of heme pathway enzyme genes has shed much light on the structure of these genes and in abnormal conditions such as the porphyrias. Inherited deficiencies of uroporphyrinogen decarboxylase (porphyria cutanea tarda and hepatoerythropoietic porphyria), porphobilinogen deaminase (acute intermittent porphyria), delta aminolevulinate dehydrase (Doss porphyria) and uroporphyrinogen III synthase (congenital erythropoietic porphyria) have been investigated at the nucleic acid level. In this paper, the already known mutations of each gene are described.
\end{abstract}

As for other inherited diseases, the use of molecular biology techniques is.likely to transform our understanding of the porphyrias.

Keywords:

Heme biosynthesis - porphyria - genetic disease - mutation

\section{Zusammenfassung:}

Molekularbiologische Fortschritte in der Genetik der Enzyme des Hämbiosyntheseweges haben Aufklärung zur Struktur der Gene und der Entstehung der Porphyrien gebracht. Die angeborenen Defizienzen der Uroporphyrinogen-Decarboxylase (Porphyria cutanea tarda, hepatoerythropoetische Porphyrie) Uroporphyrinogen-ISynthase (akute intermittierende Porphyrie), Delta-Aminolaevulinsäuredehydratase (Doss-Porphyrie) und Uroporphyrinogen-III-Synthase (erythropoetische Porphyrie) wurden genetisch untersucht. In dieser Publikation sind die schon bekannten Mutationen der Gene beschrieben.

Gleich anderer angeborener Erkrankungen führt die Anwendung molekularbiologischer Techniken zu einem besseren Verständnis der Porphyrien.

Schlüsselwörter:

Hämbiosynthese - Porphyrien - genetische Erkrankungen - Mutationen

\section{Introduction}

The porphyrias form a group of disorders of heme biosynthesis in which specific patterns of overproduction of heme precursors are associated with characteristic clinical features. Each type of porphyria is the result of a specific reduction in the activity of one of the enzymes of the heme biosynthetic pathway (1) (fig. 1).

During the past decade the isolation of all the enzymes of the heme pathway facilitated the study of some of their physicochemical and catalytic properties and enabled specific antibodies to be obtained. The development of these antibodies and the introduction of the techniques of molecular biology have permitted the molecular cloning of cDNAs and genes encoding several enzymes on the pathway from various species (see ref. 1). In this paper, we review recent progress made using molecular probes in the study of human porphyrias. New information is rapidly accumulating and data are available about four porphyrias, acute intermittent porphyria, hepatoerythropoietic porphyria (and/or porphyria cutanea tarda), congenital erythropoietic porphyria and Doss porphyria, all of which have been investigated at the nucleic acid level.

\section{Molecular Pathology}

\section{of Acute Intermittent Porphyria}

Acute intermittent porphyria (AIP) is an autosomal dominant disorder resulting from a partial deficiency in por- phobilinogen (P.BG) deaminase. In affected individuals the mean activity of the deficient enzyme is $50 \%$ of normal, which is in keeping with the heterozygous state of these subjects. Most people with this genetic enzyme deficiency, however, remain asymptomatic.

The molecular heterogeneity of the mutations responsible for AIP is indicated by immunological studies of the defective enzyme. Different authors documented the existence of cross reacting immunological material (CRIM)negative and CRIM-positive mutations (2), the former be-

Fig: Inherited enzyme deficiencies in the porphyrias

\begin{tabular}{|c|c|c|}
\hline Enzymes & & Porphyrias \\
\hline Glycine - & & - Succinyl CoA \\
\hline ALA synthetase & $\begin{array}{c}\downarrow \\
\text { ALA }\end{array}$ & \\
\hline ALA dehydrase & $\underset{\text { PBG }}{\downarrow}$ & Doss porphyria \\
\hline PBG desaminase & $\begin{array}{c}\downarrow \\
\text { UROI }\end{array}$ & Acute intermittent porphyria \\
\hline URO III cosynthetase & $\stackrel{\downarrow}{\text { URO III }}$ & Günther's disease \\
\hline URO decarboxylase & $\underset{\text { COPRO }}{\Downarrow}$ & Porphyria cutanea \\
\hline COPRO oxydase & $\begin{array}{c}\downarrow \\
\text { PROTOgen }\end{array}$ & Coproporphyria \\
\hline PROTOgen oxydase & $\begin{array}{c}\downarrow \\
\text { PROTO }\end{array}$ & Variegate porphyria \\
\hline Ferrochelatase & $\underset{\text { HEME }}{\downarrow}$ & Protoporphyria \\
\hline
\end{tabular}

Lab.med. 15: 457 (1991) 
Table 1: PBG Deaminase Mutant Classes (in Erythrocytes)

\begin{tabular}{lcccc}
\hline & $\begin{array}{c}\text { ACTIVIT (A) } \\
(\%)\end{array}$ & $\begin{array}{c}\text { CRIM (B) } \\
(\%)\end{array}$ & RATIO B/A & \\
\hline Control & 100 & 100 & 1 & CRIM-negative \\
Type 1 & 50 & 50 & 1 & \\
Type 2 ("Finnish") & 100 & 100 & 1 & \\
Type 3 & 50 & 85 & 1.7 & CRIM-positive \\
Type 4 & 50 & 280 & 5.7 & \\
\hline
\end{tabular}

ing present in about $85 \%$ of the affected families. In addition some families with AIP laccording to clinical and biochemical criteria) have been described but without the PBG deaminase deficiency that exists in red blood cells of the patients $(3,4)$. A classification of the different AIP subtypes based on protein studies is shown on table 1.

Before describing the mutations already found on the PBG deaminase gene, we draw attention to two features:

- This gene gives rise to two tissue specific isoenzymes encoded by different mRNAs (5): the non-erythroid form is ubiquitous, whereas the erythroid form is found only in erythroid cells.

- Three restriction fragment length polymorphisms (RFLPs) of the human PBG deaminase gene have recently been described (6-8). These polymorphic sites are in the same gene map region of the PBG deaminase gene (within the first intron).

\section{AIP without the PBG Deaminase Deficiency in Red Blood Cells (type 2)}

In families where the enzymatic deficiency seems to be restricted to non-erythropoietic cells, the defect could result from a mutation located either in the non-erythroid specific sequences of the PBG deaminase gene or in a distinct gene the product of which is important in the transregulation of PBG deaminase expression in non-erythroid cells. In order to distinguish between these two hypotheses we tested the linkage between the AIP phenotype and RFLPS of the PBG deaminase gene in a large Dutch kindred (9). By haplotyping of 68 individuals from this family, we showed the existence of a tight linkage, with no evidence of recombination. These data, taken with the normal PBG deaminase activity in the patients' red cells, strongly suggested that the mutation responsi- ble for AIP in this family was situated within the PBG deaminase gene and was likely to involve its nonerythroid part. Similar studies in a Finnish family also established a tight linkage between the phenotype and the PEG deaminase locus (10). When parts of the gene specifically involved in its expression in non-erythroid cells were sequenced a $G \rightarrow A$ transition was observed in the Dutch family at the first position of the first intron. This modifies the normal splice consensus sequence CGGTGAGT to CGATGAGT. The base change was confirmed by a direct study of the patient's genomic DNA.

Similar mutations have previously been shown to abolish completely normal splicing. Since the first intron interrupts the sequence coding for the non-erythroid isoform of PBG deaminase (11), it is to be expected that an abnormal splicing would lead to detrimental effects on that gene product. In contrast, in erythroid cells transcription of the gene starts $2.8 \mathrm{~kb}$ downstream from the identified mutation and so it is logical that this mutation has no consequence on the expression of the PBG deaminase gene in these cells. This provide an example of a mutation located within an ubiquitously expressed gene, which affects its functioning in certain tissues only, as would be expected from the mechanism of the differential transcription and splicing.

In the Finnish family a different point mutation was found within the non-erythropoietic exon (10): at the last position of exon 1, a single base substitution ( $C G \rightarrow C T$ ) also leads to a splicing defect (table 2). These findings have practical implications: in the families studied it is now possible to detect gene carriers by direct DNA analysis of the subjects (by hybridization of PCR amplified sequen. ces to mutation-specific oligonucleotides). A similar ap. proach will be more generally applicable when the var. ious AIP mutations have been identified.

\section{CRIM Positive AIP (type 3)}

In this group, PBG deaminase activity is low in the red blood cells but there is evidence of a structurally abnormal protein. It was therefore logical to assume that a pathological mRNA was also present in nucleated cells from the affected patients and that the mutations were lying within the coding sequence of the mRNA.

The first mutation found in this type of AIP was recently described by our team (12): using in vitro amplification

Table 2: Mutations in the porphobilinogen deaminase gene

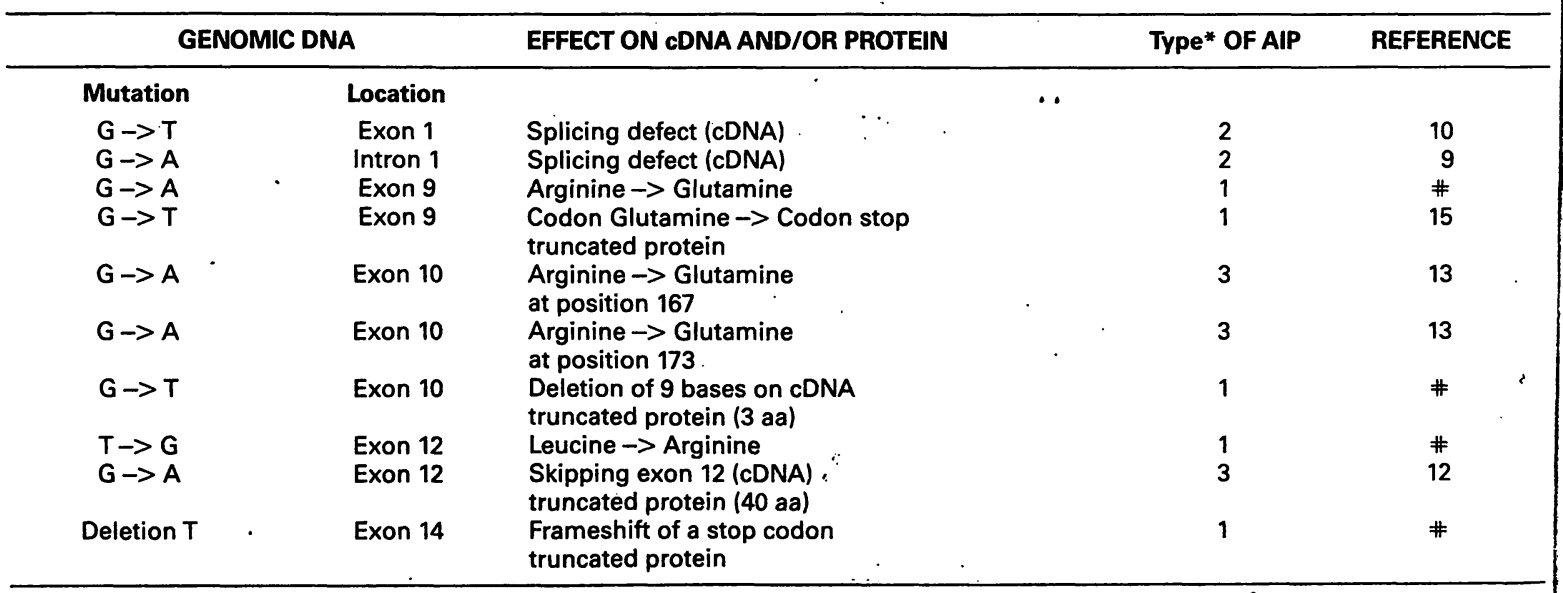

* see Table 1

\# Delfau, MH et al., unpublished observations 
of the patient's RNA isolated from lymphoblastoid cells, we found evidence of the presence of two amplified fragments, one of normal and the other smaller size. By directly sequencing the abnormal fragment we found that exon 12 of the gene was absent. By sequencing genomic fragments containing exon 12 we determined that a $G \rightarrow$ A substitution caused aberrant RNA splicing and resulted in skipping exon 12 in the mature mRNA. This mRNA (with exon 11 precisely linked to exon 13) encodes a truncated protein in which the $\mathbf{4 0}$ aminoacid residues encoded by exon 12 are missing (table 2).

More recently, two other mutations have been found in patients with the same phenotypic subtype. One mutation was found in four independent families: a CG $\rightarrow$ CA substitution in exon 10 resulting in Arginine to Glutamine replacement. The other mutation (CG $\rightarrow C A$, also lying in exon 10 but further downstream) was found in two unrelated families. In both cases, the Arginine to Glutamine substitution led to dramatic alterations in the catalytic properties of mutated enzyme (13).

\section{CRIM Negative AIP (type 1)}

In this commonest type of AIP erythrocyte PBG deaminase is low and no structurally abnormal protein has been found with immunological methods. No mutation had yet been fully characterized by the start of 1990 although the probable absence of exon 13 from mRNA from one patient was shown in 1988 by RNase mapping experiments (14).

Recently Elder et al. (15) described a $\mathrm{C} \rightarrow \mathrm{T}$ transition that abolishes a Pst $I$ recognition site in exon 9 of the PBG deaminase gene and converts a codon for glutamine to a stop codon. This mutation was not found in 43 other unrelated patients. Our groups found four different mutations, each present in only one of the twenty families screened for their presence (see table 2). These mutations were either a single base substitution or a single base deletion resulting in a single amino acid substitution or in truncated proteins produced either by splicing defects or by frameshifts in reading the genetic code.

In summary, the heterogeneity of the molecular defects in AIP should be emphasized. Whereas some mutations lead to a CRIM positive phenotype, others are CRIM negative. The same mutation has never been found among different families with this last phenotype.

\section{Molecular Analysis of URO Decarboxylase Defects}

Inherited uroporphyrinogen decarboxylase defects in man are responsible for familial (or type II) porphyria cut. anea tarda (PCT) and hepatoerythropoietic porphyria (HEP) (16). In familial PCT, an autosomal dominant disor. der, no CRIM has been identified as the product of the mutant gene $(17,18)$. In HEP, which is apparently inheri. ted as an autosomal recessive disease, several CRIM neg. ative and positive forms have been reported $(19,20)$. In three HEP patients from different families, cell free trans. lation experiments clearly established the presence and the function of uroporphyrinogen decarboxylase mRNA (21). In one mutant CDNA clones were obtained by screening a lymphoblastoid cDNA library established from the patient's mRNA. Using CDNA sequencing, our group identified a point mutation ( $G \rightarrow A$ ) at position 860 , which led to the replacement of a glycine (GGG) by a glutamic acid (GAG) at position 281. This amino acid substitution was shown to be responsible for producing an unstable protein that is very rapidly degraded (22). The use of hybridization with oligonucleotides specific for the identified mutation allowed us to screen for the presence of the same abnormality in different patients with HEP and PCT (23).

Detection of the mutation in only three of the five CRIMnegative HEP cases tested showed a molecular heterogeneity of the mutations in this group. Since this mutation was not detected in any of 13 unrelated patients with fa. milial PCT, it remains questionable whether familial PCT is caused by a single or various mutations and whether some cases of HEP are due to homozygosity for the same mutation responsible for familial PCT. Recently in a family with PCT Kushner et al. (24) found a cDNA substi. tution ( $G \rightarrow T$, also at nucleotide 860 ) that changed amino acid 281 from glycine to valine. The half life of the mutant enzyme was 12 hours instead of 102 hours, as is the case for normal enzyme. This mutation was not found in seven other PCT pedigrees, however, confirming the molecular heterogeneity of this group.

Very recently Garey et al. (25) found in a pedigree with fa. milial PCT a splice site mutation ( $G \rightarrow C$ point mutation at the first position of the $5^{\prime}$ end of intron 6 ) that causes exon 6 to be deleted from the mRNA. The shortened protein lacked catalytic activity and was rapidly degraded This point mutation was identified in five of 22 unrelated pedigrees with familial PCT.

\section{Congenital Erythropoietic Porphyria}

Congenital erythropoietic porphyria (CEP), Günther's disease is a rare disorder of heme biosynthesis inherited in an autosomal recessive fashion. The recent isolation and sequencing by Tsai et al. (26) of a full lenght cDNA encoding uroporphyrinogen III synthase (cosynthetase) allowed us to investigate the enzymatic defect at molecular level in two patients (27). Data on the first patient, showed that some clones (obtained from amplified cDNA fragments) carried a $T$ to $C$ transition at nucleotide 217 leading to a Cysteine to Arginine substitution at position 73 in the protein. Other clones carried a $C$ to $T$ change at nucleotide 158, resulting in a Proline to Leucine substitution at position 53 in the protein. Each mutation was found in only one of both parents, confirming that the patient was a genetic compound. The second patient was found to be homozygous for the same mutation in 53. This accorded with the fact that this patient was born form consanguinous parents. Recently, Desnick et al. (28) also identified the replacement in some patients of a Cysteine by an Arginine at position 73 in the protein. Moreover, one of their patients carried on the other allele the replacement of an Alanine by Valine at position 66 (a C to T transition in nucleotide 197): Further studies will give more details about the heterogeneity of this rare disease.

\section{Doss Porphyria.}

This acute hepatic porphyria has an autosomal recessive pattern of inheritance and ALA dehydrase activity shows in erythrocytes and bone marrow cells $(29,30)$ a dramatic decrease ( $1 \%$ of mean control) as expected for homozygotes. All cases of Doss porphyria were CRIM-positive (31) suggesting that a structural mutation was in a coding sequence of the ALA dehydrase gene. Very recently, Ishida et al. (32) identified two independant mutant alle- 
les in the proband's cells: one mutant allele was shown to result in aminoacid substitution at residue 274 (Alaine $\rightarrow$ Threoninel. Studies on the characterization of the other mutation are in progress.

\section{Conclusion}

In human porhyrias other mutations will be identified and this will provide new tools for the diagnosis of gene carriers. This is particularly important in porphyrias with acute manifestations lacute intermittent porphyria, coproporphyria and variegate porphyria) since the prevention of acute attacks rests on the detection of asymptomatic carriers among members of cDNAs, gene therapy in the most severe porphyrias should also affected families.

Finally, with the availability of cloned normal gene and cDNAS, gene therapy in the most severe porphyrias should also become the focus of investigations.

References:

1. GRANDCHAMP, B., NORDMANN, Y.: Recent advances in molecular genetics. EnzYmes of the Heme Biosynthesis Pathway: Semin Hematol 25, 303-311 (1988).

2. DESNICK, R. J., OSTASIEWICSZ, L. T., TISHLER, P. A., MUSTAJOKI, P.: Acute intermittent porphyria: Characterization of a novel mutation in the structural gene for porphobilinogen deaminase. J. Clin. Invest. 76, 865-874 (1985).

3. MUSTAJOKI, P.: Normal erythrocyte uroporphyrinogen I synthase in a kindred with acute intermittent porphyria. Ann. Intern. Med. 95, 162-166 (1981).

acute intermittent porphyria. Ann. Intern. Med. 95, 162-166 (1981). the Netherlands. Heterogeneity of the enzyme porphobilinogen dearninase. Neth. $J$.

the Netherlands. Heterogen
Med. 29, 393-399 (1986). 5. GRANDCHAMP, B., DE VERNEUIL, H., BEAUMONT, C., CHRETIEN, S., WALTER, O., NORDMANN, Y.: Tissue-specific expression of porphobilinogen deaminase: Two isoenzymes from a single gene. Eur. J. Biochem. 162, 105-110 (1987).

6. LEE, J. S., ANVRET, M.: A Pst1 polymorphism for the human porphobilinogen deaminase gene. Nucl. Acids Res. 15, 6307 (1987).

7. LEE, J. S., ANVRET, M. LINDSTEN, J., LANNFELT, L., GELLERFORS, P., WATTER BERG, L. FLODERUS, Y., THUNELL, S.: DNA polymorphisms within the porphobilinogen deaminase gene in two Swedish families with acute intermittent porphyria. Hum. Genet. 79, 379-381 (1988).

8. LLEWELLYN, D. H., ELDER, G. H., KALSHEKER, N. A., MARSH, O. W.: DNA polymorphism of human porphobilinogen deaminase gene in acute intermittent porphyria. Lancet 2, 706-708 (1987).

9. GRANDCHAMP, B., PICAT, C., MIGNOTTE, V., WILSON, J. H., TE VELDE, K., SAND KUYL, L., ROMEO, P. H., GOOSSENS, M., NORDMANN, Y.: Tissue specific splicing mutation in acute intermittent porphyria. Proc. Natl. Acad. Sci. USA 86, 661-664 (1989). 10. GRANDCHAMP, B., PICAT, C., KAUPPINEN, R., MIGNOTTE, V., PELTONEN, L., MU STAJOKI, $P$, ROMÉO, P. H. GOOSSENS, $M$, NORDMANN, $Y$ : Molecular analysis of acute intermittent porphyria in a finnish family with normal erythrocyte porphobilinogen deaminase. Eur. J. Clin. Invest. 19, 415-418 (1989).

11. CHRETIEN, S., DUBART, A., BEAUPAIN, D., RAICH, N., GRANDCHAMP, B., ROSA, J, GOOSSENS, M., ROMEO, P. H.: Alternative transcription and splicing of the human porphobilinogen deaminase gene result either in tissue-specific or in housekeeping expression. Proc. Natl. Acad. Sci. USA 85, 6-10 (1988).

12. GRANDCHAMP, B., PICAT, C., DE ROOIJ, F., BEAUMONT, C., WILSON, P., DEYBACH J. C., NORDMANN, Y.: A point mutation G-A in exon 12 of the porphobilinogen deaminase gene results in exon skipping and is responsible for acute intermittent porphyria. Nucl. Acid. Res. 17, 6637-6649 (1989).

13. DELFAU, M. H. PICAT, C., DE ROOIJ, F, HAMER, K, BOGARD, M., WILSON, J. H, DEYBACH, J. C., NORDMANN, Y, GRANDCHAMP, B., BOGARD, M., WILSON, J. H., exon 10 of the porphobilinogen deaminase gene are responsible for acute intermittent exon 10 of the porphobilinogen deaminase gen

porphyria. J. Clin. Invest. 86, 1511-1516 (1990). 14. LLEWELLYN, D. H., URQUHART, A., SCOBIE, G., ELDER, G. H., KALSHEKER, N. A.
HARRISON, P. R.: Molecular analysis of acute intermittent porphyria. Biochem. Soc. Trans. 16, 799-800 (1988).

15. SCOBIE, G. A., LLEWELLYN, D. H., URQUHART, A., SMYTH, S. J., KALSHEKER N. A., HARRISON, P. R., ELDER, G. H.: Acute intermittent porphyria caused by a $C \rightarrow$ $T$ mutation that produces a stop codon in the porphobilinogen deaminase gene. Hum Genet. 85, 631-634 (1990).

16. KAPPAS, A., SASSA, S., GALBRAITH, R. A., NORDMANN, Y.: The Poirphyrias. In: Scriver, C. R., Beaudet, A. L., Sly, W. S., Valle, D., eds. The metabolic basis of inherited diseases. New York: McGraw-Hill, 6th Ed., 1, 1305-1365 (1989).
17. ELDER, G. H., SHEPPARD, D., TOVEY, J., URQUHART, A.: Immunoreactive uropor phyrinogen decarboxylase in porphyria cutanea tarda. Lancet 1, 1301-1304 (19e3) 18. DE VERNEUIL. H., BEAUMONT. C.. DEYBACH. J. C., NORDMANN, Y., SFAR, Z. KA STALLY, R.: Enzymatic and immunological studies of uroporphyrinogen decarboxylase in familial porphyrie cutanea carda and hepatoerythropoiatic porphyria. Am. J. Hum. Genot 36, 613-622 (1984).

19. ELDER, G. H. SMITH, S. G. HERRERO, C. MASCARO, J. M. LECHA, M., MU. NIESCA, A M., CZARNECKI, D. B., BRENAN, J., POULOS, V., DE SALAMANCA. R. E.: Hepatoerythropoietic porphyria: A new uroporptryrinogen decarboxylase defect of ho mozygous porphyria cutanea tarda. Lancet 1, 916-919 (1981).

20. SASSA, S., DE VERNEUIL, H., ANDERSON, K. E., KAPPAS, A.: Purification and properties of human erythrocye uroporphyrinogen decarboxylase: Immunological demonstration of the enxyme defect in porphyria cutanea tarda. Trans. Asece. Am Physicians $96,65-75(1984)$.

21. DE VERNEUIL, H.. BEAUMONT, C., GRANDCHAMP, B. PHUNG, L N. NORDMANN, Y.: Molecular heterogeneity of uroporothrinogen decarboxylace deficiency in hepatoY: Molecular heterogeneity of uroporphyrinogen decarboxylase deficiency in hepato erythropoietic porphyri.

22. DE VERNEUIL, H., GRANDCHAMP, B., BEAUMONT, C., PICAT, C., NORDMANN, Y.: Uroporphyrinogen docarboxylase structural mutant (Gly $281 \mathrm{Glu}$ ) in a case of porphyria. Scienco 234, 732-734 (1986).

23. DE VEANEUIL, H., HANSEN, J., PICAT, C., GRANDCHAMP, B., KUSHNER, J., ROBERTS, A., ELDER, G. H., NORDMANN, Y.: Prevalence of the 281 (Gly-Glu) mutation in hepatoerythropoietic porphyria and porphyria cutanea tarda. Hum. Genet 78, 101-102 (1988).

24. GAREY, J. R., HANSEN, J. L. HARRISON, L. M., KENNEDY, J. R., KUSHNER, J. P.: A point mutation in the coding region of üroporphyrinogen decarboxylase associated with familial porphyria cutanea tarda. Blood 73, 892-895 (1989).

25. GAREY, J. R., HARRISON, L. M., FRANKLIN, K. F., METCALF, K. M., RADISKY, E. S. KUSHNER, J. P.: Uroporphyrinogen decarboxylase: A splice site mutation causes the deletion of exon 6 in mutiple families with porphyria cutanea tarda. J. Clin. Invest. 86, 1416-1422 (1990).

26. TSAI, S. F., BISHOP, D. F., DESNICK, R. J.: Human URO III-synthase: molecular cloning, nucleotide sequence and expression of a full-length cDNA. Proc. Natl. Acad. Sci USA 85, 7049-7053 (1988).

27. DEYBACH, J. C., DE VERNEUIL, H., BOULECHFAR, S., GRANDCHAMP, B., NOROMANN, Y.: Point mutations in the Uroporphyrinogen III synthase gene in congenital enthropoietic porphyria (Gúnther's disease). Blood 75, 1763-1765 (1990).

28. WARNER, C. A., YOO, H. W., TSAI, S. F., ROBERTS, A. G., DESNICK, R. J.: Congenital erythropoietic porphyria: Characterization of the genomic structure and identification of mutations in the uroporphyrinogen III synthase gene. Am. J. Hum. Genet. 47 (3), 321 (abstr.) (1990).

29. DOSS, M., VON TIEPERMANN, R., SCHNEIDER, J., SCHMID, H.: New type of hepatic porphyria with porphobilinogen synthase defect and intermittent acute clinical manifestation. Klin. Wochenschr. 57, 1123-1127 (1979).

30. THUNELL, S. HOLMBERG, L., LUNDGREN, J.: Aminolaevulinate dehydratase porphyria in infancy. A clinical and biochemical study. J. Clin. Chem. Clin. Biochem. 25, 5-14 (1987).

31. DE VERNEUIL, H., DOSS, M., BRUSCO, N., BEAUMONT, C., NORDMANN, Y.: Here ditary hepatic porphyria with delta aminolevulinic dehydrase deficiency. Immunologic characterization of the non-catalytic enzyme. Hum. Genet. 69, 174-177 (1985). 32. ISHIDA, N., FUJITA, H., NOGUCHI, T., DOSS, M., KAPPAS, A., SASSA, S.: Message amplification phenotyping of an inherited delta-aminolevulinate dehydratase deficiency in a family with acute hepatic porphyria. Biochem. Biophys. Res. Comm. 172. 237-242 (1990).

\section{Acknowledgments}

We thank Mrs. Catherine Guyomard for typing the manuscript.

Address and reprint request:

Prof. Yves Nordmann, M. D.

Centre Français des Porphyries

Hôpital Louis Mourier

178 rue des Renouillers

92701 Colombes Cedex, France 


\section{இCล: v०น Du Pont}

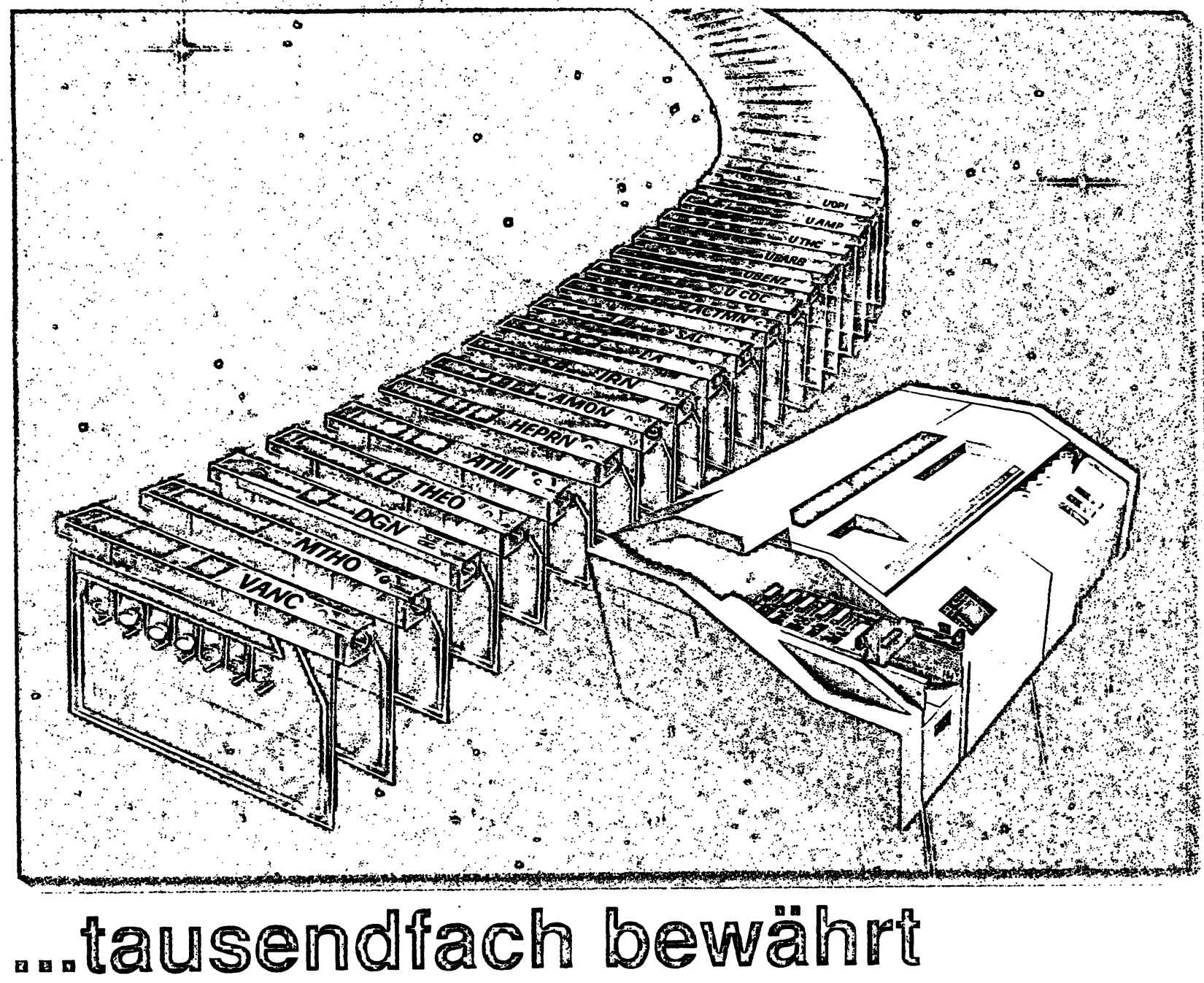

Fast achtzig Bestimmungen stehen mit dem aca ${ }^{3}$ auf Abruf bereit. 13 verschiedene Enzyme, 14 Spezialuntersuchungen, 18 Pharmaka-Bestimmungen sowie Bestimmungen für Hormone, Gerinnung und Immunologie sind ein einzigartiges Angebot.

\section{Zuverlässige, reproduzierbare Ergebnisse} sind das Markenzeichen des aca ${ }^{\circledR}$. Eine ausgereifte, tausendfach bewährte Chemie, deren Reaktionsabläufe hermetisch versiegelt ablaufen, machen den aca ${ }^{\circledR} \mathrm{zu}$ dem sichersten und zuverlässigsten Referenzgerät in vielen Labors der Welt.

\section{Schnelles, kostengünstiges Arbeiten} zeichnen den aca ${ }^{\circledR}$ aus. Kein Reagenzienverlust, keine Vorbereitungszeit, kein Warmlaufen, der aca ${ }^{\circledR}$ ist sofort einsatzbereit.

Lassen auch Sie sich überzeugen! Wir führen Ihnen den aca gerne vor. Anruf genügt. Tel.: 06172 / 872535 
Isolierung und Identifizierung pathogener Mikroorganismen sind die Voraussetzungen für Diagnose, Therapie, Verhütung von Infektionen und zur Infektionskontrolle.

In dem vorliegenden Buch werden die bisher in jedem qualifizierten mikrobiologischen Labor eingeführten kulturellen und biochemischen Verfahren beschrieben.

Die wichtigsten Daten von ca. 400 als Krankheitserreger geltenden oder aus differentialdiagnostischen Gründen im Bereich der Humanmedizin interessierenden Bakterienspezies sind in einem kompakten Abriß zusammengefaßt.

Der erste Teil des Buches informiert über Gewinnung, Transport und Verarbeitung von Untersuchungsmaterialien, der Hauptteil enthält sehr ausführlich kommentierte Tabellen zur Identifizierung der Mikroorganismen, und im Anschluß daran werden die im Text erwähnten Methoden unter Angabe von Bezugsquellen für notwendige Hilfsmittel erläutert.

Die Gliederung in acht Bakteriengruppen erfolgt in konventioneller Weise anhand der Morphologie und des Gramverhaltens unter
Berücksichtigung der Sauerstofftoleranz. Bei gramnegativen und grampositiven Stäbchen wird die Orientierung durch ein am Kapitelanfang positioniertes Leitschema erleichtert. Es basiert auf wenigen schnell überprüfbaren Kriterien und verweist auf die ausführlich kommentierten Tabellen. Diese werden durch die Beschreibung der Anzuchtbedingungen, der Nährmedien, Färbeverfahren und Hinweise auf Bezugsquellen für die in der Bundesrepublik erhältlichen Diagnostika ergänzt.

Die zur Bezeichnung der Mikroorganismen gewählte Nomenklatur entspricht den „Approved lists of bacterial names" und folgt den von der American Society for Microbiology herausgegebenen Angaben des "International Journal of Systematic Bacteriology".

Das zum Gebrauch am Arbeitsplatz bestimmte Buch wendet sich an Mikrobiologen, Hygieniker, Pharmazeuten, medizinisch-technische Assistentinnen und alle diejenigen, die routinemä.Big bakteriologische Untersuchungen durchführen oder sich im Praktikum auf diese Tätigkeit vorbereiten. 


\title{
Stand und Perspektiven der Standardisierung der immunchemischen Plasmaprotein-Bestimmung
} - Kritikpunkte / Ansprüche -

\author{
Art and Perspectives of the Standardization for the Immunochemical Plasmaprotein \\ Quantitation - Critiscism and Claim -
}

\section{S. Baudner}

Aus den Forschungslaboratorien der Behringwerke AG, Marburg

\section{Zusammenfassung:}

Es wird über den Stand der Technik und über neue Perspektiven bezüglich der Standardisierung immunchemischer Plasmaprotein-Bestimmungen berichtet. Unter Berücksichtigung der "Neuen Richtlinien der Bundesärztekammer" werden die wichtigsten internationalen Protein-Referenz-PräparationenMHO für IgG, IgA, IgM, Albumin und Transferrin beschrieben. Der Bezug von IU zu g unter Verwendung von Umrechnungsfaktoren und deren Abhängigkeiten im Immunoassay werden dargelegt. Auf der Basis der komplexen Antigen-Antikörper-Reaktion werden vier Postulate zum besseren Verständnis der Wechselbeziehung zwischen Meßsignalgröße und Meßwert für eine Protein-Konzentration entwickelt und diskutiert. Akzeptable Empfehlungen und mögliche Lösungen für ein besseres Kontroll-System der Plasmaprotein-Bestimmung werden vorgeschlagen: die Entwicklung und Herstellung einer neuen Protein-Referenz-Präparation mit Beschreibung der Charakteristika und Struktur der deklarierten Proteine.

Schlüsselwörter:

Plasmaproteine - Standardisierung - Immunoassay - Internationale Referenzpräparation - Antigen-Antikörper-Reaktion

\section{Summary:}

The state of the art and new perspectives for the standardization of the immunochemical protein determination are reported. With respect to "Neue Richtlinien der Bundesärztekammer" the most important WHO IRP's for IgG, IgA, IgM, albumin and transferrin are described. The regard from $I U$ to $g$ by using conversion factors and the dependencies on different influences are explained. On the basis of the complex antigen-antibody-reaction four postulates for a better understanding of the relationship between the signal size measured and the value calculated for the protein concentration are developed and discussed. Acceptable recommendations and possible solutions for a better control system of the plasma protein determination by establishing a new protein reference preparation with defined protein structure and characteristics are presented.

\section{Keywords:}

Human plasma proteins - standardization - immunoassays - international reference preparations - antigenantibody-reaction

\section{Einleitung}

Etwa 20 bis 25 Human-Plasmaproteine werden heute wegen ihrer diagnostischen Bedeutung zur Beurteilung krankhafter Veränderungen routinemäßig in klinisch-medizinischen Laboratorien mit Hilfe von Immunoassays quantitativ bestimmt. Für spezielle Fragestellungen können weitere - ca. 20 bis 30 Proteine - quantifiziert werden. Der quantitativen Bestimmung eines Plasmaproteins liegt in der Regel die Antigen-Antikörper-Reaktion zugrunde. Methodologisch gesehen gehört sie zu den chemischen Methoden. Die Kinetik unterliegt im wesentlichen dem Massenwirkungsgesetz.

Für ein und dasselbe Plasmaprotein steht heute oftmals eine Vielzahl von immunchemischen Bestimmungsmethoden zur Verfügung. Dieser Umstand hat den Weg zu einer optimalen Qualitätssicherung sicherlich nicht erleichtert. Die Diskrepanz der Analysenergebnisse für ein und denselben Parameter in Abhängigkeit von der eingesetzten Methode ist ein oft diskutiertes Dilemma. Die Festlegung von Referenz-Werten einzelner Plasmaproteine für eine ausgewählte gesunde Population ist bis heute mit Unsicherheiten behaftet. Der Arzt ist daher teilweise in der Interpretation der vorliegenden Labordaten und in der von inm erwarteten Diagnose überfordert. Die zulässigen Grenzen der medizinischen Erfordernisse (1) und die beobachteten Schwankungen der Analysenresultate sind für einige Proteine kaum oder aber nur mit groBer Kompromißbereitschaft kongruent zur Deckung zu bringen.

Die Richtlinien der Bundesärztekammer $(1,2)$ zur Qualitätssicherung in medizinischen Laboratorien haben ver- 
sucht, durch die gesetzliche Einführung sowohl einer laborinternen Qualitätskontrolle (Präzisionskontrolle und Richtigkeitskontrolle) sowie einer externen Qualitätskontrolle (durch Überprüfung der Richtigkeit mittels Ringversuchsproben) Unsicherheitsfaktoren und subjektive wie objektive Fehlerquellen so weit als möglich auszuschalten. Präzision, Richtigkeit, Spezifität und Nachweisgrenzen wurden definiert. Das große Anliegen, mit dem Zielwert dem natürlichen wahren Wert eines Parameters möglichst nahezukommen, war und ist der Referenzmethodenwert, den ausgewählte Referenz-Institutionen unter Verwendung einer publizierten Referenzmethode festlegen. Im Gegensatz zu vielen erkannten niedermolekularen Parametern der klinischen Chemie konnte bisher für die quantitative Bestimmung von Plasmaproteinen eine Referenzmethode nicht etabliert werden. Statt dessen wurde die radiale Immundiffusion (RID) zur Ermittlung von Sollwerten der Plasmaproteine empfohlen. Solange die zugehörigen Reagenzien wie z. B. Protein-Standard(und Kontroll-)Präparate auf der einen Seite und die antikörperhaltigen Antisera auf der anderen Seite nicht hinreichend standardisiert sind, wird es auch in Zukunft wohl kaum eine Referenzmethode für die PlasmaproteinBestimmung geben können.

Daher wurde es frühzeitig als richtig erkannt, auf dem Weg zu einer Standardisierung der immunchemischen Plasmaprotein-Bestimmung zunächst durch die Bereitstellung internationaler Referenz-Präparationen (IRP's) durch internationale Institutionen, wie z. B. durch die WHO, voranzukommen. Da das Verständnis erst in den letzten Jahren mehr und mehr dafür gewachsen ist, daß die Immunreaktivität der Plasmaproteine, d. h. ihre physikalisch-chemische Wechselwirkung mit Antikörpern, sehr stark von der jeweiligen Struktur abhängt und daß damit verbunden das jeweils verwendete Meßprinzip diese mögliche Variabilität unterschiedlich reflektiert, werden sowohl Qualität wie auch Akzeptanz dieser IRP's recht kontrovers beurteilt. Teilweise sind auch nur eine gewisse Bequemlichkeit und Scheu vor einem Umdenken $(\mathrm{IU} / \mathrm{ml}$ statt $\mathrm{mg} / \mathrm{dl}$ ) zu konstatieren. Dennoch wird der Zugang zu einer optimalen Standardisierung der immunchemischen Plasmaprotein-Bestimmung nur durch die Bereitstellung und allgemeine Akzeptanz solcher Präparationen erreicht. Vergleichbarkeit von Analysen-Ergebnissen von Labor zu Labor und von Land zu Land und damit die Erfüllung der medizinischen Erfordernisse im Sinne einer optimalen Diagnose setzen die Anwendung von IRP's voraus. Eine Referenzmethode zur immunchemischen Bestimmung von Plasmaproteinen ist danach und davon abhängig zu etablieren.

Zur Beurteilung des Standes und der Perspektiven der immunchemischen Plasmaprotein-Bestimmung sollen drei Gesichtspunkte diskutiert werden:

1. Verfügbare IRP's/Norteile und Kritikpunkte

2. Immunchemische und nicht-immunchemische Postulate für Immunoassays

3. Kriterien für neue, internationale Protein-Referenz-Präparationen

\section{Verfügbare internationale

Referenz-Präparationen (IRP's)

1.1 WHO IR-Standard for Human-Serum Immunoglobulins: IgG, IgA and IgM / Lot 67/86

Die erste internationale Referenz-Präparation mit. der Code-Nr. 67/86 befaßte sich mit der Standardisierung der immunchemischen Bestimmung von IgG, IgA und IgM. Sie wurde bereits 1967 aus Human-Serum gewonnen und ist noch heute als Lyophilisat, in Ampullen eingeschmolzen, von der WHO erhältlich.

\section{Die Lyophilisatmenge beträgt $81,47 \mathrm{mg}$ pro Ampulle.}

Eine Ampulle enthält definitionsgemäß 100 Einheiten $\lg G, \lg A$ und $\lg M$.

Dies bedeutet: Eine Einheit ist diejenige Menge des jeweiligen Immunglobulins, die in $0,8147 \mathrm{mg}$ der gefriergetrockneten IRP-Lot $67 / 86$ vorhanden ist.

Laut Vorschrift des WHO-Expertenkomitees soll das Lyophilisat exakt mit $1 \mathrm{ml}$ Aqua dest. aufgelöst werden. Da sich infolge dieser Prozedur eine Volumenexpansion der Flüssigkeitsmenge auf etwa $1,06 \mathrm{ml}$ einstellt, ist zu beachten, daß nach Rekonstitution der Trockensubstanz mit $1 \mathrm{ml}$ Aqua dest. die Definition der Konzentration des jeweiligen Immunglobulins zu einem anderen Wert führt:

Die vorschriftsmäßig rekonstituierte Lösung pro Ampulle enthält 94,4 IU/ml IgG, IgA und $\lg M$.

In Ringversuchen wurde versucht, auch die absolute Konzentration in $\mathrm{mg} / \mathrm{dl}$ zu ermitteln. Die Ergebnisse der ersten Vergleichsstudie schwankten erheblich. Eine Deklaration in $\mathrm{mg} / \mathrm{dl}$ wurde daher mit Recht für nicht opportun und gerechtfertigt gehalten. Die quantitative Bestimmung der drei Immunglobuline lgG, IgA und IgM erfolgte vorwiegend mit der radialen Immundiffusion. Es wurden zur quantitativen Bestimmung des Gehaltes eigene Protein-Standard-Präparate und ebenfalls eigene, unterschiedliche Antisera der Versuchslaboratorien eingesetzt, Reagenzien, die die Diskrepanz der Analysen-Ergebnisse verursachten.

Das Verhältnis von höchster zu niedrigster Konzentration der Resultate von acht Versuchslaboratorien, die zu einer statistischen Auswertung der Daten herangezogen wurden, war:

\section{2,17 für $\lg G ; 3,26$ für $\lg A ; 5,0$ für $\lg M$}

Es gab eine zweite Vergleichsstudie, an der sich 12 international renommierte Laboratorien beteiligten. Hierbei wurde die WHO-IRP/Lot 67/86 zur Erstellung von Bezugskurven in der radialen Immundiffusion eingesetzt. Wenn man an einer solchen gemeinsam verwendeten ProteinReferenz-Präparation Immunglobuline in unbekannten Serumproben mißt, nimmt die Vergleichbarkeit der AnaIysen-Ergebnisse in einem erfreulichen Maße zu. Dieser relativ erfreulich enge Streubereich wurde auch nicht dadurch wesentlich verschlechtert, daß jedes Laboratorium eigene spezifische Antisera gegen IgG, IgA und IgM benutzen durfte (Erklärung Punkt 2.3).

Das Verhältnis von höchster zu niedrigster Konzentration der verschiedenen Laboranalysen-Ergebnisse lag bei:

$$
\text { 1,36 für } \lg G ; 1,17 \text { für } \lg A ; 1,31 \text { für } \lg M
$$

Die Ergebnisse aus den beiden Vergleichsstudien wurden publiziert. Dabei wurden auch die statistischen Mittelwerte in $\mathrm{mg} / \mathrm{dl}$ für $\mathrm{lgG}$, IgA und $\lg M$ und die sich daraus ableitenden Umrechnungsfaktoren zum definierten Wert: von $94,4 \mathrm{IU} / \mathrm{ml}$ mitgeteilt (4).

Verǵleicht man die bis dato erhaltenen firmenabhängigen Meßergebnisse in $\mathrm{mg} / \mathrm{dl}$ (Bezugssystem: ProteinStandard-Präparate der jeweiligen Firma) mit den Resultaten in IU/ml (Bezugssystem: WHO-IRP Lot 67/86), so kommt man zu firmenspezifischen Umrechnungsfaktoren (Conversion Factors). 
Die Deklaration der Ergebnisse in $\mathrm{IU} / \mathrm{ml}$ bzw. die Bekanntgabe der Umrechnungsfaktoren erlauben eine bessere Vergleichbarkeit der Analysenergebnisse von Labor zu Labor unabhängig vom jeweiligen Testsystem und erfüllen damit eine sinnvolle Anforderung an die Standardisierung der immunchemischen Protein-Bestimmung bei den Immunglobulinen. Weil das firmeneigene Bezugssystem unterschiedlich ist, so sollten sich auch die Umrechnungsfaktoren von Firma zu Firma unterscheiden. Hierbei kommt es nicht allein auf den Reinheitsgrad der eingesetzten Immunglobulin-Präparationen der Firmen an, sondern insbesondere auch auf deren physikalisch-chemische Struktur. So hat z. B. der Aggregationszustand einen wesentlichen Einflúß auf den Umrechnungsfaktor und damit auf die Analysenergebnisse. Ebenso führen monoklonale oder polyklonale Immunglobulin-Präparationen, als Primär-Standards eingesetzt, zu erheblichen Unterschieden der Quantifizierung.

Spätere Versuche, die Analysendaten auch mit Hilfe moderner Techniken, wie z. B. der Turbidimetrie und der Laser-Nephelometrie, zu erstellen, führten zu der Erkenntnis, daß mit methodenabhängigen Umrechnungsfaktoren von $\mathrm{g} / \mathrm{l} \mathrm{zu} \mathrm{IU} / \mathrm{ml}$ gerechnet werden muß. Darüber hinaus wurden auch Abhängigkeiten von der Charge der verschiedenen Standard-Präparationen von Firmen beobachtet. Diese Beobachtungen mögen zu einer Kritik der IRP's für manche Proteine geführt haben, die zum Teil eine Schwächung der gewünschten Akzeptanz, ja sogar eine gewisse Gleichgültigkeit gegenüber der Anwendung der IRP's zur Folge gehabt haben mag.

Besonders kritisch ist die immunchemische Bestimmung von IgM - möglicherweise besonders wegen des schwankenden hohen Molekulargewichtes von MG $>900000 \mathrm{D}$ - geblieben, während. Korrelationsanalysen für die Immunglobuline IgG, IgA unter Einbezug der IRP Lot. 67/86 je nach Methode eine zum Teil recht gute Vergleichbarkeit der Analysenergebnisse bis heute aufweisen.

\subsection{WHO IRP for 6 Human Serum-Proteins for Immunoas- says-Lot 4/2 bzW. Lot 6 HSP}

Mit Blick auf die Richtlinien der Bundesärztekammer sind neben den drei diskutierten Immunglobulinen auch Ringversuche für die Plasmaproteine Albumin und Transferrin vorgesehen. Für diese beiden letztgenannten Proteine fungiert als WHO IRP eine Referenz-Präparation, die im Jahre 1978 von einem Experten-Komitee der WHO (5) etabliert wurde. Sie ist die IRP für 6 Human Serumproteine (6 HSP), und zwar für Albumin, $\alpha_{1}$-Antitrypsin, Coeruloplasmin, Transferrin, C3/C3c und $\alpha_{2}$-Makroglobulin. Im Gegensatz zur IRP Lot. 67/86 wurde die Konzentration der sechs deklarierten Plasmaproteine definitionsgemäß mit $100 \mathrm{IU} / \mathrm{ml}$, d. h. nach Rekonstitution des Lyophilisates mit $1 \mathrm{ml}$ Aqua dest., festgelegt:

Etwa 3 Jahre später (6) wurden auch die drei Immunglobuline IgG, IgA und IgM unter Bezugnahme auf die erste WHO/IRP Lot. 67/86 nachkalibriert. Für die Immunglobuline ergaben sich unter Beachtung der statistisch relevanten Ergebnisse folgende arbiträre Einheiten:

$114,2 \mathrm{IU} / \mathrm{ml} \lg \mathrm{G}$

$114,2 \mathrm{IU} / \mathrm{ml} \mathrm{lgA}$

$141,6 \mathrm{IU} / \mathrm{ml} \mathrm{lgM}$

\subsection{Vergleich WHOIIRP 6 HSP versus CDC/US-nat. RP Lot} 120575 C

Mit Rücksicht auf internationale Standardisierungsbestrebungen für Plasmaproteine ist interessant zu wissen, daß die WHO/IRP 6 HSP aus dem gleichen Ausgangsmaterial wie eine heute noch gültige USA-nationale Referenz-Präparation mit der Bezeichnung CDC Lot $120575 \mathrm{C}$ hergestellt wurde.

Die beiden Referenz-Präparationen WHO/IRP 6 HSP und CDC/US-nat. RP Lot $120575 \mathrm{C}$ sind bis zum heutigen Zeitpunkt die wichtigsten Referenz-Materialien im Sinne der Standardisierung der immunchemischen Protein-Bestimmung. Das Serum von 85 ausgewählten gesunden Blutspendern aus der Region Atlanta/Georgia/USA (7) führte zu einer Serum-Mischung, die aufgearbeitet, d. h. delipidisiert, und konserviert wurde. Das Ausgangsmaterial wurde dann in zwei Teilmengen unterteilt. Ein Anteil wurde unter der Federführung von CDC (Centers of Disease Control) in Atlanta abgefüllt und lyophil getrocknet, während der zweite Teil nach Marburg geschickt wurde und dort unter firmeninternen Bedingungen abgefüllt und einer Lyophilisation unterzogen wurde. Der entscheidende Unterschied für beide Referenzmaterialien liegt im Abfüllvolumen (Atlanta-Präp.: 1,5 ml; MarburgPräp.: $1,3 \mathrm{ml}$ ) und damit im Trockengewicht der beiden Lyophilisate (Atlanta-Präp.: 129,23 mg; Marburg-Präp.: $111,37 \mathrm{mg}$ ). Das Verhältnis der beiden Trockengewichte beträgt 1,160. Dieser theoretische Unterschied wird auch bei einer Nachprüfung der Protein-Konzentrationen, z. B. mit Hilfe der RID, bestätigt (8). Im Durchschnitt liegen die Konzentrationen der Proteine in der CDC/US-nat. RP etwa $+10,1 \%$ (Bereich $+6,1$ bis $+14,9 \%$ ) höher als in der später zur WHO/IRP 6 HSP deklarierten Marburger Charge. Die um $16 \%$ höheren Werte in der US-nat. Referenz-Präparation (d. h. theoretisch $116 \mathrm{IU} / \mathrm{ml}$ für jeden Analyten gegenüber der mit $100 \mathrm{lU} / \mathrm{ml}$ definierten Konzentration in der WHO/IRP Lot 4/2) werden auch für die drei Immunglobuline IgG, IgA und IgM sehr gut bestätigt (+ 14,0 bis $+14,9 \%)$, wenn die Deklaration in $\mathrm{IU} / \mathrm{ml}$ erfolgt. Abweichungen von der theoretischen Relation können $u$. a. durch den unterschiedlichen Trocknungsgrad (Restfeuchte) erklärt werden.

In der US-nat. Referenz-Präparation wurden auch Sollwerte für C4, saures $\alpha_{1}$-Glykoprotein und Haptoglobin festgelegt, deklariert in $\mathrm{g} / \mathrm{l}$ und zusätzlich in $\mathrm{IU} / \mathrm{ml}$ für $\mathrm{C} 4$.

Während für $\mathrm{C} 4$ und weitere Komplement-Komponenten wie $\mathrm{C} 1 \mathrm{q}, \mathrm{C} 3, \mathrm{C5}$ und Faktor B sowie für die gesamte Komplement-Aktivität selbst auch eine WHO/IRP (9) existiert, wurde für die Plasmaproteine saures $\alpha_{1}$-Glykoprotein und Haptoglobin bisher noch keine IRP etabliert (Angaben nur in $\mathrm{g} / \mathrm{l}$ ). Allerdings gibt es für viele weitere Plasmaproteine IRP's der WHO, in denen jeweils nur ein einzelnes Plasmaprotein deklariert und mit $\mathrm{IU} / \mathrm{ml}$ definiert ist, so z. B. für $\alpha$-Fetoprotein, $\beta_{1} \mathrm{SP} 1-\mathrm{Glykoprotein,} \beta_{2}-\mathrm{Mi}$ kroglobulin, CRP und Ferritin (Literatur in 8). Über die Beurteilung der Qualität dieser „Solo-IRP's" wurde bisher wenig bekannt.

1.4 Umrechnungsfaktoren von $\mathrm{IU} / \mathrm{ml} \mathrm{zu} \mathrm{mg} / \mathrm{dl}$ (SI-Einheiten: $g / l)$

Vor der Etablièrung von IRP's für diverse Plasmaproteine haben Reagenzien-Hersteller Immunoassays zur quantitativen Bestimmung von Plasmaproteinen auf den Markt gebracht, deren Meßwertangabe in der Regel mit Massenkonzentrationen in $\mathrm{mg} / \mathrm{dl}$ bzw. g/l erfolgte. Gewöhnlich kalibrieren die Hersteller ihre Protein-Standard- und Kontroll-Präparationen unter Bezugnahme auf firmeneigene, hochgereinigte Plasmaproteine, die in Form von Primär-Standards als Kalibratoren in firmeneigenen Immunoassays verwendet werden. Da sich die als Kalibrato- 
ren benutzten hochgereinigten Protein-Präparationen hinsichtlich ihrer Herkunft und ihrer physikalisch-chemischen Struktur-Eigenschaften sowie bezüglich des Reinheitsgrades von Firma zu Firma - wie schon bei den Immunglobulinen dargelegt - unterscheiden können, ist eine Vergleichbarkeit der Analysenergebnisse im Labor des Anwenders beim Wechsel von einem zu einem anderen Immunoassay bei einigen Proteinen nicht oder unzureichend gegeben.

Eine Brücke zu den IRP's wird über die Einführung von sogenannten Umrechnungsfaktoren gebaut. Der Umrechnungsfaktor läßt sich berechnen aus der Relation des gefundenen Wertes in $\mathrm{mg}$ (Bezug auf ein firmeninternes Meßsystem) zum definierten WHO/IU-Wert (10). Durch diese Konvertierung in IU wird die gewünschte Vergleichbarkeit der Laborresultate weltweit erreicht. Aus diesem Grunde ist die bevorzugte Deklaration von Meßdaten in $\mathrm{IU} / \mathrm{ml}$ mit Nachdruck zu befürworten, auch wenn der Wunsch nach Angaben in absoluten Konzentrationen bei vielen Laborärzten vorwiegt. Der Abstand bzw. die Nähe zum sogenannten "wahren Wert" ist in diesem Zusammenhang eine zweitrangige Frage; sie wird durch die Einführung von $\mathrm{IU} / \mathrm{ml}$ nicht gelöst.

Aufgrund der obigen Ausführungen ist der Umrechnungsfaktor firmenspezifisch, d. h. in der Regel von Firma zu Firma variabel. Es ist allerdings auch damit zu rechnen, daß er für ein ausgewähltes Protein nicht für alle Zeit konstant ist. Eine Reihe von Faktoren kann die Größe des Umrechnungsfaktors von Fall zu Fall mit recht unterschiedlichem Grad und Trend beeinflussen. $U$. a. sind folgende Abhängigkeiten für den Umrechnungsfaktor zu bedenken:

- die physikalisch-chemischen Struktur-Eigenschaften und immunreaktiven Qualitäten einer hochgereinigten Protein-Präparation, die als Primärstandard/Kalibrator zur Festlegung von Sollwerten eingesetzt wird.

- die chargen- und laufzeitabhängige Qualität der Proteine in Protein-Standard- und Kontroll-Präparationen mit Matrix-Charakter.

- die immunreaktiven wie auch methodenabhängigen Eigenschaften des antikörperhaltigen Reagenzes.

- der Einfluß von Matrixelementen und interferierenden Substanzen sowie das unterschiedliche Mitwirken von Hilfsreagenzien in der Antigen-Antikörper-Reaktion (Beschleunigung/Nerlangsamung).

- das Meßprinzip des eingesetzten Immunoassays (Immunpräzipitationen in Gelen/lmmunkomplexe in Automatentechniken).

- die Hardware und Software der verwendeten Instrumente und Auswertung.

Bei all diesen Möglichikeiten besteht eine zusätzliche Abhängigkeit von der Charge der jeweils verwendeten Reagenzien und Instrumente. Darüber hinaus ist das Verhalten geforderter Eigenschaften wie Homogenität, Linearität, Parallelität und Stabilität $u$. a. wegen der leichten Veränderlichkeit mancher hochmolekularer Proteinstrukturen sicherlich auch stark von der Laufzeit der Reagenzien abhängig.

Auf diesen Unwägbarkeiten basieren viele Probleme und Diskrepanzen bei immunchemischen Analysenverfahren. Ansatzpunkte zur bėsseren Interpretation solcher Beobachtungen und zum besseren .Verständnis zukünftiger Standardisierungsbestrebungen sollen im nächsten Teil erläutert werden.

\section{Die Optimierung der Standardisierung von Immunoassays - 4 Postulate}

\subsection{Meßsignal versus Meßwert}

In Informationsunterlagen für Immunoassays begegnet man in der Regel der Formulierung: Die Größe eines Meßsignals ist proportional zum Meßwert eines Proteins in einer Probe, d. h., je höher ein Meßsignal, um so höher ist auch der Meßwert und/oder umgekehrt: je höher ein Meßwert, um so höher sollte auch das Meßsignal sein. Für kompetitive Immunoassays wäre diese Proportionalität reziprok anzusetzen.

Eine solche Information ist stark verkürzt und kann zu falschen Rückschlüssen und Assoziationen führen. Da es sich in der Regel bei Immunoassays um sogenannte Antigen(Hapten)-Antikörper-Reaktionen handelt, ist bei der Entstehung eines Meßsignals außer dem Antigen noch ein weiteres Protein maßgeblich beteiligt, nämlich der Antikörper. Dies bedeutet, daß die Größe eines Meßsignals eine bestimmte Menge eines Antigen(Hapten)-Antikörper-Reaktionsproduktes widerspiegelt. Die Stöchiometrie der Antigen-Antikörper-Reaktion hängt von sehr vielen Faktoren ab. Dieses meßtechnisch wichtige Reaktionsprodukt sollte im wesentlichen auf der Wechselwirkung des zu analysierenden Proteins mit den Antikörpern im Reagenz basieren. Darüber hinaus ist aber mit unbekannten, mehr oder weniger großen Beimengungen im Antigen-Antikörper-Reaktionsprodukt zu rechnen, bedingt zum Teil durch Wechselbeziehungen der AntigenAntikörper-Komplexe mit Komplement-Komponenten, zum anderen aber auch durch Beteiligung der Matrixeffekte und der in der Antigen-Antikörper-Reaktion interferierenden Substanzen. Möglicherweise werden auch Signale registriert und für eine Meßwertbestimmung herangezogen, die gar nicht durch immunchemische Antigen-Antikörper-Reaktionen zustande kommen.

Die beiden Begriffe Messung und Meßwertbestimmung (11), die in einer Wechselbeziehung zueinander stehen, sind für sich eigenständige Vorgänge und wie folgt zu definieren:

Jede Messung bedeutet, das Signal eines Standards mit dem Signal einer Probe zu vergleichen.

Jede Meßwertfestlegung bedeutet, die Quantität eines Standards mit der Quantität einer Probe zu vergleichen.

In Immunoassays gilt der Vergleich dem Signal bzw. der Quantität eines Protein/Standard-Antikörper-Reaktionsproduktes mit den entsprechenden Größen eines Protein/ Proben-Antikörper-Reaktionsproduktes.

Eine gleichsinnige ${ }^{\circ}$ Wechselbeziehung und damit eine Proportionalität (ob direkt oder indirekt) zwischen Signal und Meßwert können nur vorausgesetzt werden, wenn 4 Postulate (12) erfüllt sind. Es handelt sich hierbei im wesentlichen um 2 immunchemische Einflußgrößen (Antigen/Antikörper) und 2 nicht-immunchemische Faktoren (Matrix/Meßprinzip), die die Größe des Meßsignals und damit die davon abgeleitete Festlegung eines Meßwertes verursachen und bestimmen. Meßwerte sollten bevorzugt in $\mathrm{U} / \mathrm{ml}$ deklariert werden.

\section{2.'Postulat 1 (Antigen)}

Unterschiedliche physikalisch-chemische Struktur-Eigenschaften von Proteinen in Untersuchungsmaterialien und in Referenz-Präparationen bedeuten auch ein unterschiedliches immunchemisches Reaktionsverhalten in einem Immunoassay. 


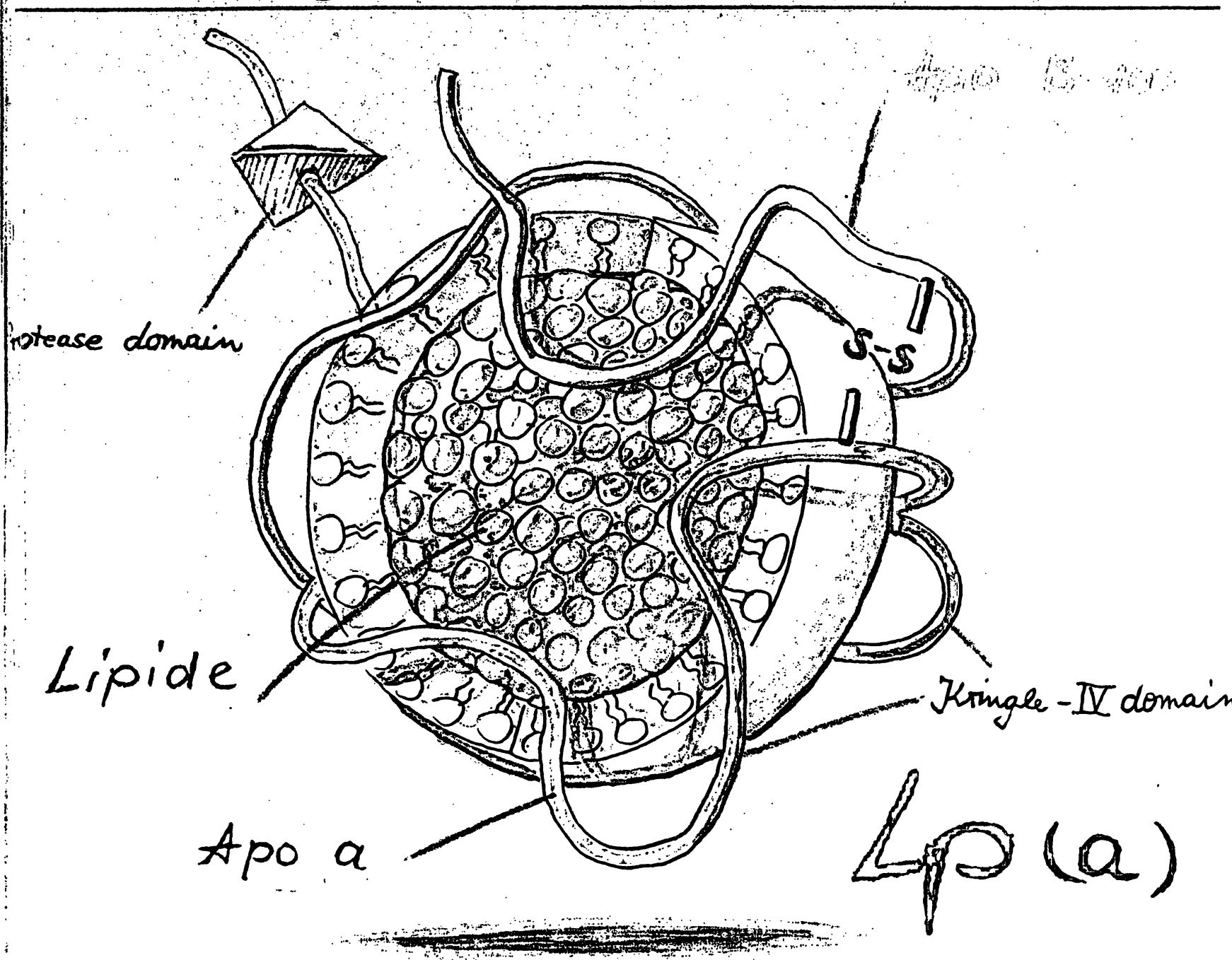

$L p(a)$ ist ein unabhängiger Risikofaktor für Atherosklerose. Sequenzhomologien von Apo(a) mit Plasminogen deuten auf einen $\mathrm{Zu}$ sammenhang von thrombotischen und atherosklerotischen Prozessen hin. $L p(a)-K o n z e n t r a t i o n e n$ über $30 \mathrm{mg} / \mathrm{dl}$ verstärken bei gleichzeitiger LDL-Erhöhung das Atherosklerose-Risiko um ein Vielfaches.
IMMUNO ist Pionier in der $L p(a)-$ Diagnostik. In über 100 Publikationen wird seit mehrals 10 Jahren die Qualität von IMMUNO-Reagenzien dokumentiert.

\section{NEU!}

Mit IMMUNOZYM Lp(a) steht Ihnen erstmals ein Einschritt-ELISA für die Routine-Diagnostik zur Verfügung.

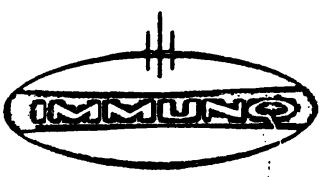

Ich interessiere mich für $L p(a)$-Diagnost und bitte um Zusendung folgender Unterlagen:

| $\square$ ELISA IMMUNOZYM Lp(a)

| $\square$ Andere Methoden (Rocket-Elektrophorese, Nephelometrie, Phenotyping)

$\square$ Preisliste Immuno-Diagnostika

$\square$ Besuch des Diagnostik-Referenten

$\square$ Sonstiges:

(1)

IMMUNO GmbH Geschäftsbereich Diagnostika Postfach $103080 \quad 6900$ Heidelber 
Das Ziel einer optimalen Standardisierung der immunchemischen Proteinbestimmung wird nur erreicht, wenn das erste immunchemische Postulat erfüllt ist. Es lautet:

Die gleichsinnige Wechselbeziehung, d. h. direkte oder indirekte Proportionalität, zwischen einem Meßsignal und dem zugehörigen Meßwert für die Konzentration eines Proteins wird nur erreicht, wenn die immunchemischen, reaktiven Eigenschaften des Proteins - im wesentlichen Anzahl und Affinität der Epitope - uniform und identisch sind in:

- Primär-Protein-Reinpräparation (Standard).

- Sekundär-Protein-Matrix-Referenz-Präparation (IRP).

- Tertiär-Protein-Matrix-Standard-Serum (Hersteller-Produkt).

- Tertiär-Protein-Matrix-Kontroll-Serum (Hersteller-Produkt).

- Protein-Analyt in einer Untersuchungsprobe (Patientenprobe).

Die geforderte Identität der verfügbaren Anzahl und reaktiven Qualität der Epitope sollte chargenunabhängig gewährleistet sein ohne Unterschied der Herkunft (Institution/Hersteller).

Epitope, auch Antigen-Determinanten genannt, sind relativ kleine Bereiche der stereochemisch festgelegten Tertiär/Quartär-Struktur eines Proteins. Hierbei handelt es sich weniger um Abschnitte der fortlaufenden Polypeptidkette selbst als vielmehr um Oberflächensegmente von Raumstrukturen.

Diese Raumstrukturen sind nicht als intakt und unveränderlich anzusehen. Sie hängen von den jeweiligen physiko-chemischen Struktur-Eigenschaften der Proteine ab. Dies bedeutet, daß die Existenz und damit die Verfügbarkeit von immunreaktiven Epitopen für die Wechselwirkung mit entsprechenden Antikörpern im Falle instabiler Proteine sehr variabel sein können (Abnahme und $\mathrm{Zu}$ nahme $\hat{=}$ Neo-Epitope).

Weitere Einzelheiten sind der Literatur (8) zu entnehmen.

\subsection{Postulat 2 (Antikörper/Antiserum)}

Eine optimale Standardisierung der immunchemischen Proteinbestimmung wird nur erreicht, wenn auch das zweite immunchemische Postulat erfüllt ist. Es lautet:

Die gleichsinnige Wechselbeziehung, d. h. direkte oder indirekte Proportionalität; zwischen einem Meßsignal und dem zugehörigen Meßwert für die Konzentration eines Proteins wird nur erreicht, wenn das immunchemische Verhalten des Antiserums

- im wesentlichen die Qualität der Population vorhandener Antikörper - chargenunabhängig uniform und identisch ist, und zwar hinsichtlich:

- Verfügbarkeit der Anzahl an monoklonalen Antikörpern.

- mengenmäßiges Verhältnis dieser Antikörper untereinander.

\section{- Spezifität, Affinität und Avidität.}

- Stabilität (Matrix-Effekte).

Bis heute ist die Anzahl von monoklonalen Antikörpern in einem konventionell hergestellten Antiserum weder für den Hersteller noch für den Anwender bekannt. In Abhängigkeit von den jeweiligen Immunisierungsbedingungen verursachen Epitope auf den Immunisierungsantigenen eine nicht vorhersagbare und bis heute nicht exakt definierte Immunantwort. Es bleibt offen, welche Epitope die Synthese korrespondierender Antikörper initiieren. Dafür fehlt zur Zeit mit wenigen Ausnahmen noch das analytische Instrumentarium.

Ganz im Vordergrund steht die Sicherstellung der Spezifität eines Antiserums. Darunter versteht man das eingeschränkte Reaktionsverhalten eines monospezifischen Antiserums mit einem einzigen Antigen/Hapten-Individuum. Dieses wichtige Kriterium sollte mindestens mit der Sensitivität und Nachweisgrenze sichergestellt werden, die ·für den Meßbereich eines Immunoassays, für den ein solches antikörperhaltiges Reagenz verwendet wird, relevant ist.

Für die Signalbildung einer Antigen-Antikörper-Reaktion selbst ist die Antikörper-Aktivität, d. h. die AntikörperMenge und die Antikörper-Avidität, von großer Bedeutung. Die Beurteilung dieser Qualität ergibt sich in der Regel pragmatisch aus der Anwendung im vorgesehenen Immunoassay.

Trotz möglicher großer Schwankungen der AntikörperZusammensetzung (= Population eines Antiserums) kann der Einfluß des zweiten immunchemischen Postulates in den meisten Fällen dann vernachlässigt werden, wenn das erste immunchemische Postulat für den antigenhaltigen Teil erfüllt ist. Ein solcher Schluß resultiert aus der Tatsache, daß im Falle der immunchemischen Identität der antigenhaltigen Testmaterialien ein Antiserum nur mit den gleichen Epitopen reagieren kann. Noch möglicherweise zusätzlich vorhandene Antikörper kommen in der Antigen-Antikörper-Reaktion nicht zur Geltung. Das Reaktionsverhalten eines Antiserums wird in solchen Fällen einzig und allein maßgeblich von der Antigenseite her beeinflußt und bestimmt. Bei Ungleichheit der Epitope wirkt sich das zweite Postulat aus.

Weitere Einzelheiten sind der Literatur (8) zu entnehmen.

\subsection{Postulat 3 (Matrix/Meßprinzip)}

Die Größe eines Meßsignals wird auch von einer Reihe nicht-immunchemischer Einflußfaktoren mitbestimmt.

Eine optimale Standardisierung der immunchemischen Proteinbestimmung wird nur dann erreicht, wenn auch das dritte - nicht-immunchemische - Postulat erfüllt ist. Es lautet:

Eine gleichsinnige Wechselbeziehung, d. h. direkte oder indirekte Proportionalität, zwischen einem Meßsignal und dem zugehörigen Meßwert für eine Protein-Konzentration kann nur dann erreicht werden, wenn die eingesetzte immunchemische Methode so standardisiert ist, daß die Größe des Meßsignals, die allein durch das Antigen-Antikörper-Reaktionsprodukt bewirkt und bedingt sein sollte, nicht verfälscht wird im Sinne einer Erhöhung oder Erniedrigung

- durch Matrix-Effekte und interferierende Substanzen (Postulat 3a).

- durch das Meßprinzip der eingesetzten Meßmethode selbst (Postulat 3b).

Postulat 3a

Matrixeffekte werden $u$. a. durch lipämische, hämolytische, salzhaltige, rheumafaktorhaltige Sera ausgelöst. Der verbleibende oder vorhandene Anteil an Lipoproteinen in antigenhaltigen Referenz-Materialien und Proben ist von einflußreicher Bedeutung. Durch die Präsenz dieser hochmolekularen Partikel werden hohe Blindwerte hervorgerufen, die die Signalgröße mitgestalten können. Mikrobielle Kontaminationen sind ebenfalls unter diesem Gesichtspunkt zu sehen. 
Zu den interferierenden Substanzen, die das Antigen-Antikörper-Reaktionsprodukt beeinflussen können, gehören z. B. Arzneimittel und andere Stoffe in Untersuchungsmaterialien, wie Metabolite. Auch künstlich zugesetzte Konservierungs- und Stabilisierungsmittel dürfen in diesem Zusammenhang nicht vernachlässigt werden.

\section{Postulat $3 b$}

Das methodologische Prinzip eines Immunoassays hat ebenfalls einen entscheidenden Einfluß auf den Trend einer Antigen-Antikörper-Reaktion. Die Größe des Meßsignals wird je nach Immunoassay von unterschiedlichen, physikalisch-chemischen Eigenschaften des Antigen-Antikörper-Reaktionsproduktes (Größe, Anzahl der Partikel) bestimmt. Mit Zunahme des Molekulargewichtes eines Proteins, z. B. infolge Aggregation, kann ein Meßsignal in einer Technik - z. B. in der RID - kleiner werden, während es in einer anderen Technik - z. B. in der Nephelometrie - zu höheren Werten führt.

Dies bedeutet, daß Veränderungen der Protein-Eigenschaften während der Laufzeit zu gänzlich gegenläufigen Trends in der Signalgröße und damit in dem davon abgeleiteten Meßwert führen können.

Auch die anfängliche Molekülgröße der Antikörper in Antisera (Klasse, Immunkomplexe) ist von unterschiedlicher Wirkung auf das Meßprinzip.

Bei kinetischen Fixed-Time-Techniken dürfte die Initialphase, d. h. der Keimträger für die sich nach und nach vergrößernden Antigen-Antikörper-Makromoleküle, von nachhaltiger Bedeutung sein. Für die Start-Signalgröße spielen Avidität des Antiserums und Blindwerte eine große Rolle. Ferner hat der zeitliche Abstand zwischen erster und zweiter Messung der Signalgrößen einen entscheidenden Einfluß auf die Richtigkeit der Meßwerte hochmolekularer Proteine. Zur Bildung von Immunkomplexen müssen sich Epitope und korrespondierende Antikörper finden, ein Vorgang, der temperaturabhängig ist und mit Zunahme des Molekulargewichtes von Proteinen komplexer und damit in der Regel langsamer abläuft.

Zusatzreagenzien zur Beschleunigung oder Verlangsamung kinetischer Reaktionen können die Meßergebnisse je nach Ausgangssituation der beiden erstgenannten Postulate in den Testmaterialien von Fall zu Fall unterschiedlich intensiv beeinflussen und damit die Signalgröße des eigentlichen Antigen-Antikörper-Reaktionsproduktes verfälschen.

Weitere Einzelheiten sind der Literatur (8) zu entnehmen.

\subsection{Postulat 4 (Arbiträre Units)}

Eine optimale Standardisierung der Proteinbestimmung - und damit die gewünschte Vergleichbarkeit der Analysenergebnisse - wird erreicht, wenn auch das vierte nicht-immunchemische - Postulat beachtet wird. Es lautet:

Wenn eine gleichsinnige Wechselbeziehung, $d . h$. direkte oder indirekte Proportionalität, zwischen einem Meßsignal und dem Meßwert für eine Protein-Konzentration (Quantität) besteht, sollten die Werte für eine ProteinKonzentration bevorzugt in arbiträren Einheiten (z. B. IU/ml) deklariert werden.

Die Quantitäten von Protein-Konzentrationen in IRP's werden generell mit solchen Einheiten definiert. Für davon abgeleitete Protein-Standard- und Kontroll-Präparate von Reagenzien-Herstellern sollte ebenfalls die Deklaration in $\mathrm{IU} / \mathrm{ml}$ für Plasmaproteine bevorzugt werden. Das gleiche gilt für den Laborarzt auf der Seite der Meßergebnisse für Untersuchungsproben. Nur auf einem solchen Bezugswege wird eine internationale Vergleichbarkeit der Laborresultate erreicht.

Der bis heute übliche Transfer von arbiträren Einheiten in absolute Mengenangaben wie $\mathrm{mg} / \mathrm{dl}$ oder $\mathrm{g} / \mathrm{l}$ ist nur dann und deshalb zu rechtfertigen, weil durch solche Umrechnungen eine Vergleichbarkeit mit früheren Wertangaben in Informationsmaterialien und Publikationen zugänglich wird.

Vom wissenschaftlichen Standpunkt (11) her gesehen ist der Transfer wegen der unter Punkt 1.4 diskutierten Schwankungsgrößen unzulässig bzw. problematisch. Ein Umrechnungsfaktor von IU/ml zu g/l unter Bezugnahme auf eine ausgewählte hochgereinigte Protein-Präparation mit definierten physikalisch-chemischen Struktur-Eigenschaften wird in der Regel chargenabhängig einmalig sein. Für ein Verbot des Transfers absoluter Konzentrationen von einem hochgereinigten Primär-Protein-Standard (Einwaage) zu einer sekundären Protein-Serum-ReferenzPräparation (IRP) dürfte schon die unterschiedliche Matrix-Qualität Grund genug sein. Natürlich ist der Hauptgrund für die Problematik in der möglicherweise vorhandenen, unterschiedlichen Immunreaktivität zu suchen. Darüber hinaus fehlt für ein solches Transfer-Ansinnen eine geeignete Referenzmethode (13), wie sie in der klinischen Chemie für viele niedermolekulare Substanzen beschrieben wurde. Ein bevorzugter Kandidat für eine Referenzmethode für Plasmaproteine wäre erst dann gefunden, wenn bei ihm das nicht-immunchemische Postulat 3 erfüllt ist.

Mit Berücksichtigung der hier dargelegten Postulate lassen sich für den Zahlenwert eines Umrechnungsfaktors (UF) von IU zu mg im wesentlichen drei Anteile beschreiben:

a) Der einfache Dimensionsfaktor (DF) für das Verhältnis von IU zu g.

Der Umrechnungsfaktor ist mit dem Dimensionsfaktor identisch, wenn die drei diskutierten Postulate erfüllt sind. Dieser Fall ist in der Regel nicht oder nur annäherungsweise gegeben. Er wurde aber bisher als pràgmatischer Ausweg (bei einigen relativ stabilen Proteinen problemlos) angewandt.

b) Der immunchemische Faktor (IF).

Er berücksichtigt die beiden Postulate 1 und 2 und damit den immunreaktiven Teil der Antigen-AntikörperReaktion. Vạriabilität des Antigens und des Antiserums vorausgesetzt, muß auch mit einer Variabilität des Umrechnungsfaktors gerechnet werden. Eine Chargenabhängigkeit für IF ist dann zu unterstellen. Die Berücksichtigung von IF führt über eine Korrektur des DF zum "riçhtigeren" Wert von UF.

c) Der nicht-immunchemische Faktor (NF).

Er berücksichtigt die Anteile der nicht-immunchemischen Einflüsse, die sich auf Matrixeffekte und auf das Meßprinzip selbst beziehen. Der Umrechnungsfaktor wird in der Regel methodenabhängig sein. Es bleibt offen, ob dieser nicht-immunchemische Anteil das Meßsignal multiplikativ oder additiv beeinflußt. Die zusätzliche Berücksichtigung von NR (neben IF) über eine Korrektur von DF führt zum „richtigeren“ Werit von UF.

Die Beachtung dieser mehr theoretisch erörterten $\mathrm{Zu}$ sammenhänge für die Festlegung eines Umrechnungsfaktors von IU zu $\mathrm{g}$ ist erschwert durch das Fehlen optimaler technischer Analysenmöglichkeiten. Um so überzeugender muß das Postulat 4 Akzeptanz finden. 


\section{Empfehlungen zur Herstellung von Protein-Serum-Referenz-Präparationen}

Bei der Absicht, international akzeptable Protein-SerumReferenz-Präparationen zu etablieren, ist das erste immunchemische Postulat (Antigen) zu bedenken und soweit als möglich zu erfüllen. Denn über den kaskadenhaften Zusammenhang, angefangen von den physiko-chemischen Struktur-Eigenschaften über das immunreaktive Verhalten von Proteinen bis hin zu einem Meßsignal und schließlich - davon abgeleitet - zu einem Meßwert, dürfte kein Zweifel bestehen.

Soweit die genannten Postulate für diese Kaskade an einer Stelle nicht erfüllt werden können, dürften sich bei immunchemischen Analysenverfahren Unwägbarkeiten für die Meßsignalgrößen und damit falsche Ergebnisse für die Meßwerte einstellen.

Solche Fallbeispiele für unklare Situationen bei der Protein-Bestimmung sind genügend bekannt:

- unterschiedlicher Aggregationszustand

(Immunglobuline IgG, IgM).

- unterschiedlicher Fragmentierungsgrad

(Komplement-Komponenten C3/C3c; C4/C4c).

- starke Strukturveränderungen bei Proteinen mit Übergängen vom funktionsaktiven zum inaktiven Zustand ( $\alpha_{1}$-Antitrypsin $/ \alpha_{2}$-Makroglobulin).

- individueller Polymorphismus bei vielen Plasmaproteinen (Haptoglobin-Typ 1-1, Typ 1-2, Typ 2-2).

\subsection{Idealer Lösungsweg}

Eine Protein-Referenz-Präparation wird gewöhnlich durch Mischen von einzelnen Sera gesunder Blutspender hergestellt. Es ist selbstverständlich, daß für die Auswahl gesunder Blutspender gewisse, konventionell abgesprochene Anforderungen (z. B. "Virus-Sicherheit") erfüllt sein müssen.

Theoretisch ist zu erwarten, daß Protein-Serum-ReferenzPräparationen dann eine besondere Güte und Qualität besitzen, wenn die Inhaltsstoffe die intakte In-vivo-Struktur auch in vitro weiter beibehalten haben. Dies bedeutet, daß eine Mischung frischer Sera gesunder Blutspender ohne Behandlung und Aufarbeitung die beste Grundlage zur Herstellung einer Protein-Matrix-Referenz-Präparation darstellt. Für einen solchen Idealfall dürfte auch die gleichsinnige Wechselbeziehung der Signal-MeßwertProportionalität sowohl für die Referenz(Standard)-Präparation wie auch für das Protein in der Untersuchungsprobe im Immunoassay gegeben sein.

Wegen der Instabilität vieler Plasmaproteine dürften solche Protein-Serum-Referenz-Präparationen aus Gründen einer möglichst langen Haltbarkeit und Stabilität nur im flüssigen Zustand tief eingefroren bei $-20^{\circ} \mathrm{C}$ oder besser bei $-70^{\circ} \mathrm{C}$ aufbewahrt und versandt werden.

\subsection{Pragmatische Anforderungen / Konsequenzen}

Der Versandweg für bei Minus-Temperaturen gelagerte Produkte dürfte problematisch sein, insbesondere bei großen Entfernungen und für Länder mị mangelhaftem technischen Instrumentarium.

Es ist bekannt, daß wechselhafte Temperaturen während des Versandweges einen vernachlässigbaren Einfluß auf die Stabilität von Proteinen haben, wenn Protein-Referenz-Präparationen in gefriergetrockneter form vorliegen. Für Serum-Lyophilisate ist eine Kühlkette meistens nicht erforderlich. Allerdings spricht erfahrungsgemäß gegen die Lyophilisation von frischen Serum-Mischungen die leicht nachprüfbare Tatsache, daß die bereits in frischen Sera vorhandenen und zu Fehlmessungen Anlaß gebenden Blindwerte durch den Vorgang der Lyophilisation um ein Vielfaches ansteigen. Dieser Anstieg hängt mit der häufig beobachteten Denaturierung der vorhandenen Lipoprotein-Partikel wie HDL, LDL und VLDL zusammen. Denn während des Wasserentzugsprozesses kann die Wasserlöslichkeit der Lipoproteine irreversibel geschädigt werden.

Es ist bekannt, daß man dem Vorgang der Denaturierung durch Schutzmaßnahmen, z. B. durch Zugabe von Stabilisatoren, entgegenwirken kann. Die Denaturierung läßt sich allerdings nicht gänzlich ausschließen, da der Restfeuchte-Gehalt in Lyophilisaten noch nicht optimal gesteuert werden kann. Darüber hinaus dürfen solche Zusatzstoffe die Proportionalität der Signal/Meßwert-Relation nicht zusätzlich belasten.

Gegen gefriergetrocknete Protein-Referenz-Präparationen spricht auch eine weitere Erfahrung: flüssige ProteinSerum-Referenz-Präparationen, ob als Standard- oder Kontroll-Präparate eingesetzt, haben ihre Vorzüge in Automatentechniken wegen der leichteren Handhabbarkeit gegenüber den lyophil getrockneten. Die Rekonstitution von Lyophilisaten mit Aqua dest. kann zusätzliche Fehlerquellen mit sich bringen.

Die geschilderten Zielanforderungen an die Qualität von Referenz-Präparationen haben ihren eigenen Stellenwert mit unterschiedlichem Bezug (Reproduzierbarkeit der Analytik; Logistik der Handhabbarkeit). Einen sehr hohen Stellenwert hat sicherlich die Forderung, eine Denaturierung der Protein-Struktur soweit als möglich zu verhindern. Danach sollte auch dem Wunsch nach einer möglichst langen Haltbarkeit während der Laufzeit und nach einer klaren Lösung mit möglichst geringem Blindwert Beachtung geschenkt werden. Da die Eigentrübung eines Serums insbesondere von den Lipoprotein-Partikeln und anderen wenig hydrophilen Bestandteilen verursacht wird, sollten diese Substanzen aus einem Protein-SerumReferenz-Material durch eine entsprechende Manipulation entfernt werden.

\subsection{Stabilisierung von Serum-Mischungen}

Die bisherigen IRP's wurden bevorzugt mit Freon 113 stabilisiert. Dieses Verfahren hat nicht zu dem gewünschten Erfolg relativ niedriger Blindwerte geführt. Erhebliche Restmengen an .zum Teil denaturierten Lipoproteinen können noch heute in den IRP's nachgewiesen werden. Zur Entfernung der unerwünschten Lipoproteine wurde sehr oft die Flotation diskutiert, die allerdings sehr aufwendig und bei großen Serummengen aus technischen Gründen unzweckmäßig (Gefāhr der mikrobiellen Kontamination) ist. Fällungsmethoden bzw. absorptive Verfahren scheinen den Vorzug zu haben. Bei diesen Techniken kommt es darauf an, daß mit der gewünschten Entfernung der instabilen Bestandteile die Konzentration der ausgewählten Proteine durch Fraktionierung nicht reduziert wird. Ferner darf die intakte Protein-Struktur nicht beschädigt werden. Bezüglich solcher Anforderungen hat der heutige Stand der Technik Fortschritte gemacht.

\subsection{Verfahren zur Analyse von Struktur-Veränderungen}

Eine Abnahme der Protein-Konzentration kann in Immunoassays schnell nachgeprüft werden. Viel schwieriger ist es, mit Hilfe analytischer Verfahren den möglichen Ablauf einer Protein-Strukturveränderung (meistens verantwortlich für den vom 'Sollwert abweichenden Befurid) 
gegenüber dem In-vivo-Zustand zu analysieren und zu beschreiben.

Folgende Analysenverfahren lassen sich zur Charakterisierung einsetzen:

- Messung der Protein-Konzentration von Zeit zu Zeit in einem Immunoassay - unter Verwendung verschiedener Antisera (Abnahme bzw. Zunahme der Meßsignalgröße).

- Überprüfung der Linearität in Abhängigkeit von der Verdünnungsstufe (unter Berücksichtigung des Meßbereiches eines Immunoassays).

- Vergleichsuntersuchungen zur Parallelität in einem Immunoassay in bezug auf eine ausgewählte ReferenzPräparation (mit nachweislich intakter Protein-Struktur).

- Korrelationsanalyse in verschiedenen Immunoassays (unter Zuhilfenahme von einem Panel an Proben).

- physikalisch-chemische Trennverfahren, kombiniert mit anschließender Immunfixation (z. B. zweidimensionale Immunelektrophorese; Immunoblotting).

- Analyse der Epitope mit Hilfe monoklonaler Antikörper (sehr aufwendig und heute noch eine theoretische Forderung).

Um eine Verbesserung gegenüber den bisher existierenden IRP's zu erhalten, ist es notwendig, Protein-Strukturen für solche IRP's entsprechend dem Stand der Technik exakt zu definieren.

Im Falle von Abweichungen gegenüber der In-vivo-Struktur sind solche Veränderungen zu beschreiben und nach Möglichkeit von Zeit zu Zeit neu zu charakterisieren. Der mögliche Einfluß auf die Vergleichbarkeit der Ergebnisse ist bekanntzugeben.

\subsection{Weitere Möglichkeiten zur Herstellung einer IRP}

Sollten die geschilderten notwendigen Eingriffe zur Stabilisierung von Referenz-Präparationen von unerwünschten Stuktur-Veränderungen der Proteine belgeitet sein, so ist eine weitere Möglichkeit zur Herstellung von ProteinMatrix-Referenz-Präparationen in Betracht zu ziehen. In Anlehnung an die Herstellung einiger IRP's wäre es denkbar, in vivo-adäquate Proteine bzw. Protein-Fraktionen vorzureinigen und diese in intakter Form in eine stabile Matrix mit geringer Eigentrübung aufzunehmen. Als Matrix könnte eine stabilisierte Serum-Mischung, eine konzentrierte albuminhaltige Lösung oder, auch ein inertes Medium dienen, das stabilisierende und schützende Funktionen hat.

\subsection{Interim Secondary Serum Reference Preparation for Plasma Proteins ISRP/PP-Lot 91/0619}

Seit Jahren beschäftigt sich ein IFCC-Komitee mit der Optimierung der Standardisierung immunchemischer Plasmaprotein-Bestimmungen, seit zwei Jahren mit der Etablierung einer neuen Referenz-Präparation.

Diesem Komitee gehören fünf Mitglieder an, die aus europäischen Ländern und aus den USA kommen. Nach mehreren Vorbesprechungen, die insbesondere darauf abzielten, die europäischen wie auch amerikanischen Standardisierungsbestrebungen auf einen Nenner zu bringen, wurde bereits im Februar 1990 mit der Sammlung von Serum gesunder Blutspender an fünf verschiedenen europäischen Blutspende-Zentren begonnen. Im Dezember 1990 wurden diese Einzelsera, für deren Blutspender die geforderten Zertifikate zur Absicherung.des
Gesundheitszustandes vorliegen, nach Marburg gesandt und unmittelbar nach Ankunft einem Stabilisierungsverfahren unterworfen. Hierfür wurden insgesamt sieben Einzelpools entsprechend der unterschiedlichen Herkunft bzw. dem unterschiedlichen Zeitpunkt der Blutspende-Aktion hergestellt, jeweils für sich stabilisiert, dialysiert, konzentriert, konserviert und sterilfiltriert. Die auf diese Weise vorgefertigten Einzelpools wurden gemischt. Seit dem 20. Dezember 1990 existiert aus dieser Aktion ein Serum-Gesamtpool von etwa 40 Liter. Dieser Gesamtpool soll im Laufe des 2. Quartals $1991 \mathrm{zu} 1 \mathrm{ml}$ abgefüllt und danach gefriergetrocknet werden, vorausgesetzt, daß eine vom Gesamtpool abgezweigte Pilotcharge mit etwa 800 Abfüllungen gewisse Qualitätsmerkmale und Stabilitätsdaten erfüllt. Diese Kriterien wurden insbesondere in Absprache mit BCR = Bureau Communitaire de Reference (Europäisches Büro für Standardisierungsfragen in Brüssel) und mit verantwortlichen Mitgliedern von CAP (College of American Pathologists/USA) festgelegt. Sobald die Abfüllungen des Endproduktes ISRP zur Verfügung stehen, sollen zunächst 14 Plasmaproteine, und zwar

die 3 Immunglobuline $\lg$, IgA und $\lg M$, die Komplement-Komponenten C3 und C4,

die Transport-Proteine Präalbumin, Albumin, Transferrin und Haptoglobin,

die Inhibitoren $\alpha_{1}$-Antitrypsin und $\alpha_{2}$-Makroglobulin sowie ferner saures $\alpha_{1}$-Glykoprotein und Coeruloplasmin sowie CRP unter Bezugnahme auf bereits existierende IRP's kalibriert werden.

Die CRP-Konzentration wird absprachegemäß durch Zugabe einer CRP-Fraktion (Hersteller: Prof. Pepys/England) auf einen Wert von etwa 35 bis 40 mg/l aufgestockt.

Das europäische Büro für Standardisierungsfragen hat die Teilnehmer für den Kalibrierungsringversuch festgelegt. In den USA ist für diese Aufgabe CAP verantwortlich. Die ausgewählten Teilnehmer gehören sowohl Institutionen, Organisationen als auch verschiedenen Diagnostika-Herstellerfirmen. an. Bei gutem Verlauf der geplanten Operationen ist damit zu rechnen, daß im Herbst 1991 die Analysenergebnisse nach einem statistischen Verfahren, von IFCC-Mitgliedern erarbeitet und erprobt, ausgewertet und Interessenten zur Verfügung gestellt werden können. Diese Sollwerte (assigned values) sollen sowohl für den europäischen Markt als auch für amerikanische Anwender, soweit sie durch CAP organisiert sind verbindlich sein. Es ist $\mathrm{zu}$ vermuten, daß Institutionen wie die WHO und CDC/Atlanta (USA) diesen Beitrag des IFCC-Komitees unterstützen werden.

\section{Schluß}

Bekannterweise sind die Richtlinien der Bundesärztekam mer zur Qualitätssicherung in medizinischen Laboratorien so lange ausgesetzt, bis die Bereitstellung optimaler Protein-Referenz-Präparationen eine eindeutige Festlegung der Zielwerte für die fünf genannten Lageparameter erlaubt. Unabhängig von dieser Aussetzung der Zertifikatspflicht bis zum 31. 12. 1991 soll die Teilnahmepflicht an zwei Ringversuchen pro Jahr für die Proteine $\lg G, \lg \hat{A}$, IgM, Albumin und Transferrin beibehalten werden. Diese Maßnahmen sind zu befürworten.

Allerdings ist dieser Zustand für Diagnostika-Benutzer sicherlich unbefriedigend. Denn vom Anwender wird schon heute eine sehr wichtige und verantwortungsvolle Tätigkeit abverlangt, nämlich mit Hilfe der bereitgestell- 
ten Diagnostika und Testsysteme eine Diagnose zu erstellen, d. h. auf der Basis von teilweise kritischen Meßdaten eine Interpretation und damit verbunden eine Entscheidung über die Frage „gesund oder krank" zu treffen.

Diese Anforderung an den heutigen Labormediziner basiert in der Tat auf einem hohen Anspruch. Er ist auf der einen Seite von einer oftmals menschlich folgenschweren Erwartung durch den Patienten belastet und wird auf der anderen Seite mit Software/Hardware-Widersprüchen von zum Teil unwägbaren Labordaten konfrontiert. Dieser Konfrontation eines hohen Anspruches mit den möglichen Widersprüchen der tatsächlich verfügbaren Labordaten hat sich der Diagnostiker von heute zu stellen: fürwahr keine beneidenswerte Aufgabe, eine dafür aber um so höher einzuschätzende Leistung.

\section{Schrifttum:}

1. Qualitätssicherung der quantitativen Bestimmungen im Laboratorium - Neue Richtlinien der Bundesārztekammer. Dt. Ärztebl. 85, A $697-A 712$ (1988).

2. Übergangsregelungen zu den Richtlinien der Bundesärztekammer. Dt. Árzteblatt 87, A 493-A 495 (1990); 88, B 222 (1991).

3. ROWE, D. S., ANDERSON, S. G., GRAB, B.: A Research Standard for Human Serum Immunoglobulins $\lg G$, IgA and IgM. Bill. Wid. Hith. Org. 42, 535 (1970).

4. HUMPHREY, J. H., BATTY, I.: International Reference Preparation for Human Serum lgG, IgA, IgM. Immunochemistry 11, 759 (1974).

5. W.H.O.: International reference preparation of six human serum proteins. Albumin, $\alpha_{1}$-Antitrypsin, $\alpha_{2}$-Macroglobulin, C3, Ceruloplasmin and Transferrin for immunoassay. Recommendations for use (June 1979).

6. REIMER, C. B., SMITH, S. J., WELLS, T. W.: Collaborative calibration of three established reference preparations for specific proteins in human sera as secondary standards for $\lg A$, Ig $M$ and $\lg G$. J. Biolog. Stand. 9, 393 (1981).

7. REIMER, C. B., SMITH, S. J., et al.: Progress towards international reference standards for human serum proteins. J. Biolog. Standardization 6, 133 (1978).

8. BAUDNER, S.: Standardisierungsfragen zur immunchemischen Bestimmung von Plasmaproteinen. Behring Inst. Mitt. 86, 67-115 (1990).

9. VAN ES, L., SMITH, S. J., et al.: International collaborative study of four candidate reference preparations for the antigenic and enzymatic measurement of human Serum Complement Components. WHO/BS/80.12./81 (WHO-Communications).

10. BECKER, W.: Die Standardisierung immunchemischer Plasmaproteinbestimmungen. Laboratoriumsblätter 30, 25 (1980).

11. BŪTTNER, J.: Philosophy of measurement by means of immunoassays. Scand. J. Clin. Lab. Inv. I Suppl. 205, 11-20 (1991).

12. BAUDNER, S.: Measurement signal versus value in immunoassays for human plasmaproteins. Scand. J. Clin. Lab. Inv. / Suppl. 205. 70-78 (1991).

13. STAMM, D.: Reference materials and reference methods in clinical chemistry. J. Clin. Chem. Clin. Biochem. 17, 283-297 (1979).

Anschrift des Verfassers:

Dr. S. Baudner

Behringwerke AG

Postfach 1140

3550 Marburg

\section{Epreztitactio:

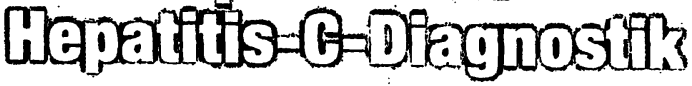

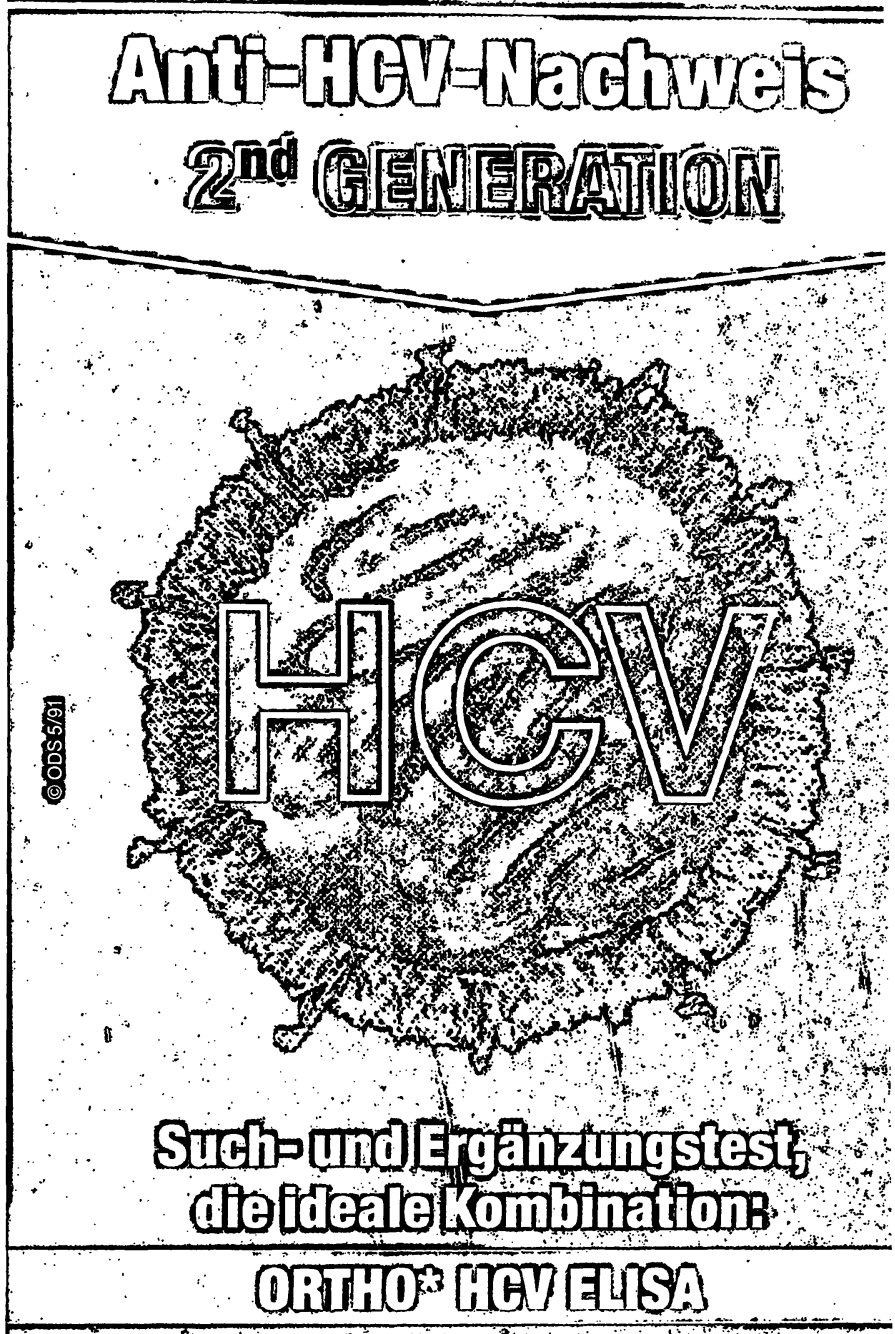

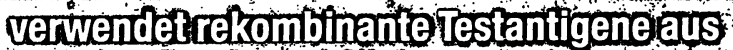

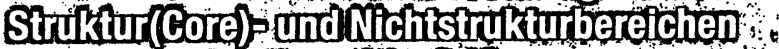
oes:Heprafits:Civitus

$-p$

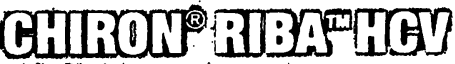

Weistitonurefinem Testaistatz

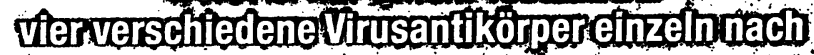

Vorteflederzweifen Generafton:

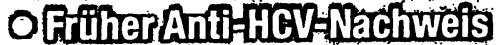
OGesfeigertesensitivitatund Spezilitat? $\therefore$ ooptinteitetestpackmng

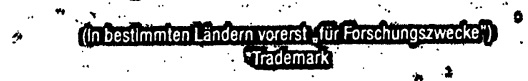

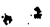
4 Otho Diagnostic Systems amb

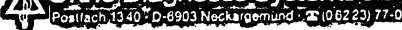
SATाRON
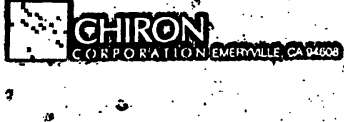


\title{
Infrarot-Spektroskopie und ihre potentiellen Möglichkeiten in der Klinischen Chemie
}

\author{
Potential Applications of Infrared Spectroscopy in Clinical Chemistry
}

H. M. Heise

Institut für Spektrochemie und angewandte Spektroskopie, Dortmund

\begin{abstract}
Zusammenfassung:
Die Einsatzmöglichkeiten der Infrarot-Spektroskopie für die Klinische Chemie sind in den letzten Jahren dank verbesserter Spektrometer und Techniken gewachsen. Prinzipiell sind zwei unterschiedliche Anwendungen für den klinischen Analytiker von Interesse: Zum einen ist dies die diskrete Probenahme von Blut, Gewebe u. a. mit nachfolgender Analyse und zum anderen der Einsatz von online-Senșoren, die hauptsächlich extrakorporal für den Arzt wichtige Parameter zu messen erlauben. Für den ersten Anwendungsbereich ist als etablierte Methode die quantitative Harnsteinanalyse zu nennen, die über den Vergleich von Bibliotheksspektren vorgenommen wird. Der Einsatz der IR-Spektroskopie in Kombination mit chromatographischen Methoden zur Untersuchung von Medikamenten, toxischen Substanzen und ihren Metaboliten ist wegen einer möglichen weiteren Reduzierung der Nachweisgrenzen noch nicht ausgeschöpft. Einen großen Raum im Routinebetrieb der klinischen Chemie nimmt die Bestimmung von Blutsubstraten ein. Durch die Verwendung breitbandiger spektraler Informationen kann bei kleinen Probevolumina eine quantitative Bestimmung für eine Anzahl reagenzlos und zerstörungsfrei durchgeführt werden, so daß für diesen Anwendungsbereich onlineSensoren vorstellbar sind. Geräte zur Überwachung von z. B. Narkosegasen und zur Bestimmung der Sauerstoffsättigung in Blut und Gewebe basieren ebenfalls auf IR-spektrometrischen Grundlagen, während die apparative Entwicklung zur nichtinvasiven Bestimmung von Substraten (z. B. Glucose) noch im Stadium der Grundlagenforschung steht.
\end{abstract}

Schlüsselwörter:

Infrarot-Spektroskopie - Harnsteinanalyse - forensische Analytik - Blutanalytik - Oximeter - Entwicklung von online-Sensoren

\section{Summary:}

The potential of infrared spectroscopy for clinical chemistry has been increased by improvements in instrumentation and sample processing. In principle, two different application fields for the clinical analyst exist: the first is a combination of discrete sampling with subsequent analysis, the second is the application of extracorporeal online-sensors for monitoring purposes. For the first category the IR-analysis of urinary calculi is an established method relying on library component spectra. The combination of IR-spectrometry with chromatography for the analysis of drugs, toxic compounds and their metabolites provides new possibilities as the detection limits are still lowered. Most of the workload in the clinical laboratory is involved in the analysis of blood substrates. Using broad spectral information a number of these compounds can be nondestructively determined from small sample volumes without reagents, so that the development of online-sensors is within reach. Apparatus for the monitoring of anaethetic gases, for example, and blood and tissue oxygenation exist already, whereas the noninvasive determination of blood substrates like glucose, is still in the stage of pure research.

Keywords:

Infrared spectroscopy - analysis of urinary calculi - forensic analysis - blood analysis - oximeter - development of online-sensors

\section{Einleitung}

Die Klinische Chemie ist heutzutage nicht nur in Diagnosezentren und Kliniklaboratorien, sondern auch in den Arztpraxen zu finden. Als Trend sind Versuche festzustellen, die Diagnostik weiter zu vereinfachen, um bereits dem Patienten mittels einfacher Teststreifen Möglichkeiten zur Pro- und Metaphylaxe an die Hand zu geben. Der Einsatz der Infrarot-Spektroskopie ist diesem Trend gegenläufig, da der Aufwand hinsichtlich einer Spektrometeranschaffung relativ groß ist und der Einsatz von entsprechend ausgebildetem Personal notwendig ist. Jedoch ist auch hier die Entwicklung von miniaturisierten, für spezielle Aufgaben einsetzbaren Sensoren vorstellbar, die auf diesem Meßprinzip basieren und bei denen der Bedienungsaufwand durch Mikroprozessorsteuerung erheblich reduziert ist.
Prinzipiell ist die IR-Spektroskopie für die Strukturaufklärung und Identifizierung von organischen und anorganischen Stoffen eine hilfreiche physikalische Methode. Wegen des hohen Informationsgehaltes ihrer Spektren gehört sie zu den wichtigsten Analysenmethoden im chemischen Labor und wird vielseitig zur quantitativen Analyse von Haupt- und Nebenkomponenten von Untersuchungsproben eingesetzt. Im Bereich der Klinischen Chemie hat sich die IR-Spektroskopie bereits in den siebziger Jahren für die Harnsteinanalyse etablieren können (1). In den letzten 15 Jahren hat eine stürmische instrumentelle Weiterenwicklung stattgefunden; zum einen hatte dies die Ab́lösung der dispersiven Spektrometertypen durch Fourier-Transform-(F-T)-Spektrometer zur Folge, und zum anderen. wurden neue Techniken verbreitet, die insbesondere die Untersuchung von wässrigen biotischen Systemen ermöglichen, so daß weitere Anwendungsbereiche 


\section{Zuviventässigkelti}

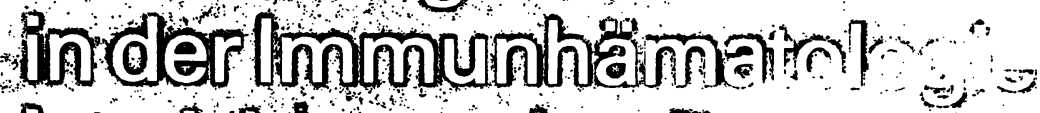

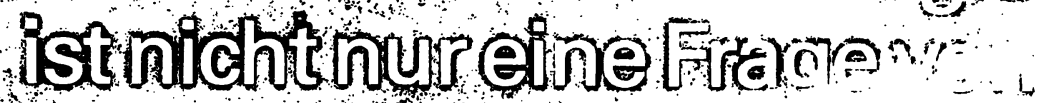
Ouallitat' on of Service - sondertiauch oles * Systenas:

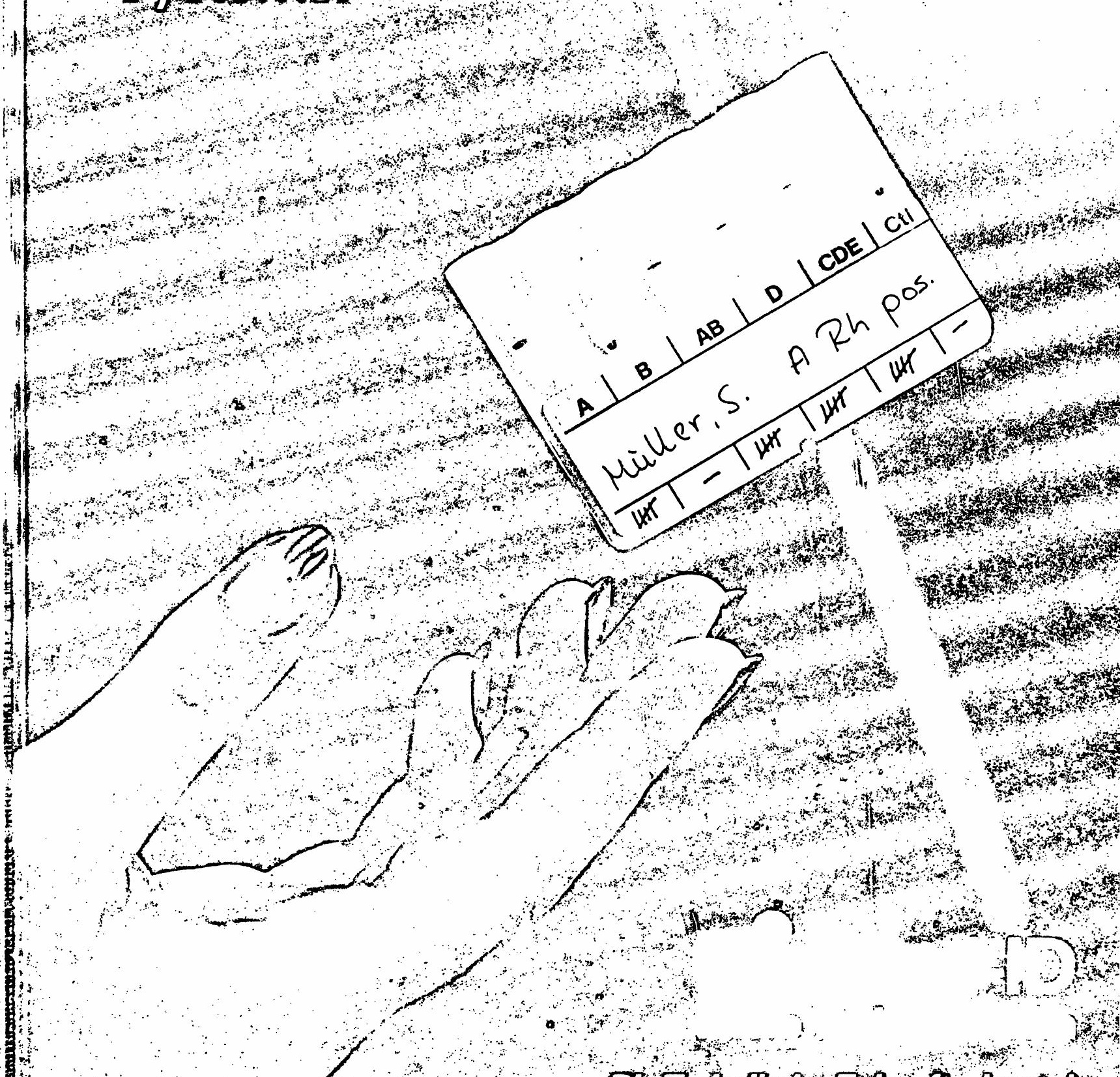

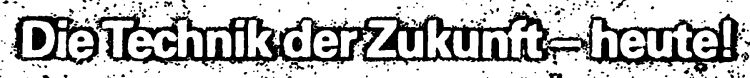




\section{DiaMed-ID \\ Micro Typing System}

\section{Die neue Milkromethode in der Blutrgruppenserologie.}

In der Immunhämatologie sind, bis in die heutige Zeit, die Möglichkeiten einer Standardisierung der Methoden und einer Automation zum größten Teil unbefriedigend.

Die angebotenen Verfahren und Geräte eignen sich nur für große Serien-Untersuchungen und ermöglichen nicht die umfassende Blutgruppen-Diagnostik einschließlich der Antikörpersuchtests und der Verträglichkeitsprobe (Coombstest). Versuche, die in der Blutgruppenserologie anfallenden Bestimmungen auf Mikrotiterplatten durchzuführen, sind ebenfalls nicht vorbehaltlos befriedigend.

In praktisch allen anderen Bereichen der modernen Diagnostik ist gerade die Standardisierung seit langem selbstverständlich. Das Personal wird dadurch entlastet, die Testdurchführung und die Untersuchungsergebnisse sind zuverlässiger. Eine standardisierte Methode ist auch im Rahmen der unerläßlichen Qualitätssicherung besser kontrollierbar.

Es gibt keinen Grund mehr, in der Immunhämatologie auf die Standardisierung und automatische Testverfahren länger zu verzichten.

\section{DiaMled-ID Micro Typing System}

- Standardisierung von Arbeitsmethode und Ergebnis

- Zeitersparende einfach durchzuführende Technik

- Vollständige Spender- und Patientenprofile einschließlich Antikörpersuchtests und Verträglichkeitsproben (indirekter und direkter Coombstest)

- Coombstest ohne Waschvorgang

- Direkte Dokumentation der Reaktionen und Ergebnisse auf dem Reaktionsträger

- Eignet sich für große wie kleine Labors, für wenige wie für zahlreiche Bestimmungen
DiaMed-ID Micro Typing System
O Antigenbestimmungen
O Antikörpersuchteste
- Antikörper-Identifizierung
○ Verträglichkeitsproben

\section{DiaMed-ID Micro Typing System - Experten schreiben:}

....Zusammenfassend haben sich nach unseren Ergebnissen aus der Vergleichsstudie Vorteile für das ID-MicrotypingSystem in bezug auf Sensivität, Handhabung, Ablesbarkeit/Interpretation der Resultate und Umweltbelastung ergeben verglichen mit dem Röhrchentest.

Aus "Das Ärztliche Laboratorium” Heft 5/91

Dr. Walter Hitzler, Klinisches Labor und Blutbank (Leiter: PD Dr. Dr. D. Mathias), Chirurgische Universitätsklinik (Ärztl. Direktor: Prof. Dr. Ch. Herfarth), Heidelberg, Im Neuenheimer Feld 110

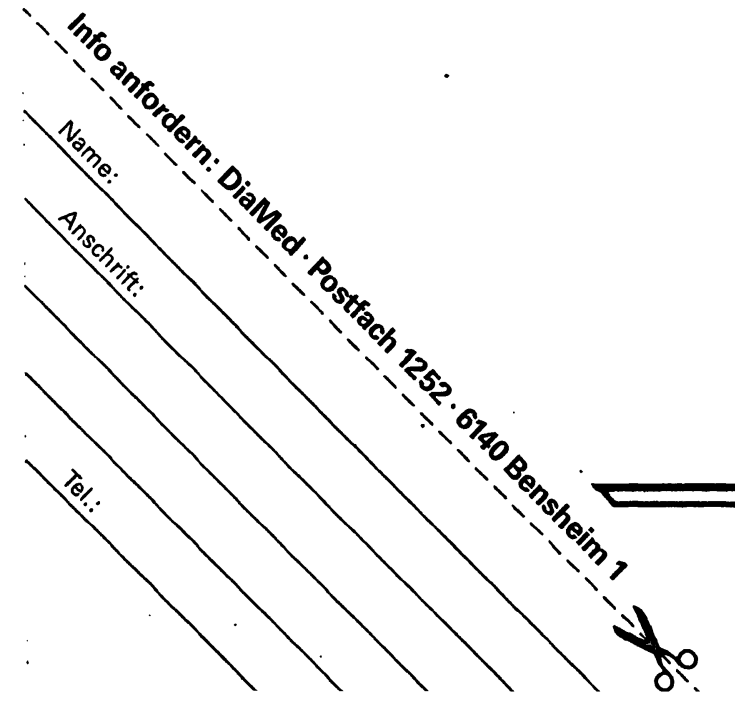


auch für die Klinische Chemie erschlossen werden. Durch eine Optimierung der Spektrometereigenschaften und dank verbesserter Detektoren konnten die Nachweisgrenzen für die IR-Spektrometrie weiter verringert werden, die auch quantitative Analysen im Mikro- und Spurenbereich erlauben. Mit speziellen Präparationstechniken können so bereits Subnanogramm-Mengen untersucht werden, womit die Leistungsfähigkeit dieser Methode unter Beweis gestellt werden kann.

\section{Methodenübersicht}

\section{a) Experimentelle Grundlagen}

Die physikalischen Grundlagen für die IR-Spektroskopie beruhen auf der Wechselwirkung zwischen Molekülen und elektromagnetischer Strahlung mit Wellenlängen zwischen $780 \mathrm{~nm}$ und $1 \mathrm{~mm}$. Als übliche Größe zur Charakterisierung der Strahlung haben sich die Wellenzahlen mit $\bar{v}=1 / \lambda\left(\mathrm{cm}^{-1}\right)$ durchgesetzt, so daß dem genannten Bereich Werte zwischen $12800 \mathrm{~cm}^{-1}$ und $10 \mathrm{~cm}^{-1}$ entsprechen. So schließt sich an das sichtbare Licht das kurzwellige Nahinfrarot (NIR) an, während zum langwelligen, sogenannten Ferninfrarot die Mikrowellen angrenzen. Das hauptsächlich verwendete Phänomen ist die Absorption von Strahlung, durch die die Moleküle in energiereichere Schwingungszustände angeregt werden. In Abbildung 1 ist das experimentelle Schema für IR-spektrometrische Messungen skizziert. In den üblichen IR-Spektrometern wird die zú untersuchende Probe mit einem beheizten Kontinuumsstrahler beleuchtet. Für die Spektralzerlegung kommen u. a. Gittermonochromatoren, Interferenzfilter und Interferometer in Frage. Bei Geräten mit Interferometern liegen als primäres Signal Interferogramme vor, die in die spektralen Informationen über eine FourierTransformation (FT) mittels Computer umgesetzt werden (Prinzip der Fourier-Transform-Spektrometer). Auch der Einsatz von IR-Lasern ist möglich; hierbei kann im Prinzip auf dispersive Elemente verzichtet werden, da diese Strahlungsquellen bereits monochromatische, nach Möglichkeit abstimmbare Strahlung liefern (für eine ausführliche Einführung in die apparativen Details sei auf (2) verwiesen).

Am häufigsten wird mit kommerziell erhältlichen Spektrometern im Bereich von 4000 bis $400 \mathrm{~cm}^{-1}$ (mittleres IR) gemessen, wobei unterhalb von $2000 \mathrm{~cm}^{-1}$ der besonders informationsreiche sogenannte Fingerprintbereich zu finden ist. Als zwei Beispiele seien Spektren von Albumin und Glucose in Abbildung 2 gezeigt, die mit der Kaliumbromid-Preßtechnik für Feststoffe erhalten wurden. In letzter Zeit wird vermehrt auch die NIR-Spektroskopie genutzt; speziell ist diese für die Routine- und Prozeßanaly-
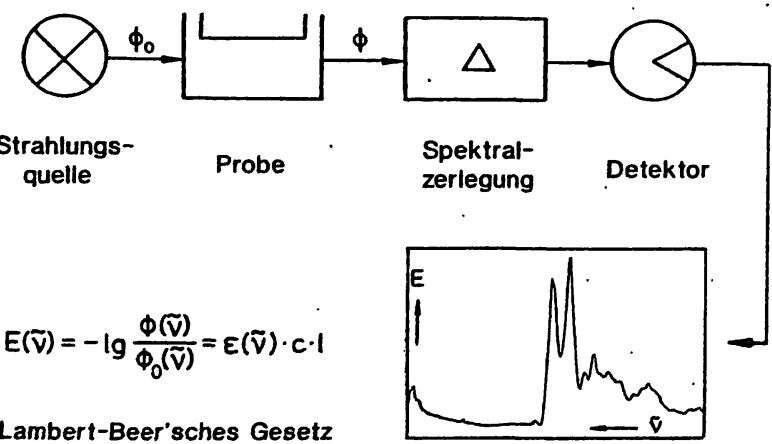

Abb. 1: Schema zum Aufbau eines Transmissionsexperimentes mit quantitativer Auswertung (E Extinktion, $\varepsilon(\bar{v})$ substanzspezifischer Extinktions-Koeffizient, c Konzentration, I Probenschichtdicke)
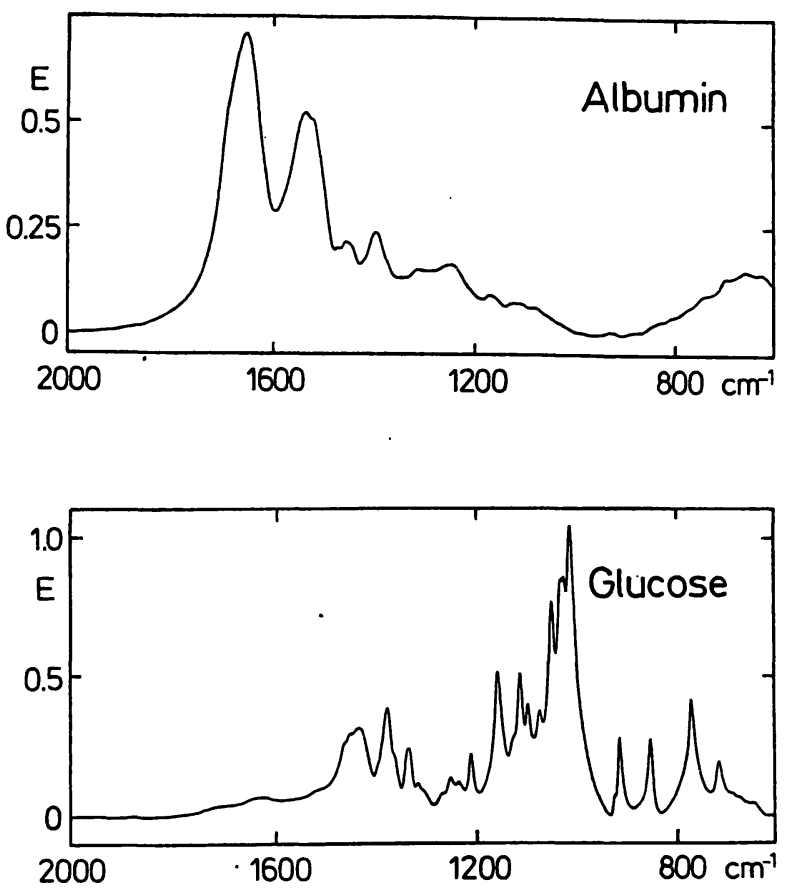

Abb. 2: Beispiele für IR-Spektren von Feststoffen mit ihrem Fingerprintbereich.

tik in der Futter- und Lebensmittelindustrie, aber auch in der pharmazeutischen Chemie eingesetzt worden. Auch ist über vielversprechende Ansätze für den Bereich der Klinischen Chemie zu berichten, auf die im weiteren noch detailliert eingegangen wird.

Üblicherweise, wie bereits in Abbildung 1 angedeutet, werden Transmissonsexperimente durchgeführt. Andere wichtige, neuerdings vielfach eingesetzte Techniken verwenden die abgeschwächte Totalreflektion (ATR), die sich insbesondere für Messungen von biotischen Proben im mittleren IR durchgesetzt hat (Abb. 3). Eine Literaturübersicht hierzu findet sich in (3). Die Eindringtiefe der Strahlung in das optisch dünnere Probenmedium liegt in der Größenordnung der Wellenlänge der verwendeten Strahlung. Für ein bestimmtes, häufig verwendetes Zubehör, die Micro-Circle-Zelle mit ZnSe-Kristall, resultieren bedingt durch Mehrfachreflektionen für wässrige Proben effektive, d. $h$. Transmissionsexperimenten entsprechende Schichtdicken von ca. $10 \mu \mathrm{m}$ für den Bereich von 1000 $\mathrm{cm}^{-1}$, wobei das hier vorliegende Probenvolumen von 25 $\mu l$ gegenüber dem für die prinzipielle Durchführung dieser Experimente notwendige relativ groß ist.

Bei einer weiteren, häufig eingesetzten Technik wird die Messung der in die Substanz-eingedrungenen, aber diffus reflektierten Strahlung verwandt. Der mit festen Proben verbundene Präparationsaufwand läßt sich reduzieren, da die zu untersuchende Probe meist nur mit einem IR-transparenten Pulver, überwiegend das bereits bei der Preßtechnik für Transmissionsmessungen genannte $\mathrm{Ka}$ liumbromid, gemörsert zu werden braucht. Auch lassen sich Lösungeh von z. B. chromatographischen Fraktionen nach Abdampfen des Lösungsmittels spektroskopieren. Einige Erfahrungen aus der Mikro- und Spurenanalyse mit dieser Technik sind in (4) beschrieben. Eine schematische Darstellung des Meßprinzips und von verschiedenen Zubehören ist in Abbildung 4 gezeigt. Anzumerken bleibt, daß die Art der Probenpräparation und Meßtechnik zu etwas unterschiedlichen Spektren wie leichten Bandenverschiebungen und anderen Intensitäten führen 


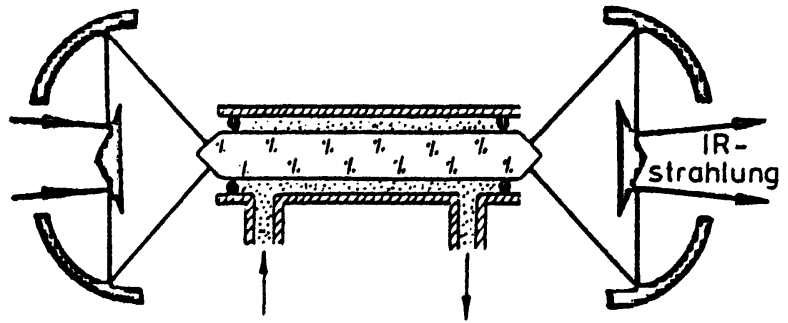

a

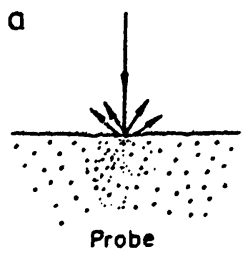

b

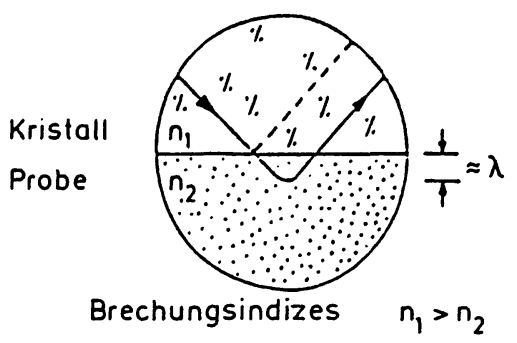

Abb. 3: Experiment mit abgeschwächter Totalreflektion (ATR) für flüssige Proben.

kann, die spezifisch für die entsprechenden experimentellen Bedingungen sind. Dies ist insbesondere bei einer qualitativen Analyse über eine Spektrenbibliothekssuche zu bedenken.

\section{b) Einsatz und prinzipielle Verwendungsmöglichkeiten}

Die Anwendungsbereiche der IR-Spektroskopie für die Klinische Chemie sind relativ weit gefaßt. Als Diskussionsrahmen kann Abbildung 5 dienen, die den Einsatz am Patienten, insbesondere auch als Weiterentwicklung zum online-Sensor, beleuchtet. Naturgemäß nimmt die diskrete Probenahme mit nachfolgender Analyse den größten Raum ein, da dieses hergebrachter, konventioneller Technik entspricht. An Untersuchungsobjekten können Gewebs- und Blutproben, aber auch beispielsweise Nierensteine vorliegen. Wie schon in der Einleitung angesprochen, spielt die IR-Spektroskopie für die Harnsteinanalyse eine wichtige Rolle. Weiter verbreitet ist hier nur die Röntgenspektroskopie, wobei der Einsatz anderer Methoden wie z. B. die chemische Analyse und die Polarisationsmikroskopie weniger häufig vertreten sind. Über das Leistungsvermögen verschiedener Harnsteinanalysemethoden wurde kürzlich anläßlich eines internationalen Ringversuches in dieser Zeitschrift berichtet (5). Da die genaue qualitative und quantitative Analyse für das diagnostische und therapeutische Vorgehen von großer Wichtigkeit ist, gehen Bestrebungen dahin, die quantitative Analyse weiter zu verbessern und zu automatisieren. Die Zuverlässigkeit eines hierzu neu entwickelten Programmes wurde anhand einer größeren Probenpopulation für die Praxis getestet (6). Grundlage sind die computergespeicherten Bibliotheksspektren von reinen Harnsteinkomponenten. Als weitere Information ist kürzlich ein Spektren-Atlas in Buchform erschienen (7). Für den Praktiker als nützliche Literatur ist auch der Bericht von $\mathbf{R}$. Stark zu empfehlen (8).

Mittels der neu in den Vordergrund gerückten IR-Mikroskopie ist es möglich, auch eine lokale Analyse zur Untersuchung der Schalenstruktur der Nierensteine durchzuführen. Üblicherweise werden von den verschiedenen Schalen kleinste Mengen im Nanogrammbereich mittels
C

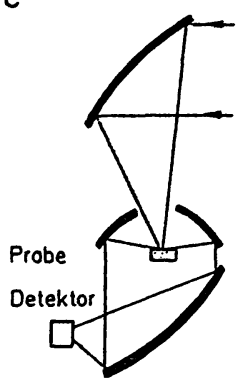

Abb. 4: Messung der diffusen Reflektion setzt) wand deutlich geringer ausfällt. bunden ist.

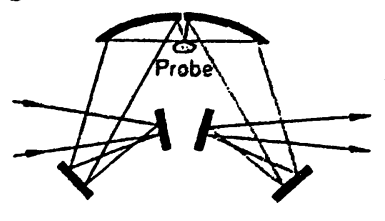

d

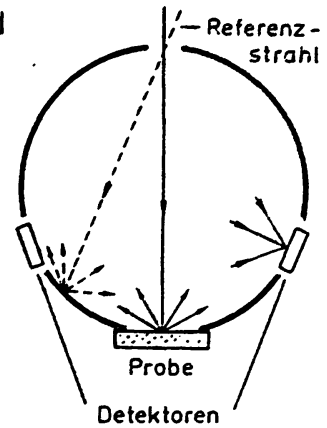

a) Meßprinzip, b) Probenkammerzubehör, c) Zubehör mit eigenem Detektor, d) Ulbricht-Kugel (hauptsächlich im NIR einge-

Skalpell entnommen und Probenobjekte mit Durchmesser bis ca. $50 \mu \mathrm{m}$ in Transmission spektroskopiert (9). Bestrebungen gehen dahin, auch in Reflektion Spektren aufzunehmen, da mit dieser Technik der Präparationsauf-

In der gleichen, eben zitierten Arbeit (9) wurden auch verschiedene Bakterienkulturen anhand ihrer typischen Proteinspektren charakterisiert. Eine ähnliche Fragestellung liegt bei der Unterscheidung von gesundem und malignem Gewebe mittels IR-Spektroskopie vor. Ein kürzlich erschienener Beitrag (10) gibt spezielle Hinweise für die Präparation von Mikrotomschnitten zur IR-mikrospektroskopischen Untersuchung, die von der sonst üblichen Praxis im pathologischen Labor abweicht. Andere Hinweise zur Vorbereitung von Gewebsproben zur Aufnahme von Reflektionsspektren sind in Referenz (11) zu finden.

Ein anderer breiter Themenkreis ist mit spurenanalytischen Fragestellungen befaßt, die Problemen der forensischen Medizin gleichen. Diese biomedizinischen Anwendungen der IR-Spektroskopie erfordern nach der Probenahme eine entsprechend aufwendige Probenaufarbeitung (Clean-up), wie sie auch z. B. für die Rückstandsanalytik von Pflanzenschutzmitteln erforderlich ist. In der Hauptsache werden zur erforderlichen weiteren Trennung der noch vorliegeñden komplexen Substanzgemische chromatographische Methoden nachgeschaltet, wobei zur Identifikation eine spektroskopische Detektion einge-

Im großen Umfang wird die Dünnschichtchromatographie (DC) mit ihrem Vorteil der Einfachheit und breiten Verfügbarkeit eingesetzt. Hinweise für die Elution und Aufarbeitung von DC-Fraktionen für die nachfolgende IRspektroskopische Analyse sind z. B. in der bereits zitierten Arbeit (4) zu finden. Der apparative Aufwand ist naturgemäß für'die Gaschromatographie (GC), meistens mit Ein'satz von effizienten Trennkapillaren, und der Flüssigkeitschromatographie mit der überwiegend zu findenden Hochdruckflüssigkeitschromatographie (HPLC) bedeutend größer. Jedoch erlauben kommerzielle Interfaces zur.Kopplung der GC und der FT-IR-Spektroskopie auch 
den unproblematischen Einsatz für die Routine. Hauptsächlich ist hier die sogenannte Lightpipe-Technik zu finden (s. Abb. 6), bei der die gasförmige Fraktion durch eine innen mit Gold beschichtete Kapillare geschickt und hierbei online spektroskopiert wird. Insbesondere ist an die Untersuchung von Medikamenten und deren $\mathrm{Me}$ taboliten in biotischer Matrix zu denken. Gerade zur Aufklärung von auftretenden Isomeren, die von der üblicherweise eingesetzten Massenspektroskopie nicht unterschieden werden können, leistet die IR-Spektroskopie wertvolle Hilfe. Eine systematische Studie von verschiedenen Wirkstoffen, von speziellem Interesse für den Bereich forensische Medizin, wurde vor kurzem mit dieser Technik vorgestellt (12). Die erforderlichen Mengen für eine Identifizierung liegen im Bereich von 50 bis $500 \mathrm{ng}$ für die zu untersuchenden Komponenten. Eine àndere Anwendung liegt im toxikologischen Bereich, bei dem z. B. die Identifizierung der Vergiftungsursache wichtig ist. Beispiele mit Literaturangaben hierzu sind in einem Übersichtsartikel von Lacroix et al. zu finden (13).

Weiterentwicklungen der GC-FTIR-Kopplung führen zu niedrigeren Nachweisgrenzen im Subnanogrammbereich. Sie nutzen Techniken, bei denen die gaschromatographischen Fraktionen bei tiefen Temperaturen in kleinen Flecken mit Durchmessern von $100 \mu \mathrm{m}$ kondensiert werden. Bei der aufwendigen Matrixisolationsspektroskopie wird die Probe z. B. bei $15 \mathrm{~K}$ zusammen mit dem inerten Trägergas Argon oder Stickstoff aufgefroren. Die resultierenden Spektren zeigen gegenüber denen normaler Feststoffe besonders schmale Absorptionsbanden, was für die Empfindlichkeit und Selektivität der Methode von Vorteil ist. So konnten z. B. ohne Probleme 22 Isomere eines Dioxins (TCCD Tetrachlorodibenzo-p-dioxin) im Nanogrammbereich quantifiziert werden (14). Bei einem anderen, seit kurzem auch kommerziell verfügbaren Zubehör findet das Ausfrieren bei der Temperatur des flüssigen Stickstoffes statt, so daß sich nur der Efluent auf einem IR-transparenten Zinkselenid-Fènster niederschlägt, das anschließend spektroskopiert wird. Auch hier können Mengen im Picogrammbereich identifiziert werden (15, 16). Die so erhaltenen Spektren entsprechen vorteilhafterweise denen in bereits existierenden Bibliotheken von Feststoffspektren, die über die normalerweise verwendete Kaliumbromid-Preßtechnik erhalten wurden. Mit diesen Techniken stößt man an die prinzipiellen Grenzen der IR-spektroskopischen Analytik.

Bei einigen Fragestellungen in der Medizin ist die IRspektrometrische Analyse unproblematisch, wenn für die Probenmessung bei Vorliegen von nicht überlagerten spezifischen Absorptionsbanden Querempfindlichkeiten zu anderen Substanzen ausgeschlossen werden können. Dies ist der Fall bei bestimmten gasanalytischen Anwendungen (Kapnographie, Anästhesieüberwachung). So werden für die Bestimmung des $\mathrm{CO}_{2}$-Volumenanteils im Atemgas kleine im Atemkreislauf befindliche Sensoren eingesetzt, die als IR-Filtergeräte die für dieses Medium störsignalfreie $\mathrm{CO}_{2}$-Absorptionsbande bei $2350 \mathrm{~cm}^{-1}$ nutzen. Eingeschränkt ist diese Meßmethode bei gleichzeitiger Anwesenheit von Anästhesiegasen, da hierzu Querempfindlichkeiten existieren. Es wurden jedoch Narkosegas-Monitore auf IR-spektrometrischer Basis entwickelt, die es erlauben, $\mathrm{N}_{2} \mathrm{O}$ (Lachgas), Halothan, Enfluran bzw. Isofluran zu messen, wobei Interferenzen nicht immer ausgeschlossen werden können (17). Wiederum lassen sich diese durch eine breitbandige Analyse des Probenspektrums reduzieren. Von intelligenten Sensoren müßten in diesem Fall zumindest Warnsignale angezeigt werden. Zum prinzipiellen Aufbau der einfachen nichtdisper-

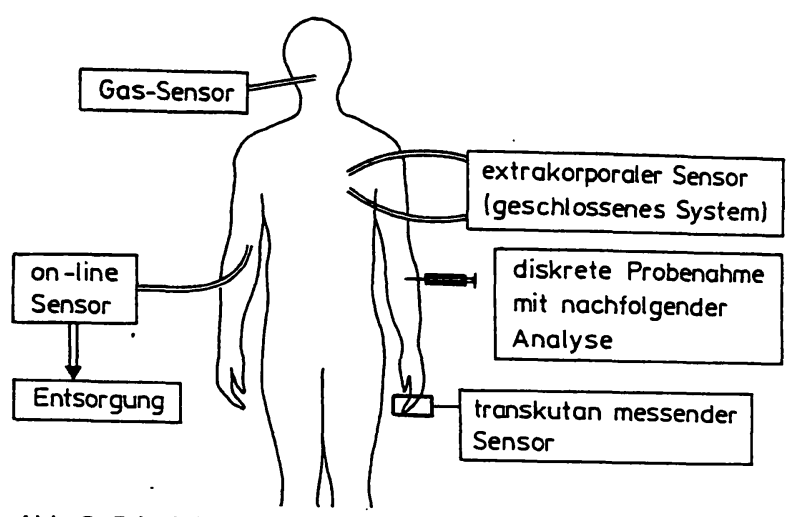

Abb. 5: Prinzipielle Möglichkeiten für Anwendungen der IR-Spektroskopie in der Klinischen Chemie

siven Filtergeräte sind weitere Informationen in den Arbeiten $(18,19)$ zu finden. Es bleibt anzumerken, daß mobile Monitore an Bedeutung verlieren, da ein Trend zu kompletten Arbeitsplatzsystemen mit eingebauten Überwachungsmodulen festzustellen ist.

Einen großen Raum innerhalb des klinisch-chemischen Labors nimmt die Blutanalytik ein, wobei die Bestimmung der Substrate nahezu die Hälfte aller Untersuchungen ausmacht (20). Bei den Substraten spielt die Bestimmung der Blutglucose die größte Rolle, da Abweichungen vom physiologischen Normbereich auf pathologische Stoffwechselstörungen hinweisen. Die IR-Spektroskopie stellt eine mögliche Alternative zu den etablierten Verfahren im Labor dar, die den Vorteil besitzt, daß sie kleine Probevolumina um $100 \mu \mathrm{l}$ zerstörungsfrei, ohne Reagenzien sowie weitere Probenvorbereitung quasi kontinuierlich zu messen erlaubt. In den letzten Jahren wurden verschiedene Versuche vorgestellt, Glucose in wäßrigen Lösungen mit der bereits beschriebenen ATR-Technik zu quantifizieren, wobei als Strahlungsquelle auch $\mathrm{CO}_{2^{-}}$ Laser eingesetzt wurden (s. z. B. [21]). Schon in den sieb-

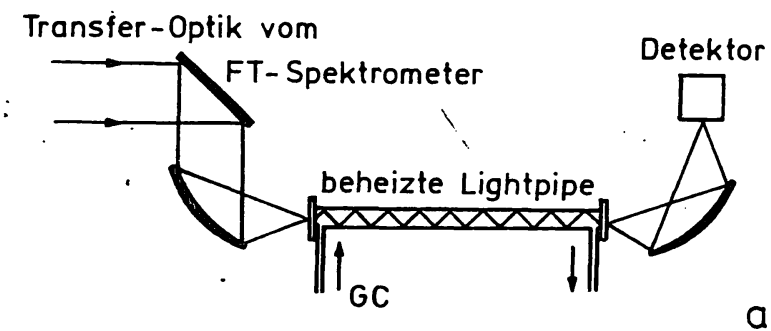

a

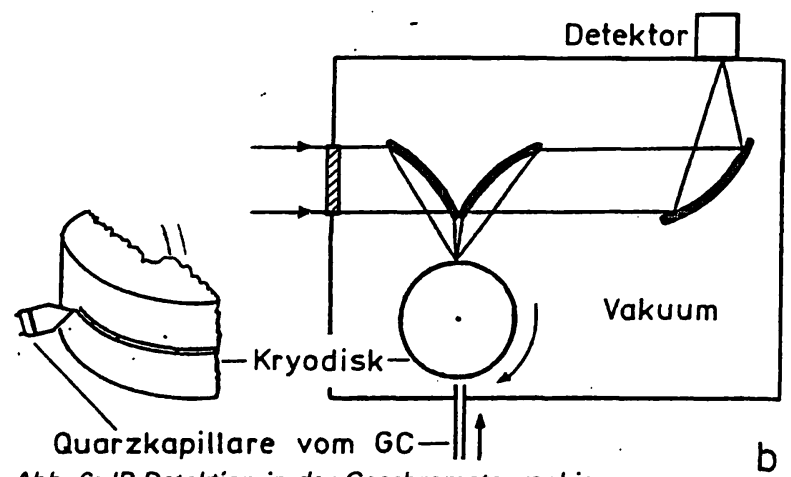

Abb. 6: IR-Detektion in der Gaschromatographie a) konventionelle Lightpipetechnik, b) Kryotechnik mit Ausfrieren der GC-Fraktionen 
ziger Jahren wurden Experimente dieser Art durchgeführt und die Möglichkeit von In-vivo-Messungen für biologische Gewebe angedeutet (22).

Obwohl die prinzipielle Eignung gezeigt werden konnte, is! für die Klinische Chemie jedoch die Variation in der Blutzusammensetzung ein Problem, wenn größere Probenpopulationen vorliegen, da eine von Störkomponenten freie Glucoseabsorptionsbande nicht existiert. Dies ist der Grund, daß univariate Auswertungen z. B. über das Glucoseabsorptionsmaximum (s. Abb. 2) nicht erfolgreich sein können. Auch bei Berücksichtigung von breiten Spektralbereichen (multivariate Auswertung) führen die klassischen Verfahren der Mehrkomponentenanalyse mit Spektrenanpassung nicht zum Ziel, da hier im Prinzip die Bestimmung aller wesentlichen Komponenten notwendig ist. Über Versuche mit Spektrenuntergrundanpassungen für das Problem der Glucosebestimmung in Vollblut wurde berichtet (23). Ohne systematischen Fehler arbeiten die sogenannten inversen Kalibrierungen, die häufig z. B. in der Futter- und Lebensmittelanalytik mittels NIR-Spektroskopie eingesetzt werden. Hierzu werden die Spektren einer größeren Probenpopulation gegen die über eine Referenzmethode gemessenen Konzentrationen der interessierenden Komponente regressiert, um entsprechende statistische Vorhersagemodelle aufzubauen.

Diese Strategie wurde u. a. für die Bestimmung von Glucose in Blut und Plasma verwendet $(3,24)$. Für EDTAPlasma liegen zusätzliche Auswertungen für andere Substrate wie Gesamteiweiß, Triglyceride, Gesamtcholesterin, Harnstoff und Harnsäure vor, wobei die Ergebnisse für die letztgenannte Komponente wegen ihrer relativ niedrigen Konzentrationen mit einem Mittelwert von ca. $50 \mathrm{mg} / \mathrm{dl}$ am schlechtesten ausfielen. Um diese Methode im klinisch-chemischen Labor zu etablieren, müssen jedoch weitere Verbesserungen angestrebt werden. Es wird sich erst dann abschätzen lassen, wie weit die IR-Spektroskopie in Analyseautomaten für die Routineanalytik als kostengünstige Alternative zu den hergebrachten Geräten Berücksichtigung finden kann.

Wie bereits gezeigt werden konnte, sind die quantitativen Ergebnisse mit personenspezifischen Kalibrierungen (25) bedeutend besser als bei größeren Patientenpopulationen mit stärkeren Variationen in der Blutzusammensetzung. Die von den letztgenannten Autoren berechnete Präzision für die IR-spektrometrische Glucosebestimmung ist nur um einen Faktor 2 schlechter als die der verwendeten Referenzmethode.

Auf dieser vorgestellten Basis können online-Sensoren mit Minutenabtastrate entwickelt werden, die wegen ihrer Größe extrakorporal im geschlossenen Kreislauf einsetzbar wären. Zu prüfen bleiben die Wartungsintervalle; da auch hier die nicht ausreichende Hämokompatibilität der verwendeten Materialien die Lebensdauer einschränkt. Zur Adsorption von Proteinen liegen zwar systematische Untersuchungen für übliche ATR-Kristallmaterialien vor (z. B. 26, 27), jedoch sind Langzeitstudien mit biotischen Flüssigkeiten wie Blut bezüglich des onlineEinsatzes erforderlich. Günstiger hinsichtlich der Lebensdauer sind Durchflußsysteme, bei denen in Intervallen kleine Proben gezogen werden, nach deren Messung entsprechende Reinigungscyclen vorgesehen sind (s. a. Abb. 5). Diese könnten vorteilhafterweise zur Bestimmung von Hintergrundspektren berücksichtigt werden, um Spektrometerinstabilitäten zu kompensieren.

Ein spezifischer ATR-Glucose-Sensor läßt sich durch Aufbringen einer immobilisierten Enzymschicht mit Glu-
cose-Oxidase auf den ATR-Kristall (Dicke kleiner $0,5 \mu \mathrm{m}$ ) realisieren (27). Nach einer Reaktionszeit von ca. 4 Minuten läßt sich ein Umsetzungsprodukt der Glucose, in diesem Fall die Gluconsäure, IR-spektroskopisch nachweisen. Dieses Verfahren hat den Vorteil, daß Matrixeffekte eliminiert werden können, indem Differenzen mit vor und nach der Reaktion aufgenommenen Spektren berechnet werden, in denen allein z. B. negative Glucose und positive Gluconsäurebanden zur Auswertung herangezogen werden brauchen. Ein übliches Problem für klinisch-chemische Proben stellt wiederum die Hämokompatibilität der Meßoberflächen dar.

Wie bereits erwähnt, wurde mehrfach die Möglichkeit einer In-vivo-Bestimmung der Glucose mittels ATR-Technik unter Einsatz von $\mathrm{CO}_{2}$-Lasern vorgeschlagen. $\mathrm{Da}$ die transkutane Messung von erheblicher Bedeutung ist, soll auf unsere Experimente mittels FT-IR-Spektroskopie eingegangen werden. Hierbei war von vornherein zu berücksichtigen, daß die Epidermis bereits eine Dicke von ca. 60 bis $100 \mu \mathrm{m}$ und mehr erlangen kann. Normalerweise reicht die Eindringtiefe der IR-Strahlung bei diesen ATRExperimenten nur in die keratinisierte Hornschicht, so daß Informationen aus tieferen, blutführenden Schichten nicht erhalten werden können. Daher gingen unsere Überlegungen dahin, als Meßobjekt die Schleimhaut der Innenlippe heranzuziehen, um zumindest Änderungen der Glucose in der interstitiellen Flüssigkeit der Epithelzellen zu messen (29). Während des Glucosetoleranztestes wurden für verschiedene Testpersonen mittels speziellem Haut-ATR-Zubehör die Innenlippenspektren registriert und in etwas größerem Abstand (ca. $15 \mathrm{~min}$ ) Kapillarblut aus der Fingerbeere entnommen und mit einer üblichen Referenzmethode (mittels Glucose-Dehydrogenase) die momentane Blutglucosekonzentration bestimmt. Für feuchte Innenlippen konnten über spezielle Kalibrierungen personenspezifische Modelle errechnet werden, bei denen die mittleren Vorhersagefehler zwischen 18 und $40 \mathrm{mg} / \mathrm{dl}$ lagen. Um die Größe unserer Epithelschichtsignale zu vergrößern, wurden weitere Experimente mit Innenlippen angestellt, die vor jeder spektroskopischen Messung trocken gewischt wurden, auch um die störenden Effekte des Speichels mit seinen Mucopolysacchariden zu reduzieren. Mit den so erhaltenen Spektrendaten ließen sich keine Modelle zur Bestimmung der Glucose berechnen, da zum einen die Glucosesignale nicht nachweisbar und zum anderen die Spektrenuntergrundschwankungen im Vergleich zur erwarteten Signalgröße recht erheblich waren. Zur Klärung unserer ersten Ergebnisse wurde eine mögliche Korrelation zwischen der Glucosekonzentration im Blut und Speichel (ca. Faktor $\mathbf{3 0 0}$ kleiner als im Blut) geprüft. Hier konnte auf eine kürzlich publizierte Studie (30) zurückgegriffen werden, bei der. jedoch Korrélationskoeffizienten kleiner 0,5 berechnet wurden. Die Autoren stellten starke testpersonenspezifische Variationen fest, die durch andere physiologische Faktoren bedingt sein können. Dies legt den Schluß nahe, daß die Modellgüte bei den feuchten Schleimhautmessungen offensichtlich von zufälligen Korrelationen (Trends in den Spektren) bestimmt wurde.

Eine in der Literatur vorgeschlagene und ausgefallene, in der Praxis am Menschen nicht realisierbare Methode besteht darin, durch die von Hornhaut befreite Epidermis per Unterdruck extrazelluläre Flüssigkeit zu saugen, deren" Glucosekonzentration mittels ATR-FTIR-Spektroskopie bestimmt werden kann. Ergebnisse wurden für Versuchskaninchen erhalten (31).

Weitere Möglichkeiten für die Untersuchung von biotischen Flüssigkeiten eröffnen sich durch die Anwendung 
der NIR-Spektroskopie. Da in diesem Spektralbereich die Wasserabsorptionen bedeutend geringer ausfallen als im mittleren IR, lassen sich einfache Transmissionsexperimente z. B. mit Quarzküvetten (Probenschichtdicken um $1 \mathrm{~mm}$ ) realisieren. In Abbildung 7 sind die NIR-Spektren einer Reihe von klinisch relevanten Substanzen angegeben, wobei das Lecithin als Beispiel für die Gruppe der Triglyceride herangezogen wurde. Es existieren bereits Versuche, mittels NIR-Filterspektrometer verschiedene Substrate wie Gesamtprotein, Cholesterin und Triglyceride in Seren zu bestimmen (32-34). Zum Teil erfolgte die Kalibration über eine stufenweise multiple lineare Regression, bei der von ca. 20 fest vorgegebenen Filterwellenlängen bestimmte als besonders signifikant herausgefunden wurden (jeweils 5 bis 7 Filter in den Literaturbeispielen). In einem anderen Ansatz wurden die gesamten spektralen Informationen verarbeitet (33). In der letzten Veröffentlichung wird insbesondere auf das Kalibrierungsproblem mit- relativ kleinen Probenpopulationen (ca. 30-40) verwiesen, mit denen die gesamte Serenvarianz im klinischen Labor nicht abgedeckt werden kann. Lodder und Mitarbeiter stellten bei ihrer größeren Population von etwa 160 Proben fest, daß Proben-Vorgruppierungen eine mögliche Reduzierung der Standardabweichungen für die Cholesterinkalibration erbringen (z. B. bis zu $10 \mathrm{mg} / \mathrm{dl}$ ) können. Um weitere Fortschritte für eine robuste Analytik zu erzielen, wurde vorgeschlagen, breitbandige Auswertungen mit z. B. FT-NIR-Spektren auf der Basis einer umfangreichen Probenpopulation vorzunehmen. Bevor diese Fragestellung nicht zufriedenstellend beantwortet ist, brauchen nichtinvasive Bestimmungen für die angesprochenen Substrate einschließlich Glucose über z. B. diffuse Reflektionsmessungen bei Eindringtiefen der Strahlung in die Haut bis ca. $1 \mathrm{~mm}$ (gilt für den Bereich um $6000 \mathrm{~cm}^{-1}$ ) nicht diskutiert zu werden.

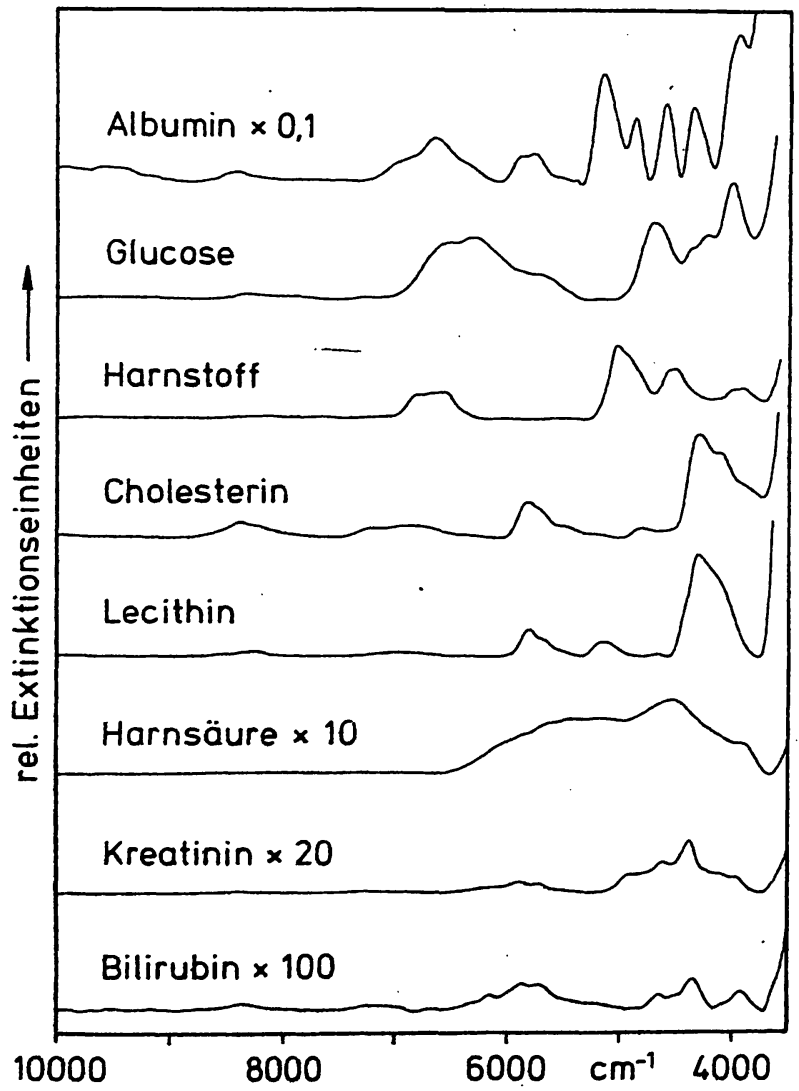

Wendet man sich dem kurzwelligen NIR-Spektralbereich mit seiner Grenze zum sichtbaren Licht zu, ergeben sich weitere klinische Anwendungen. Es existieren viele Situationen, in denen die direkte Messung des Sauerstoffgehaltes im Körper von Wichtigkeit ist. Etabliert haben sich bereits nichtinvasive spektrometrische Verfahren zur Überwachung der arteriellen Sauerstoffsättigung, die durch die unterschiedlichen Absorptionspektren des Hämoglobins in seiner oxidierten und reduzierten form ermöglicht werden. Hierbei zieht man für die Messung Kombinationen von Wellenlängen zwischen $660 \mathrm{~nm}$ und $805 \mathrm{~nm}$ (isosbestischer Punkt) heran, da für Strahlung mit kleineren Wellenlängen die Schichtdicken eines Ohrläppchens oder Fingers wegen der starken Absorptionsbanden des Hämoglobins und durch ebenfalls zunehmende Streuung nicht mehr transparent genug sind. Weitere Fortschritte brachte das Pulsoximeter, mit dem sich absolute Werte für die arterielle Sauerstoffsättigung messen lassen. Hierzu kann die Herzschlagmodulation zur Eliminierung des spektralen Hintergrundsignales herangezogen werden. Eine ausführliche Übersicht zum Aufbau dieser Geräte findet sich in (35).

Weiterentwicklungen im spektroskopischen Instrumentarium lassen neuerdings die Untersuchung von Gewebeschichten bis zu $10 \mathrm{~cm} \mathrm{zu}$, so daß sogar der cerebrale Sauerstoffgehalt im Blut und Gewebe meßbar wird. Diese Technik beruht darauf, daß neben dem Hämoglobin als Indikator für die Sauerstoffsättigung des Blutes auch das Cytochrom $\mathrm{aa}_{3}$ (auch Cytochromoxidase genannt) als wichtigstes Enzym in den mitochondrischen Membranen für die Atemkette im Gewebe einen Chromophor für den Spektralbereich von 700 bis $1000 \mathrm{~nm}$ aufweist. Von Vorteil ist, daß menschliches Gewebe für diesen Bereich (bis ca. $1300 \mathrm{~nm}$ ) die größte Durchlässigkeit

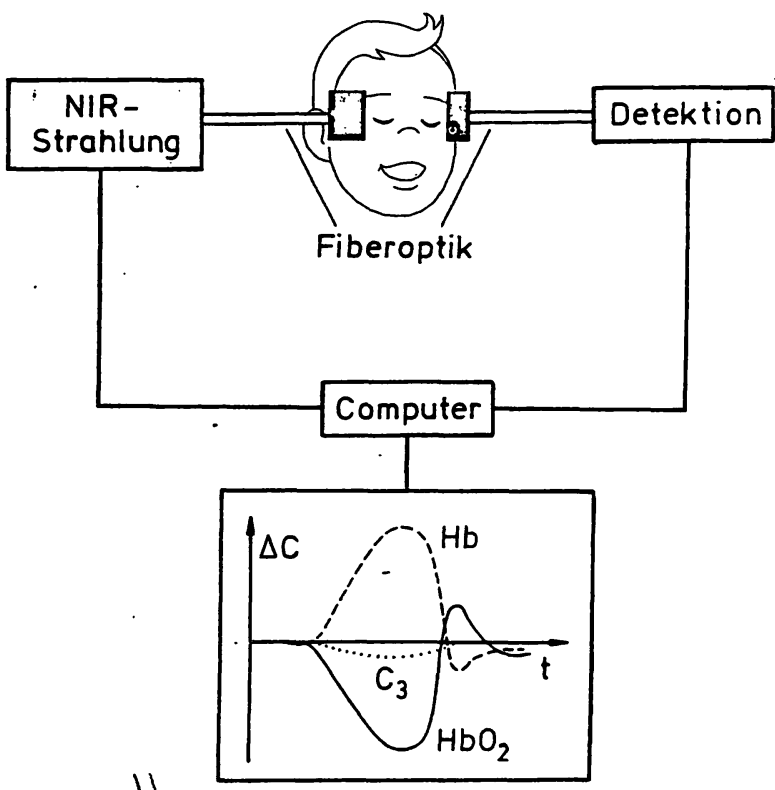

Abb. 8: Schematischer Aufbau zur Messung der cerebralen Sauerstoffsättigung in Blut und Gewebe über die Auswertung der NIR-Spektren des Hämoglobins und des Cytochrome aas.

Abb. 7: NIR-Spektren von für die Blutanalytik wichtigen Substanzen (die Intensitäten sind auf mittlere Plasmakonzentrationen umgerechnet, wobei Albumin und Lecithin als Modellsubstanzen für Gesamteiweiß und Triglyceride verwendet wurden) 
für Strahlung besitzt. Die Forschungsaktivitäten auf diesem Gebiet sind vielfältig und durchaus spektakulär zu nennen. Ein vereinfachtes Schema für den experimentellen Aufbau zeigt Abbildung 8, wobei als Strahlungsquellen gepulste Laserdioden zwischen $780 \mathrm{~nm}$ und $905 \mathrm{~nm}$ (36) oder gepulste Kryptonblitzlampen mit entsprechenden optischen Interferenzfiltern (37) eingesetzt wurden. Wegen der starken Dämpfung der Strahlung (u. a. durch Vielfachstreuung) werden bei $10 \mathrm{~cm}$ starken Gewebeschichten Extinktionen um 10 gemessen, wobei die Photomultiplier-Detektoren im Photonenzählbetrieb gefahren werden müssen. Erste klinische Erfahrungen mit diesem Monitorsystem für Neugeborene wurden bereits pübliziert (38). Weitere Verbesserungen für die Cytochrom $a^{-}{ }^{-}$ Analyse wurden kürzlich vorgetragen, wobei u. a. für die Ergebnisse breitbandige Informationen im Intervall 700 $\mathrm{nm}$ bis $900 \mathrm{~nm}$ verarbeitet wurden (39). Auch wurden Vorschläge unterbreitet, Gewebeabsorptionen und wellenlängenabhängige Weglängen simultan zu bestimmen, wobei der apparative Aufwand zur experimentellen Durchführung komplizierter werden dürfte.

\section{Schlußbetrachtung}

Insgesamt ist die technische Entwicklung in den letzten Jahren beeindruckend. Es kann festgestellt werden, daß auch die IR-Spektroskopie einen erheblichen Innovationsschub zu verzeichnen hat, durch den sich neue Möglichkeiten für die Klinische Chemie innerhalb und außerhalb ihres Routinebetriebs ergeben. Zum Teil werden die Entwicklungen recht kostspielig sein (siehe NIR-In-vivo-Spektroskopie), doch das Eindringen von physikalischen Methoden wird verstärkt die medizinische Diagnostik beeinflussen. Vielleicht vermag in der Zukunft u. a. sogar ein. relativ kleines, nichtinvasiv messendes Gerät zur Blutglucosebestimmung für den Diabetiker zu Hause aus den Forschungsanstrengungen vieler interdisziplinär arbeitenden Gruppen resultieren. Auch dies wäre technischer Fortschritt im Dienste der Gesundheit des Menschen.

\section{Danksagung}

Für die finanzielle Unterstützung durch das Ministerium für Wissenschaft und Forschung des Landes Nordrhein-Westfalen und das Bundesministerium für Forschung und Technologie wird gedankt.

\section{Schriftum:}

1. HESSE, A., SCHRUMPF, G. SCHILLING, L.: Quantitative Bestimmung von Harnstein komponenten durch Anwendung der Infrarot-Spektroskopie. Zschr. Urol. 67, 367-375 (1974).

2. GÜNZLER, H., BÖCK, H.: IR-Spektroskopie, 2. Auflage, Verlag Chemie, Weinheim (1983).

3. HEISE, H. M., MARBACH, R., JANATSCH, G., KRUSE-JARRES, J. D.: Multivariate Determination of Glucose in. Whole Blood by Attenuated Total Reflection Infrared Spectroscopy. Anal. Chem. 61, 2009-2015 (1989).

4. OTTO, A., BODE, U., HEISE, H. M.: Experiences with infrared microsampling for thin-layer and high-performance liquid chromatography. Fresenius' Anal. Chem. 331, 376-382 (1988).

5. REBENTISCH, G., BERG W. Leistungsvermögen verschiedener Harnsteinanalyse 5. REBENTISCH, G., BERG, W.: Leistungsvermogen verschiedener Haden (6. Internationaler Ringversuch), Lab.med. 14, 85-88 (1990).

methoden (6. Internationaler Ringversuch). Lab.med. 14, 85-88 (1990). 6. HESSE, A., GERGELEIT, M., SCHÜLLER, P., MOLLLER, K.: Analysis of Urinary Stones
by Computerized Infrared Spectroscopy. Clin. Chem. Clin. Biochem. 27, 639-642 (1989)

7. HESSE, A., SANDERS, G.: Infrarotspektren-Atlas zur Harnsteinanalyse. Georg Thieme Verlag, Stuttgart (1988).

8. STARK, R.: Genaue Harnsteinanalyse durch Infrarotspektroskopie. Niere Blase Prostata 5, 7-9 (1986).

9. ZACHMANN, G., SIMON, A.: FTIR-Mikroskopie. Labor Praxis (April), 342-351 (1986). 10. WONG, P. T. T., RIGAS, B.: Infrared Spectra of Microtome Sections of Human Colon Tissues. Appl. Spectrosc. 44, 1715-1718 (1990).

11. O'LEARY, T. J., ENGLER, W. F., VENTRE, K. M.: Infrared Microspectroscopy of Hu11. O'LEARY, T. J., ENGLER, W. F., VENTRE, K. M.:
man Tissue. Appl. Spectrosc. 43, 1095-1097 (1989).

man Tissue. Appl. Spectrosc. 43, $1095-1097$ (1989)."
12. KEMPFERT, K.: Forensic Drug Analysis by GC/FT-IR. Appl. Spectrosc. 42, 845-849 12. KEMPr).
13. LACROIX, B., HEVENNE, J. P., DEVEAUX, M.: Gas Chromatography with fourier Transform Infrared Spectrometry for Biomedicel Applications. J. Chromatog. 492, 109-136 (1989).

14. HOLLOWAY, T. T., FAIRLESS, B. J., FREIDLINE, C. E., KIMBALL, H. E., KLOEPFER, R. D., WURREY, C. J., JONOOBY, L. A., PALMER, H. G.: Performance of a Gas Chroma. ingraphic-Matrix Isolation - Fourier Transform Spectrometer. Appl. Spectrosc. 42. 359-369 (1988).

15. VISSER, T., VREDENBREGT, M. J.: Cryotrapping gas chromatography - Fourier Transform infrared spectrometry in environmental analysis: a pilot study. Vibrational
The Spectrosc. 1, 205-210 (1990).

16. VISSER, T., VREDENBREGT, M. J., KNECHT, J.: Infrarot-Analytik im Picogrammbe. reich - Cryo.Trapping GC/FT.IR. Labor Praxis, Januar/Februar, 26-31 (1991).

17. ZBINDEN, A. M., WESTENSKOW, D., THOMSON, D. A., FUNK, B., MAERTENS, J.: A laboratory investigation of two new portable gas analysers. Int. J. Clin. Mon \& Com. put. 2, 151-161 (1986).

18. POCKRAND, 1.: Optische Gasanalyse in der Medizin. Technisches Messen tm 52, (6) 247-252 (1985)

19. HEISE, H. M.: Infrarotspektrometrische Gasanalytik - Verfahren und Anwendungen. in Analytiker-Taschenbuch, Bd. 9, Hrsg. R. Borsdorf, W. Fresenius, H. Günzler, et al., Springer Verlag. Berlin, 331-397 (1990).

20. STAMM, D., WISSER, H.: Blutanalytik. In: Analytiker-Taschenbuch, Bd. 3, Hrsg. R. Bock, W. Fresenius, H. Günzler, W. Huber, G. Tölg, Springer Verlag, Berlin, 87-119 (1983).

21. MENDELSON, Y., LIN, B., PEURA, R. A., CLERMONT, A. C.: Carbon dioxide laser based multiple ATR technique for measuring glucose in aqueous solutions. Appl. Opt. 27, $577-581$ (1988).

22. KAISER, N.: Laser Absorption Spectroscopy with an ATR-Prism. IEEE Trans. Bio22. KAISER, N.: Laser Absorption Spe

23. KRUSE-JARRES, J. D., JANATSCH, G., GLESS, U., MARBACH, R., HEISE, H. M.: Glucose and other Constituents of Blood Determined by ATR-FTIR Spectroscopy, Clin. Chem. 36, 401-402 (1990).

24. JANATSCH, G., KRUSE-JARRES, J. D., MARBACH, R., HEISE, H. M.: Multivariate Calibration for Assays in Clinical Chemistry Using Attennated Total Reflection Infrared Spectra of Human Blood Plasma. Anal. Chem. 61, 2016-2023 (1989).

25. WARD, K. J., HAALAND, D. M., ROBINSON, M. R., EATON, R. P.: Quantitative infrared Spectroscopy of Glucose in Blood Using Partial Least-Squares Analyses. Proc. Soc. Photo-Opt. Inst. (SPIE) 1145, 607-608 (1989).

26. CHITTUR, K. K., FINK, D. J., LEININGER, R. I., HUTSON, T. B.: Fourier Transform 26. CHITTUR, K. K., FINK, D. J., LEININGER, R. l., HUTSON, T. B.: Fourier Transform
Infrared Spectroscopy / Attenuated Total Reflection Studies of Protein Adsorption in Flowing Systems: Approaches for Bulk Correction and Compositional Analysis of Adsorbed and Bulk Proteins in Mixtures. J. Colloid. Int. Sc. 111, 419-433 (1986). 27. KELLNER, R., GOTZINGER, G.: fFTIR-ATR-Spectroscopic Analysis of the Protein Adsorption on Polymer Blood Contact Surfaces. Mikrochim. Acta II, 61-74 (1984). 28. WEIGEL, CH., KELLNER, R.: Development and Performance of a novel IR-ATR-based glucose sensor system. Proc. Soc. Photo-Opt. Inst. (SPIE) 1145, 134-137 (1989).

29. MARBACH, R:: Untersuchungen zur nichtinvasiven IR-spektrometrischen Bestimmung von Blutglucose. Dissertation Universität Dortmund (in Vorbereitung).

mung von Blutglucose. Dissertation Universität Dortmund (in Vorbereitung). hydrate intake. Scand J. Dent. Res. 96, 551-556 (1988).

31. ARAI, T., TOMITO, Y., KIKUCHI, M., NEGISHI, N.: Transcutaneous Detection for Blood Glucose Change by Measurement of Effusion Fluid using suction ATR Method. XIV ICMBE and VII ICMP, Paper 8.16, ESPOO, Finland, 303-304 (1985).

32. PEUCHANT, E., SALLES, C., JENSEN, R.: Determination of Serum Cholesterol by Near-Infrared Reflectance Spectrometry. Anal. Chem. 59, 1816-1819 (1987).

33. VAN TOORENENBERGEN, A. W., BLIJENBERG, B. G., LEIJNSE, B.: Measurement of Total Serum Protein by Near-Infrared Reflectance Spectroscopy. J. Clin. Chem. Clin. Biochem. 26, 209-211 (1988).

Biochem. 26, 209-211 (1988). 34. LODDER, R. A., HIEFTJE, G. M., MOOREHEAD, W., ROBERTSON, S. P., RAND, P.: Assessment of the Feasibility of Determination of Cholesterol and Other
tuents by Near-Infrared Reflectance Analysis. Talanta 36, 193-198 (1989). 35. YOSHIYA, I., SHIMADA, Y.: Non-Invasive spectrophotometric estimation of arterial oxygen saturation. In: Non-invasive physiological measurements, Bd. 2, Hrsg. P. Rolfe, Academic Press London, 251-286 (1983).

36. COPE, M., DELPY, D. T.: System for long-term measurement of cerebral blood and tissue oxygenation on newborn infants by near infrared transillumination. Med. Biol. Eng. Comp. 26, 289-294 (1988).

37. ESSENPREIS, M., SPAHN, J., WAIDELICH, W., VERSMOLD, H. T.: Krypton filled 37. ESSENPREIS, M., SPAHN, J., WAIDELICH, W., VERSMOLD, H. T.: Krypton filled
flashlamp: a possible new light source for near infrared spectroscopy in vivo. Adv. flashlamp: a possible new light

Exp. Med. Biol. $277,59-62$ (1990). 38. WYATT, J. S., COPE, M., DELPY, D. T., RICHARDSON, C. E., EDWARDS, A. D., WRAY,
S., REYNOLDS, E. O. R.: Quantitation of cerebral blood volume in human infants by near-infrared spectroscopy. J. Appl. Physiol. 68, 1086-1091 (1990).

39. COPE, M., VAN DER ZEE, P., ESSENPREIS, M., ARRIDGE, S. R., DELPY, D. T.: Data analysis methods for near infrared spectroscopy of tissues: Problems in determining the relative cytochrome $a_{3}$ concentration, Proc. Soc. Photo Opt. Inst. (SPIE) 1431, in press (1991).

Anschrift des Verfassers:

Dr. H. M. Heise

Institut für Spektrochemie und angewandte Spektroskopie Bunsen-Kirchhoff-Straße 11

4600 Dortmund 1 


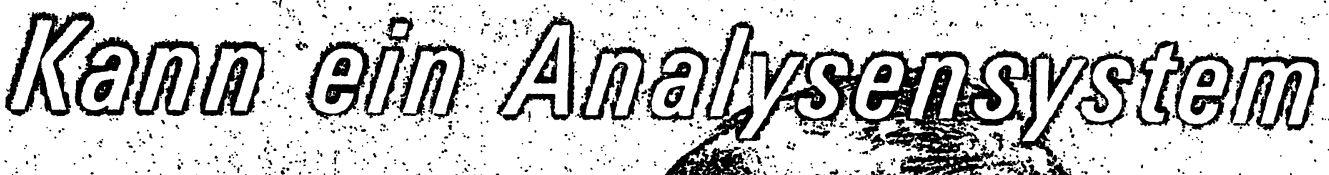

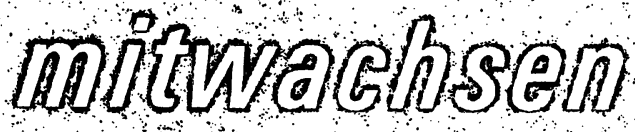




\section{Steurerdienst fürr den Arze}

Die für den Arzt einschlägigen Urteile finden Sie - nach Stichworten geordnet - in dem Loseblattwerk von Obersteuerrat Robert Linden.

Das Werk enthält u. a. die statistischen Kostensätze der Ärzte aller Fachrichtungen sowie Testbögen, die eine genaue Kostenanalyse der Praxis ermöglichen. Der Rationalisierung Ihrer Praxis dient das ausführliche „ABC der abzugsfähigen Ausgaben bei der Einkommensteuer".

\section{Hand aufs Herz}

* Verschenken Sie nicht auch Jahr für Jahr viel Celd an das Finanzamt?

* Nehmen Sie alle legalen Steuerminderungsmöglichkeiten in Anspruch?

* Stellen Sie rechtzeitig die notwendigen Anträge?

* Haben Sie Zeit und Gelegenheit, sich über Ihre berufsspezifischen Steuerfragen in den Steuerfachzeitschriften zu orientieren?

* Verlassen Sie sich ganz auf Ihren Berater?

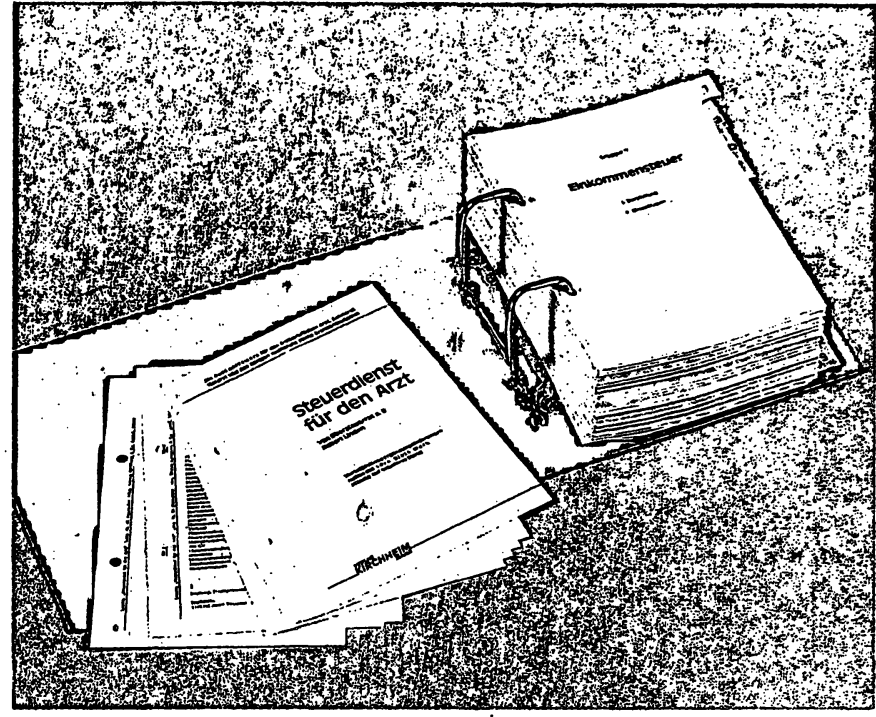

* Haben Sie schon einmal einen Praxiskostentest gemacht?

* Wissen Sie, ob Sie mehr oder weniger als Ihre vergleichbaren Kollegen verdienen?

\section{VERLAC}

KIRCHHEIM Postfach 2524,6500 Mainz 1

\section{MAINZ}

Hiermit bestelle ich ein Grundwerk „Steuerdienst für den Arzt" zum Preis von 79,80 DM und die künftig vierteljährlich erscheinenden Ergänzungslieferungen zum Seitenpreis von $-, 37 \mathrm{DM}$

Sie garantieren mir, daß ich diese Bestellung binnen einer Frist von einer Woche schriftlich widerrufen kann. Der Widerruf ist an den Verlag Kirchheim, Postfach 2524, 6500 Mainz, zu richten. Zur Wahrung der Frist genügt die rechtzeitige Absendung des Widerrufs.

Datum/Unterschrift:
Anschrift:

Name:

Straße:

PLZ/Ort: 